\title{
Abiotic Stress Responses in Legumes: Strategies Used to Cope with Environmental Challenges
}

\author{
Susana S. Araújo, ${ }^{1,2}$ Steve Beebe, ${ }^{3}$ Martin Crespi, ${ }^{4}$ Bruno Delbreil, ${ }^{5}$ \\ Esther M. González, ${ }^{6}$ Veronique Gruber, ${ }^{4,7}$ Isabelle Lejeune-Henaut, ${ }^{5}$ \\ Wolfgang Link, ${ }^{8}$ Maria J. Monteros, ${ }^{9}$ Elena Prats, ${ }^{10}$ Idupulapati Rao, ${ }^{3}$ \\ Vincent Vadez, ${ }^{11}$ and Maria C. Vaz Patto ${ }^{2}$ \\ ${ }^{1}$ Instituto de Investigação Científica Tropical (IICT), Lisboa, Portugal \\ ${ }^{2}$ Instituto de Tecnologia Química e Biológica António Xavier (ITQB), Universidade Nova de Lisboa, \\ Oeiras, Portugal \\ ${ }^{3}$ Centro Internacional de Agricultura Tropical (CIAT), Cali, Colombia \\ ${ }^{4}$ Institut des Sciences du Végétal (ISV), Centre National de la Recherche Scientifique, \\ SPS Saclay Plant Sciences, Gif sur Yvette, France \\ ${ }^{5}$ Université Lille 1, Institut National de la Recherche Agronomique (INRA), France \\ ${ }^{6}$ Universidad Pública de Navarra, Pamplona, Spain \\ ${ }^{7}$ Université Paris Diderot Paris 7, Paris, France \\ ${ }^{8}$ Department of Crop Sciences, Georg-August-University, Goettingen, Germany \\ ${ }^{9}$ The Samuel Roberts Noble Foundation, Ardmore, Oklahoma, USA \\ ${ }^{10}$ Institute for Sustainable Agriculture, Spanish National Research Council (CSIC), Córdoba, Spain \\ ${ }^{11}$ International Crops Research Institute for the Semi-Arid Tropics (ICRISAT), Patancheru, India
}

Table of Contents

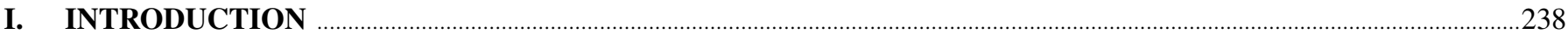

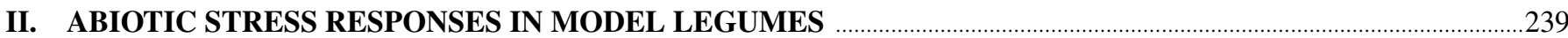

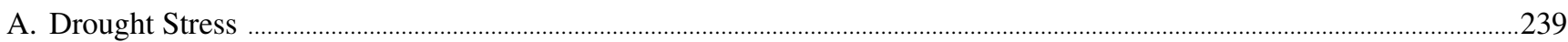

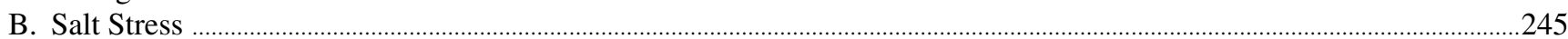



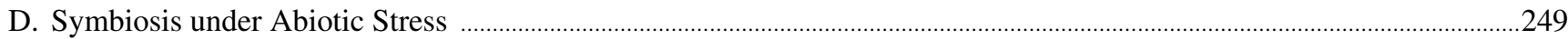

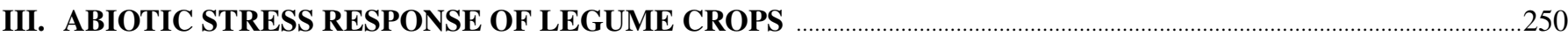



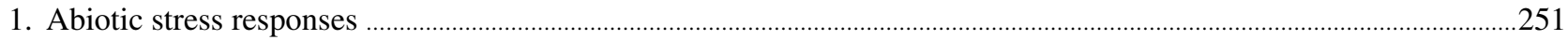

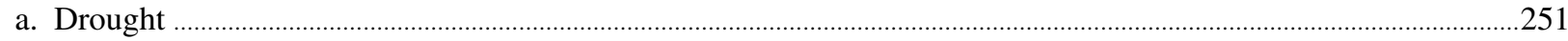

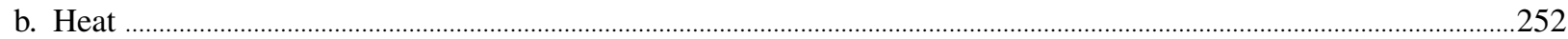







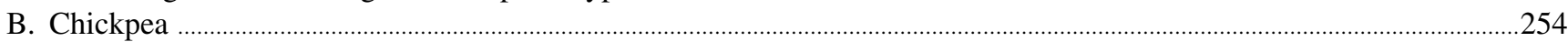

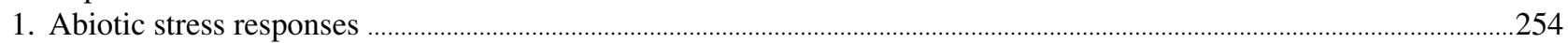

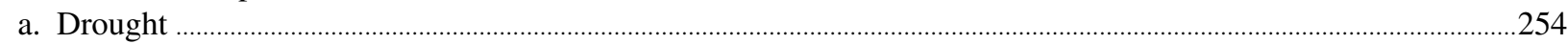

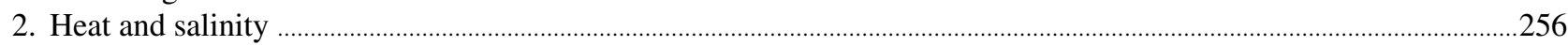

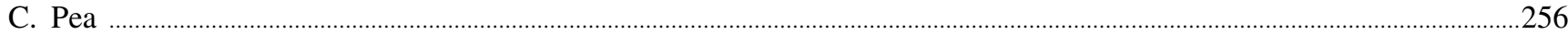

Address correspondence to Maria C. Vaz Patto, Instituto de Tecnologia Química e Biológica (ITQB), Universidade Nova de Lisboa, Oeiras, Portugal. E-mail: cpatto@itqb.unl.pt 


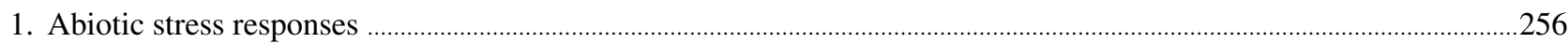

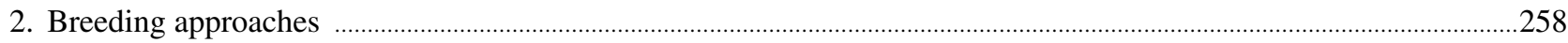

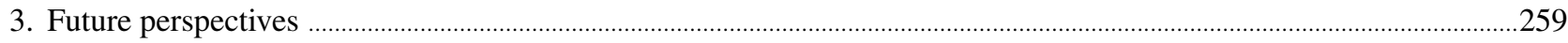



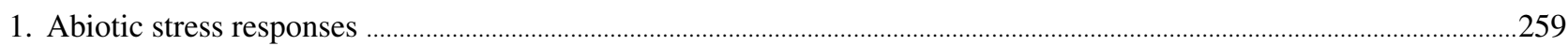

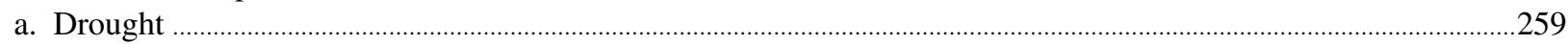





1. Abiotic stress responses …………

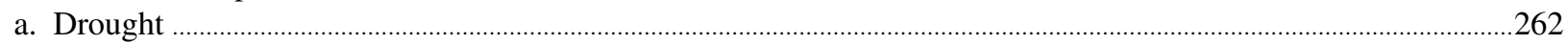

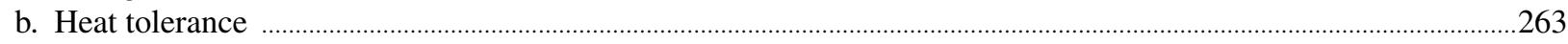

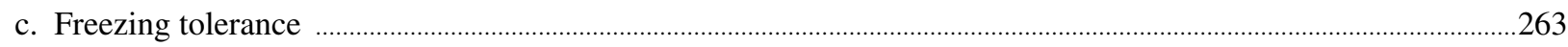

d. Soil pH and aluminum toxicity ………

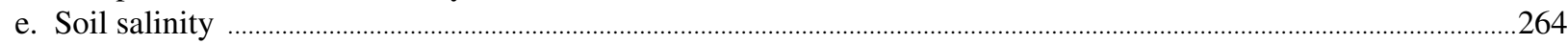

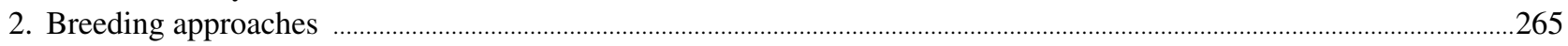

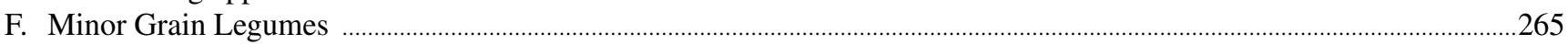



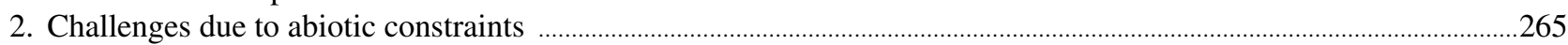

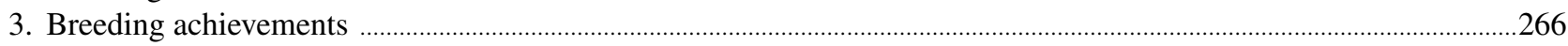



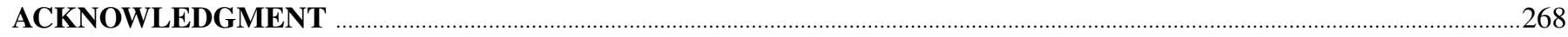

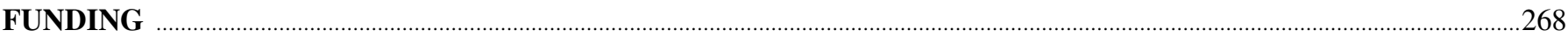

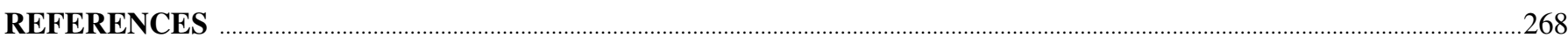

Legumes are well recognized for their nutritional and health benefits as well as for their impact in the sustainability of agricultural systems. The threatening scenario imposed by climate change highlights the need for concerted research approaches in order to develop crops that are able to cope with environmental stresses, while increasing yield and quality. During the last decade, some physiological components and molecular players underlying abiotic stress responses of a broad range of legume species have been elucidated. Plant physiology approaches provided general outlines of plant responses, identifying stress tolerance-related traits or elite cultivars. A thorough identification of candidate genes and quantitative trait loci (QTLs) associated with these traits followed. Model legumes like Medicago truncatula, Lotus japonicus, and more recently, Glycine max provided valuable translational approaches for dissecting legume responses to abiotic stresses. The challenge now focuses on the translation of the information gained in model systems in controlled environments to crops grown under field conditions. In this review, we provide a general overview of the recent achievements on the study of abiotic stress responses in a broad range of model, grain and forage legumes species, highlighting the different approaches used. Major accomplishments, as well as limitations or drawbacks are discussed across the different sections. Some perspectives regarding new approaches for screening, breeding or engineering legumes with desirable abiotic stress resistance traits are anticipated. These advances will support the development of legumes better adapted to environ- mental constraints, tackling current demands on modern agriculture and food production presently exacerbated by global climate changes.

Keywords abiotic stress, genomics, model and crop legumes, molecular breeding, phenotyping, physiology, quantitative genetics

\section{INTRODUCTION}

Legumes (Leguminosae or Fabaceae) belong to the second most important plant family in agriculture after the Poaceae or grass family. They provide the largest single source of vegetable protein in human diets and livestock feed (forages), and contribute to agriculture, the environment and human health (reviewed in Graham and Vance, 2003; Young et al., 2003; Dita et al., 2006). In developing countries, grain legumes or pulse crops represent an important component of local food consumed and are a key source of protein in the diets. They provide an input-saving and resource-conserving alternative because they fix atmospheric nitrogen, thus reducing the need for chemical fertilizers while enhancing overall crop productivity. In farming systems, legumes are often used as an inter-crop 
(e.g., combined with cereals) or in crop rotation resulting in a decrease in pests, diseases and weed populations, while enhancing the overall farm productivity and income of smallholder farmers. Based on these attributes, it is tempting to claim that legumes are one of the most promising components of the Climate Smart Agriculture concept (FAO, 2013).

Abiotic stresses play a major role in determining crop and forage productivity (Boyer, 1992; Rao, 2013), and also affects the differential distribution of the plant species across different types of environments (Chaves et al., 2003). Climate change exacerbates abiotic stress on a global scale, with increased irregularity and unpredictability, and as a result, adaptation strategies need to be developed to target crops to specific environments (Beebe et al., 2011). Within a single production region, a crop may encounter both excess and deficient moisture, depending upon the year, or even within the same growing season, when rainfall distribution becomes erratic. Higher temperatures will probably accelerate mineralization of soil organic matter, making soil constraints more intense (Lynch and St. Clair, 2004), and these in turn can limit root penetration and plant development, further intensifying the effects of unfavorable climate (Beebe et al., 2013a). Furthermore, interactions between different stress factors will likely increase damage to crop yields (Beebe, 2012; Yang et al., 2013).

A remarkable feature of plant adaptation to abiotic stresses is the activation of multiple responses involving complex gene interactions and "cross-talk," with many pathways at the wholeplant, physiological, biochemical, cellular and molecular levels (Grover et al., 2001; Le et al., 2006; Atkinson et al., 2012). Knowledge about how these biological processes are modulated by the abiotic stresses is still a challenge pursued by both public research efforts and the private sector.

Like many other crops, legume production is affected by unfavorable environmental conditions. During the last decade, researchers have focused on elucidating the various physiologic and molecular components underlying abiotic stress responses of a broad range of species, both model and crops. Although plant physiology provided a general overview of plant responses, identifying stress tolerance-related traits or the generation of better performing cultivars through breeding, further elucidation of the genetic basis of these important traits (as major responsible genes or associated Quantitative Trait Loci, QTLs), integrating molecular biology and genomics approaches, is needed to further dissect, and eventually profit from, the mechanisms underlying plant adaptation to abiotic stresses (Mir et al., 2012). Equally important will be to advance the understanding of the plant responses to the combination of multiple abiotic stresses (Mittler and Blumwald, 2010; Yang et al., 2013), especially on crop species who commonly face these challenges under field production.

This review focuses on the recent achievements in the study of legume responses to abiotic stresses, highlighting the different molecular and physiological approaches used to improve our understanding of the biology of the complex responses (Table 1). In addition, some perspectives regarding new approaches to breed or engineer plants with desirable traits are provided, aiming to develop legumes better adapted to environmental factors limiting agricultural productivity.

\section{ABIOTIC STRESS RESPONSES IN MODEL LEGUMES}

The study of the unique biological mechanisms used by legumes in response to stress conditions has been facilitated by the establishment of several model species. Medicago truncatula and Lotus japonicus have been the primary models developed to investigate plant-microbe interaction and nitrogen fixation. As sequencing costs have declined, additional legume genomes have been sequenced, and the funding available to crops such as Glycine max has enabled these to be developed to the status of genetic models in their own right (Cannon, 2013). Being the most important legume crop, the use of G. max as a model species presents several advantages over the M. truncatula or L. japonicus, providing valuable outputs in questions related to yield or grain production (e.g., grain filling or pod abortion), susceptible to be transferred among others cultivated legume. The release of almost complete genome sequences for these species (Young and Bharti, 2012) combined with the existence of genetic transformation protocols (Stewart, 1996; Aoki et al., 2002; Araújo et al., 2004) make them important tools to dissect the molecular mechanisms underlying legume adaptation to abiotic stresses. Several mutant populations and resources have been developed constituting essential tools for reverse genetics approaches aiming to understand gene function (Tadege et al., 2009). Additionally, the development of several bioinformatic tools, such as the LegumeIP ( $\mathrm{Li}$ et al., 2012) and the Legume Information System (LIS) (Gonzales et al., 2005) enables comprehensive queries based on gene annotation, gene family, synteny and relative gene expression. Bottom line, model legumes are now exciting platforms to functionally validate and derive new strategies to obtain improved legume phenotypes.

\section{A. Drought Stress}

Photosynthesis, together with cell growth, is among the primary processes to be affected by drought (Chaves, 1991). Another impact of water deficit on carbon metabolism results in changes in the pool of sugars used for signaling cellular processes or substrates for biopolymers like cellulose, starch and proteins (Chaves et al., 2009; Liu et al., 2013). Thus, it is tempting to claim that under drought the yield and quality of the harvested plant parts (e.g., grains, biomass, and stalks) may rely on the cross-talk of regulating processes at the whole plant level. Given its historical role in Australian agriculture, M. truncatula became a valuable resource for functional plant biology, namely on understanding how a plant interacts with its environment (Rose, 2008). Nunes et al. (2008) evaluated the two main components of drought resistance, drought avoidance and drought tolerance mechanisms in the mature M. truncatula $\mathrm{cv}$. Jemalong. In this study and under mild stress conditions, when the soil water content decreased to one-half of its maximum, M. truncatula plants maintained identical leaf relative water content (leaf RWC), net $\mathrm{CO}_{2}$ fixation rate, photochemical and 
TABLE 1

Some of the major achievements in breeding for resistance to abiotic stress in legume crops with indication of potential inputs from knowledge on model legumes

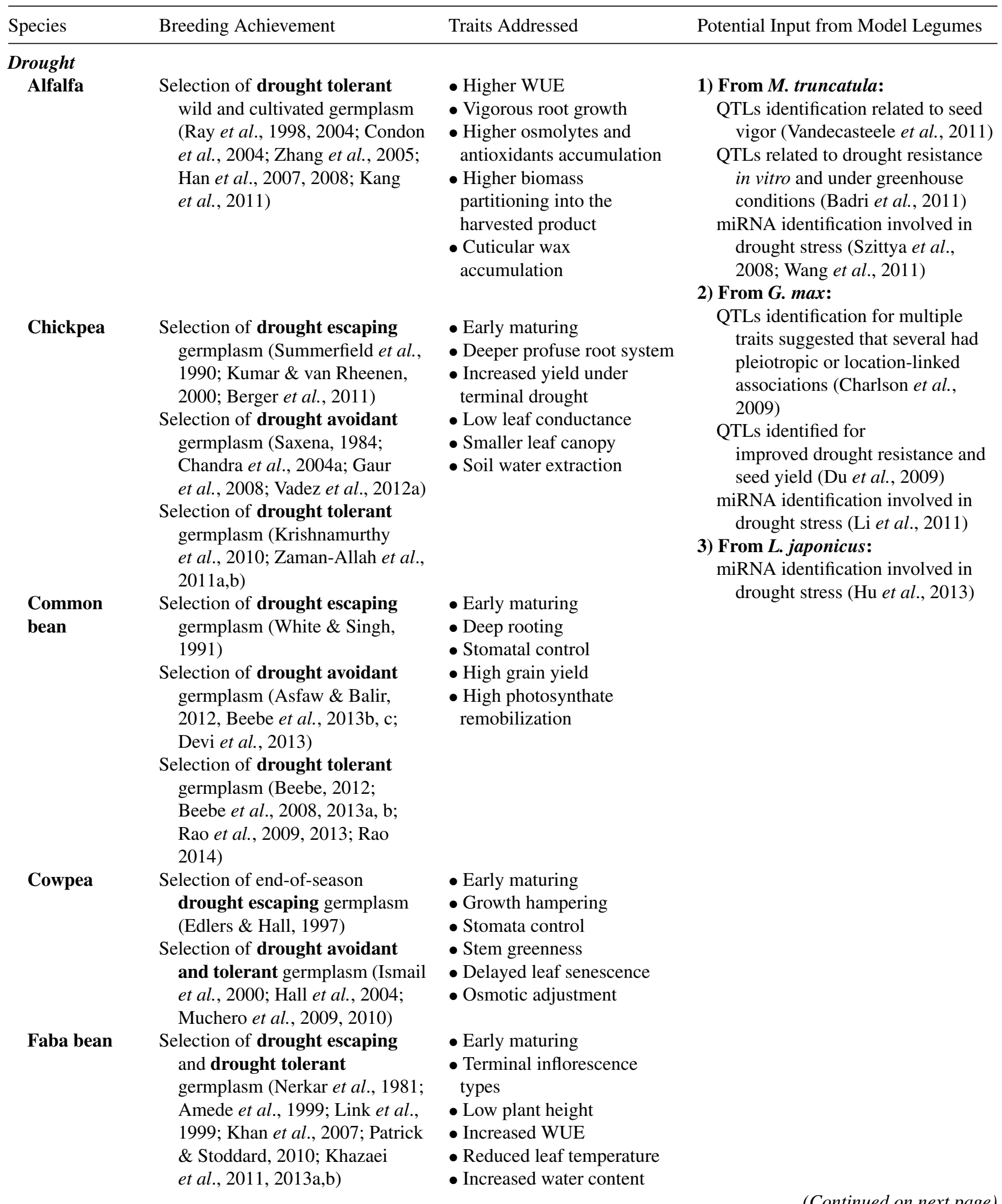


TABLE 1

Some of the major achievements in breeding for resistance to abiotic stress in legume crops with indication of potential inputs from knowledge on model legumes (Continued)

\begin{tabular}{|c|c|c|c|}
\hline Species & Breeding Achievement & Traits Addressed & Potential Input from Model Legumes \\
\hline Lentil & $\begin{array}{l}\text { Selection of drought escaping } \\
\text { germplasm (Erskine } \text { et al., } \\
\text { 2011) } \\
\text { Selection of drought tolerant } \\
\text { cultivated and wild germplasm } \\
\text { (Stoddard } \text { et al., 2006) }\end{array}$ & $\begin{array}{l}\text { - Early maturing, } \\
\text { - Early growth vigor } \\
\text { - Rapid root growth } \\
\text { - lower cell membrane injury } \\
\text { - High seedling growth } \\
\text { - Osmotic regulation } \\
\text { - High WUE }\end{array}$ & \\
\hline Pea & $\begin{array}{l}\text { Selection of drought resistant } \\
\text { and tolerant germplasm } \\
\text { (Grzesiak et al., 1997; Sanchez } \\
\text { et al., 1998, 2001; Hernandez } \\
\text { et al., 2000; Alexieva } \text { et al., } \\
\text { 2001; Hernandez \& Almansa, } \\
\text { 2002; Gonzalez et al., 2002; } \\
\text { Benjamin \& Nielsen, 2006; } \\
\text { Charlton } \text { et al., 2008) }\end{array}$ & $\begin{array}{l}\text { - Smaller root/shoot ratio } \\
\text { - Increased epicuticular } \\
\text { waxes } \\
\text { - Deeper roots } \\
\text { - Increased content of } \\
\text { antioxidants } \\
\text { - Increased osmolarity } \\
\text { - Turgor maintenance }\end{array}$ & \\
\hline Pigeon pea & $\begin{array}{l}\text { Selection of drought tolerant } \\
\text { cultivated germplasm (Odeny, } \\
\text { 2007) }\end{array}$ & $\begin{array}{l}\text { - Deep root } \\
\text { - Osmotic adjustment } \\
\text { - Photosynthetic } \\
\text { maintenance } \\
\text { - Polycarpic flowering habit }\end{array}$ & \\
\hline \multicolumn{4}{|l|}{ Water logging } \\
\hline Lentil & $\begin{array}{l}\text { Selection of water logging } \\
\text { resistant germplasm (Stoddard } \\
\text { et al., 2006) }\end{array}$ & $\begin{array}{l}\text { - Large aerenchyma or } \\
\text { air-spaces in roots } \\
\text { - High stomatal conductance }\end{array}$ & \\
\hline \multicolumn{4}{|l|}{ Salinity } \\
\hline Alfalfa & $\begin{array}{l}\text { Selection of salinity avoidance } \\
\text { cultivated germplasm (Vaughan } \\
\text { et al., 2002) } \\
\text { Selection of salinity tolerant } \\
\text { cultivated germplasm (Scasta } \\
\text { et al., 2012) }\end{array}$ & - High fibrous roots & $\begin{array}{l}\text { 1) From M. truncatula: } \\
\text { QTLs associated with the response } \\
\text { of leaves, stem and roots to } \mathrm{Na}+ \\
\text { and } \mathrm{K}+\text { uptake were mapped to } \\
\text { several genomic regions } \\
\text { (Arraouadi } \text { et al., 2012) }\end{array}$ \\
\hline Chickpea & $\begin{array}{l}\text { Selection of tolerant germplasm } \\
\text { (Vadez et al., 2007; Turner } \\
\text { et al., 2013) }\end{array}$ & $\begin{array}{l}\text { - Increased seed yield under } \\
\text { salinity not related to } \mathrm{Na} \\
\text { accumulation in the shoot }\end{array}$ & $\begin{array}{l}\text { Identification of salt adapted } \\
\text { genotypes (Mhadhbi } \text { et al., 2011; } \\
\text { Elmaghabri et al., 2013) }\end{array}$ \\
\hline Cowpea & $\begin{array}{l}\text { Selection of tolerant cultivated } \\
\text { germplasm (Chen } \text { et al., 2007; } \\
\text { Paul et al., 2011) }\end{array}$ & & $\begin{array}{l}\text { Identification of transcription factors } \\
\text { associated with improved salt } \\
\text { tolerance (De Lorenzo et al., }\end{array}$ \\
\hline Lentil & $\begin{array}{l}\text { Selection of tolerant cultivated } \\
\text { and wild germplasm (Erskine } \\
\text { et al., 2011) }\end{array}$ & & $\begin{array}{l}\text { 2007; Gruber et al., 2009; Zahaf } \\
\text { et al., 2012) } \\
\text { 2) From G. max: }\end{array}$ \\
\hline Pea & $\begin{array}{l}\text { Selection of tolerant germplasm } \\
\quad \text { (Shalid } \text { et al., 2012) }\end{array}$ & - Osmotic adjustment & $\begin{array}{l}\text { Identification of salt adapted } \\
\text { genotypes (Shao } \text { et al., 1986; }\end{array}$ \\
\hline Pigeon pea & $\begin{array}{l}\text { Selection of tolerant wild } \\
\text { germplasm (Upadhyaya et al., } \\
\text { 2013) }\end{array}$ & & $\begin{array}{l}\text { An } \text { et al., 2002; Luo et al., 2005; } \\
\text { Phang et al., 2008; Ma } \text { et al., 2010) } \\
\text { Major salt tolerance QTLs } \\
\text { conserved between wild and } \\
\text { cultivated species (Lee } \text { et al., } \\
\text { 2004; Hamwieh \& Xu, 2008) } \\
\text { (Continued on next page) }\end{array}$ \\
\hline
\end{tabular}


TABLE 1

Some of the major achievements in breeding for resistance to abiotic stress in legume crops with indication of potential inputs from knowledge on model legumes (Continued) Potential Input from Model Legumes
3) From L.japonicus:
Identification of salt adapted genotypes (Sanchez et al., 2008; Rubio et al., 2009)

\begin{tabular}{|c|c|c|}
\hline Species & Breeding Achievement & Traits Addressed \\
\hline \multicolumn{3}{|c|}{ Phosphorus, Iron and Boron deficiency } \\
\hline $\begin{array}{l}\text { Common } \\
\text { bean }\end{array}$ & $\begin{array}{l}\text { Selection of low P tolerant } \\
\text { cultivated germplasm (Lynch \& } \\
\text { Beebe, 1995; Liao et al., 2004; } \\
\text { Yan et al., 2004; Beebe et al., } \\
\text { 2006, 2013a; Beebe 2012; } \\
\text { Ramírez et al., 2013; Rao 2013) }\end{array}$ & $\begin{array}{l}\text { - Root length, orientation, } \\
\text { hair density (shallow roots) } \\
\text { - Increased P use efficiency } \\
\text { (PUE) } \\
\text { - Enhanced photosynthate } \\
\text { remobilization capacity }\end{array}$ \\
\hline Lentil & $\begin{array}{l}\text { Selection of Fe and B tolerant } \\
\text { cultivated germplasm (Erskine } \\
\text { et al., 2011) }\end{array}$ & \\
\hline \multicolumn{3}{|c|}{ Aluminum toxicity } \\
\hline Alfalfa & $\begin{array}{l}\text { Selection of tolerant genotypes or } \\
\text { rhizobia strains tolerant to acid } \\
\text { pH (Graham et al., 1994; Khu } \\
\text { et al., 2013; Reyno et al., 2013) }\end{array}$ & $\begin{array}{l}\text { - Biomass production } \\
\text { - Root growth associated } \\
\text { with Al toxicity } \\
\text { - Al translocation } \\
\text { - Cell wall modifications } \\
\text { - Isoflavonoid biosynthesis }\end{array}$ \\
\hline $\begin{array}{l}\text { Common } \\
\text { bean }\end{array}$ & $\begin{array}{l}\text { Selection of tolerant cultivated } \\
\text { and wild germplasm (Beebe } \\
\text { 2012; Butare et al., 2012; Yang } \\
\text { et al., 2013; Rao 2013) }\end{array}$ & $\begin{array}{l}\text { - Citrate release } \\
\text { - Vigorous root growth }\end{array}$ \\
\hline Pigeon pea & $\begin{array}{l}\text { Selection of tolerant germplasm } \\
\quad \text { (Choudhary et al., 2011) }\end{array}$ & - Enhanced Al extrusion \\
\hline \multicolumn{3}{|l|}{ Heat } \\
\hline Chickpea & $\begin{array}{l}\text { Selection of heat tolerant } \\
\text { cultivated germplasm } \\
\text { (Krishnamurthy et al., 2011) }\end{array}$ & $\begin{array}{l}\text { - Increased pollen } \\
\text { germination under stress }\end{array}$ \\
\hline Cowpea & $\begin{array}{l}\text { Selection of heat tolerant } \\
\text { germplasm (Ehlers \& Hall, } \\
\text { 1997) }\end{array}$ & $\begin{array}{l}\text { - Tolerant flower buds } \\
\text { - Tolerance controlled by } \\
\text { one dominant gene }\end{array}$ \\
\hline \multicolumn{3}{|l|}{ Cold } \\
\hline Alfalfa & $\begin{array}{l}\text { Selection of cold tolerant alfalfa } \\
\text { genotypes (Cunningham et al., } \\
\text { 1998; Justes et al., 2002; } \\
\text { Castonguay et al., 2009; } \\
\text { Remus-Borel } \text { et al., 2010) }\end{array}$ & $\begin{array}{l}\text { - Higher autumn dormancy } \\
\text { - Improved regrowth after } \\
\text { winter } \\
\text { - Differential remobilization } \\
\text { of proteins to plant parts } \\
\text { - Dehydrin accumulation }\end{array}$ \\
\hline Cowpea & $\begin{array}{r}\text { Selection of cold tolerant } \\
\text { germplasm (Hall, 2004) }\end{array}$ & - Dehydrin accumulation \\
\hline Faba bean & $\begin{array}{l}\text { Selection of cold tolerant } \\
\text { cultivars (Arbaoui et al., 2008b; } \\
\text { Hu et al., 2010; Link et al., } \\
\text { 2010; Mikic et al., 2011) }\end{array}$ & - Winter hardiness \\
\hline
\end{tabular}

hosphorus, Iron and Boron deficiency Common Selection of low P tolerant cultivated germplasm (Lynch \& Beebe, 1995; Liao et al., 2004; 2006, 2013a; Beebe 2012;

election of $\mathbf{F e}$ and $B$ tolerant cultivated germplasm (Erskine

Aluminum toxicity Alfalfa pH (Graham et al., 1994; Khu et al., 2013; Reyno et al., 2013)

- Cell wall modifications

- Isoflavonoid biosynthesis

- Citrate release and wild germplasm (Beebe 2012; Butare et al., 2012; Yang

(Choudhary et al., 2011)

lection of heat toleran cultivated germplasm germplasm (Ehlers \& Hall

election of cold tolerant alfalfa genotypes (Cunningham et al., Castonguay et al., 2009;

\section{election of cold tolerant} Hu et al., 2010; Link et al., ; Mikic et al., 2011)
1) From M. truncatula:

Identification of novel genes associated with $\mathrm{Al}$ toxicity, resistance and tolerance (Chandran et al., 2008)

\section{1) From M. truncatula:}

High-density genetic mapping revealed colinearity with a QTL related to freezing damage on $P$. sativum linkage group VI and syntenic markers were developed for transferability across 11 additional legume species (Avia et al., 2013; Tayeh et al., 2013a) 
TABLE 1

Some of the major achievements in breeding for resistance to abiotic stress in legume crops with indication of potential inputs from knowledge on model legumes (Continued)

\begin{tabular}{|c|c|c|c|}
\hline Species & Breeding Achievement & Traits Addressed & Potential Input from Model Legumes \\
\hline Lentil & $\begin{array}{l}\text { Selection of frost tolerant } \\
\text { cultivated and wild germplasm } \\
\text { (Eujayl et al., 1999; Kahranan } \\
\text { et al., 2004a,b; Muehlbauer } \\
\text { et al., 2006; Erskine } \text { et al., } \\
\text { 2011) }\end{array}$ & - Winter hardiness & \\
\hline Pea & $\begin{array}{l}\text { Selection of winter hardy cultivar } \\
\text { (Stoddard } \text { et al., 2006; } \\
\text { Lejeune-Hénaut } \text { et al., 2008; } \\
\text { Dumont } \text { et al., 2009, 2011; } \\
\text { Lucau-Donila et al., 2012; } \\
\text { Grimand } \text { et al., 2013; Legrand } \\
\text { et al., 2013) }\end{array}$ & $\begin{array}{l}\text { - Glucose and rafinose } \\
\text { content, } \\
\text { - RuBisCO activity } \\
\text { - Higher chloroplast and } \\
\text { chlorophyll content } \\
\text { - Increased resistance to } \\
\text { photoinhibition }\end{array}$ & \\
\hline
\end{tabular}

biochemical photosynthetic processes suggesting that plants are able to avoid leaf dehydration. On the other hand, under severe water deficit Ribulose-1,5-bisphosphate (RuBP) regeneration and Rubisco carboxylation efficiency were both decreased suggesting that non-stomatal limitations (Flexas and Medrano, 2002) also occurs in addition to mechanisms involving osmotic adjustment (Boyer and Meyer, 1979). Despite the findings previously described, further studies are needed to enhance our understanding of $M$. truncatula responses to water deprivation, including growth analyses, as well as, the characterization of accumulated osmolytes and the limitations in Rubisco carboxylation efficiency.

Soybean is the world's leading economic oilseed crop and vegetable protein for food and feed (Manavalan et al., 2009). Moreover, soybean is also recognized as a model seed legume (Young and Bharti, 2012). Several studies performed on environmentally-controlled greenhouse conditions aimed to understand soybean physiological mechanisms activated by drought, with emphasis on flowering, pod abortion, pod expansion, seed yield and individual seed weight (Desclaux and Roumet, 1996; Desclaux et al., 2000; Liu et al., 2003, 2004). Soybean plants were exposed to several water deprivation schemes and water status, ABA contents in xylem sap, leaves, flowers and pods were measured at $0,3,5,7$, and 10 days after anthesis (DAA). Overall results suggested that drought-induced decrease in water potential and increase in ABA content in flowers and pods at critical developmental stages such as early reproductive development (3-5 DAA), contribute to pod abortion in soybean, thus compromising seed yield. Additionally, decrease of carbohydrate flux from leaves to pods, together with decreased hexose to sucrose ratio in pods are suggested as potential factors contributing to pod abortion in drought-stressed soybeans (Liu et al., 2004).

Lotus japonicus, like M. truncatula, serves as a model for the study of several other species of the genus Lotus, that are widely used as pasture in temperate regions (Handberg and Stougaard, 1992; Betti et al., 2012). Recent work evaluated the impact of water deficit stress in metabolism of reactive nitrogen and oxygen species (RNS and ROS, respectively) in L. japonicus (Signorelli et al., 2013). The authors showed differential spatial distribution of oxidative and nitrosative stress as a consequence of the water deprivation imposed. The oxidative and the nitrosative stress component were higher in leaves and roots, respectively. Moreover, clear evidence of cross-talk between the different stress-signaling metabolites (proline or nitric oxide) measured were identified. Another study in M. truncatula demonstrated a cross-talk between $\mathrm{H}_{2} \mathrm{O}_{2}$ and $\mathrm{NO}$ signaling pathways in response to drought stress and rewatering, both at a local (root) and systemic (leaves) level (Filippou et al., 2011). These studies are examples of the complexity underlying plant adaptation to drought, and the question of the existence of a truly specific abiotic stress signaling responses still remains unanswered (Knight and Knight, 2001).

The genetic and molecular basis of drought resistance in legumes has been deeply dissected via QTL or gene discovery approaches through linkage and association mapping mostly in soybean (Charlson et al., 2009; Du et al., 2009) and M. truncatula (Badri et al., 2011; Vandecasteele et al., 2011). A recombinant inbred population was developed from a cross between two contrasting soybean parental lines: Kefeng1, drought tolerant, and Nannong1138-2, drought sensitive (Du et al., 2009) and used to measure multiple traits related to drought resistance and seed yield under water-stressed and well-watered conditions in field and greenhouse trials. A total of 40 QTLs were identified: 17 for leaf water status traits under drought stress and 23 for seed yield under well-watered and drought-stressed conditions in both field and greenhouse trials. Phenotypic correlations of traits studied suggested that several QTLs had pleiotropic or location-linked associations. Besides elucidating the genetic basis of drought tolerance, this study also provided 
the identification of reliable QTLs for drought resistance and improved seed yield to be incorporated into a marker-assisted selection breeding program aiming the development of highyielding soybean cultivars with improved tolerance to drought stress (Scaboo et al., 2009; Fallen et al., 2013). Seed vigor, a measure of the quality and viability of the seed, is an important trait for successful seedling establishment under unfavorable environmental conditions (Maun, 1994). The raffinose oligosaccharide family (RFO) of soluble sugars plays a major role as an energy supply for legume seedling establishment, although its role in seed vigor is not well understood. Vandecasteele et al. (2011) investigated whether the composition or amount of soluble sugars (sucrose and RFO) was part of the genetic determinants of seed vigor in $M$. truncatula using two recombinant inbred line (RIL) populations. The correlation and co-location of Suc/RFO ratio with germination and radicle growth QTLs suggested that an increased Suc/RFO ratio in seeds might negatively affect seed vigor. These examples from model legumes may provide valuable information that could be utilized to implement a marker-assisted selection breeding program aimed at developing legume cultivars with improved tolerance to drought stress.

The stomatal limitation on photosynthesis imposed by the earlier stages of water deprivation leads to deprivation of carbon and therefore excess of photochemical capacity (Chaves, 1991). In other words, the quantity of light absorbed can easily exceed the capacity of the chloroplast for using the products of the photochemical reactions. If protection mechanisms are not activated, the excess of absorbed energy may induce photooxidative damage in chloroplast structures. To cope with such injuries, plants accumulate specific stress-associated proteins such as the Early-light Inducible Proteins (ELIPs). ELIPs and ELIP-like are nuclear encoded proteins and belong to the chlorophyll a/b-binding protein (cab) family (Adamska, 1997). Transgenic M. truncatula plants overexpressing the ELIP-like DSP22 protein display higher amount of chlorophyll (Chl), lower Chl $\mathrm{a} / \mathrm{Chl} \mathrm{b}$ ratio and higher actual efficiency of energy conversion in PSII after dehydration and rehydration, also suggesting a role in pigment stabilization during water deficit stress (Araújo et al., 2013). The mechanisms by which DSP22 leads to enhanced photo-oxidative protection in M. truncatula are unclear, but the results support that the expression of photo-protective proteins, such as ELIPs, could be a useful approach to improve abiotic stress resistance in legumes.

The accumulation of osmoprotectants such as proline (Pro) is a common physiological response found in many plants grown in a wide range of biotic and abiotic stresses, including water deprivation (Yoshiba et al., 1997; Verbruggen and Hermans, 2008). The proline biosynthetic pathway in plants is well known: L-Pro is synthesized from L-glutamic acid (L-Glu) via delta(1)-pyrroline-5-carboxylate (P5C) by two enzymes, P5C synthetase (P5CS) and P5C reductase (P5CR). Like many other similar metabolites, L-Pro can be metabolized to L-Glu via P5C by action of two enzymes: proline dehydrogenase (oxidase) (ProDH; EC 1.5.99.8) and P5C dehydrogenase (P5CDH;
EC 1.5.1.12). Engineering the accumulation of Pro was used to increase drought resistance in plants, including legumes (De Ronde et al., 2004; Simon-Sarkadi et al., 2005; Kim and Nam, 2013). Transgenic soybean plants over expressing a cDNA coding for P5CR have enhanced accumulation of Pro and constituted an excellent platform to understand the role of Pro in conferring improved resistance to drought stress (De Ronde et al., 2004). Moreover, manipulation of Pro content also affected the stress-induced changes in the concentration of several other amino acids, which further suggests the coordinated regulation of their metabolic pathways (Simon-Sarkadi et al., 2005). In $M$. truncatula, the manipulation of the trehalose metabolism was shown to be a promising strategy to enhance resistance to imposed water deficit, including the recovery from severe water deficit (Duque et al., 2013), and thus could be a valuable approach for plants to maximize the use of water from a brief rain period in the middle of a severe drought period.

The discovery of non-coding RNA (ncRNA) genes, which produce functional RNA molecules rather than encoding proteins, has undoubtedly changed our understanding of gene expression regulation in living organisms (Eddy, 2001). Among ncRNAs are the microRNAs (miRNAs) who play important regulatory roles, not only in plant development, but also in stress responses by negatively affecting target gene expression post-transcriptionally. A comprehensive description of the microRNA pathway in plants, including other short-interfering RNA, can be found in Bustos-Sanmamed et al. (2013). During the last decade, several miRNA involved in drought stress have been described for M. truncatula (Szittya et al., 2008; Wang et al., 2011), G. max (Li et al., 2011), and for L. japonicus (Hu et al., 2013). Trindade et al. (2010) analyzed the expression of several conserved miRNA in $M$. truncatula to investigate if miRNA-mediated regulation of gene expression was involved in responses to water deficit. They found that up-regulation of miR398a/b and miR408 correlates with down-regulation of their targets in water deficit. Interestingly, both miRNAs appear to modulate the expression of genes encoding copper proteins, suggesting a link between copper homeostasis and $M$. truncatula adaptation to progressive water deficit. Additionally, it has been also demonstrated that in M. truncatula, transcript accumulation of the components of small RNA pathways, such as Dicer-like Argonaute genes, is also modulated under water deficit (Capitão et al., 2011). These studies demonstrated the involvement of transcriptional and post-transcriptional regulatory mechanisms mediated by small RNAs in drought stress response.

The multiple levels of complexity and cross-talk seen in legumes drought responses can benefit from the use of global System Biology to deeply understand the mechanisms involved (Jogaiah et al., 2013). In L. japonicus, four days of water withholding induced an extensive reprogramming of the transcriptome from different metabolic pathways: photosynthesis, amino acid metabolism and cell wall metabolism, among others (Betti et al., 2012). Besides elucidating the molecular mechanisms of stress response, genome-wide transcriptional analysis of two soybean genotypes under dehydration and rehydration 
conditions identified several drought-responsive genes to support further soybean breeding programs (Chen et al., 2013). Several transcriptomics, proteomics and metabolomics approaches to understand seed development and grain filling have taken advantage of the genomic resources available for $M$. truncatula and L. japonicus (Gallardo et al., 2007; Verdier et al., 2008, 2013a, 2013 b; Dam et al., 2009). To the best of our knowledge, none of the studies using the models mentioned above have been focused on the impact of drought stress on these developmental processes. Nevertheless, a very recent review reports the challenges and future prospects of soybean proteome to get new insights into the plant abiotic stress response mechanisms (Hossain et al., 2013).

\section{B. Salt Stress}

Salt stress is one of the most significant environmental constraints limiting legume productivity in arid and semi-arid regions (Asraf and Harris, 2004; Hussain et al., 2009). Soil salinity affects about 80 million hectares of arable lands worldwide (Munns and Tester, 2008). Salt stress is first perceived by the root system and impairs plant growth by inducing an osmotic stress caused by reduced water availability and from the ion toxicity due to solute imbalance in the cytosol (Munns, 2005; Conde et al., 2011). This section focuses on salt stress constraints in the model species M. truncatula, L. japonicus and G. max. Several genotypes of M. truncatula, L. japonicus and soybean are adapted for growth in varying soil salt concentrations (Shao et al., 1986; Kao et al., 2006; de Lorenzo et al., 2007; Phang et al., 2008; Lazrek et al., 2009; Ma et al., 2010; Sanchez et al., 2010, 2011; Sobhanian et al., 2011; Zahaf et al., 2012). These salt-adapted genotypes may contribute to understanding different mechanisms linked to salt stress.

Ion homeostasis is an essential factor of salt stress adaptation in salt-tolerant genotypes. In M. truncatula, the salt-tolerant TN1.11 genotype has increased root growth under saline conditions and accumulates more ions of both $\mathrm{Na}^{+}$and $\mathrm{Cl}^{-}$in shoots than in roots, when compared to the reference Jemalong A17 genotype, which has moderate sensitivity to salt. This suggests a link between growth and ion transport (Zahaf et al., 2012). In soybean, salt tolerance is partially explained by the compartmentalization of $\mathrm{Na}^{+}$into root cell vacuoles, preventing $\mathrm{Na}^{+}$ transport to the leaves (Dabuxilatu and Ikeda, 2005; Luo et al., 2005). An et al. (2002) also reported that $\mathrm{Na}^{+}$is retained in roots, whereas $\mathrm{Cl}^{-}$is transported into leaves of both salt-tolerant Dare and salt-sensitive Tachiyutaka soybean genotypes. However, the differential transport of $\mathrm{Na}^{+}$and $\mathrm{Cl}^{-}$ions in soybean roots and leaves may explain their response to salt stress. Selective mechanisms along the xylem-symplast boundary have been identified in soybean thus confirming the relationship between ion accumulation and salt tolerance (Sobhanian et al., 2010). L. japonicus is also able to prevent $\mathrm{Na}^{+}$transport into shoots (Rubio et al., 2009). Moreover, a comparative ionomic study of $L$. japonicus genotypes responding differentially to salt stress showed a strong correlation between shoot $\mathrm{Cl}^{-}$levels of stress-acclimated genotypes and plant mortality exposed to lethal salinity doses (Sanchez et al., 2011).

Overall, ion homeostasis is a complex process dependent on the specific genotype adaptation and the severity of the applied salt stress. As reported for other plant species, the $\mathrm{K}^{+} / \mathrm{Na}^{+}$ and $\mathrm{Ca}^{2+} / \mathrm{Na}^{+}$ratios and uptake selectivity control discrimination between salt tolerant and salt sensitive legume genotypes (Phang et al., 2008; Sanchez et al., 2008). Furthermore, legume homologs of ion transporters were associated with salt stress responses and include $\mathrm{Na}^{+}$transporters and $\mathrm{Na}^{+} / \mathrm{H}^{+}$antiporters (Phang et al., 2008; Benedito et al., 2010; Teakle et al., 2010). Among them, the vacuolar $\mathrm{Na}^{+} / \mathrm{H}^{+}$antiporter $\mathrm{NHX} 1$ (for $\mathrm{Na}^{+} / \mathrm{H}^{+}$eXchanger) is involved in $\mathrm{Na}^{+}$compartmentalization (Li et al., 2006; Zahran et al., 2007; Teakle et al., 2010). Several mechanisms of salt stress-tolerance involving osmoprotectants, ROS production, stress proteins and ion homeostasis in the three model legumes have been recently described (Table 2).

The global impact of salt stress, as well as the capacity to recover from the salt treatment was investigated in M. truncatula at the transcriptional level (Merchan et al., 2007). In this study, 328 genes were linked to the recovery of root growth from a salt stress in the M. truncatula salt sensitive genotype R108. Among the genes found in this study was MtZPT2-1, a TFIIIAlike transcription factor shown to be involved in modulating root adaptation to salt stress (Merchan et al., 2007). A comparative analysis of salt stress regulation in root apexes versus whole roots for the reference Jemalong A17 genotype was conducted using two complementary transcriptomic approaches; a massive quantitative real-time RT-PCR transcription factor profiling in whole roots and a Mt16K+ microarray analysis in root apexes. The results showed that 824 genes were differentially expressed when plants were subjected to early salt stress conditions, including 84 transcription factors. Interestingly, differential regulation of these transcription factors in root apexes were observed when compared to whole roots responses (Gruber et al., 2009).

The development of the Affymetrix Medicago Gene Chip further expanded large-scale transcriptomic analysis for the evaluation of Medicago salt stress responses. To facilitate access to these gene expression profiles, an expression database called $\mathrm{MtED}$, based on time-course salt experiments was developed ( $\mathrm{Li}$ et al., 2009). In addition, MtED was linked to the public resource MtGEA (M. truncatula Gene Expression Atlas, Benedito et al., 2008), which includes the gene expression levels of different plant tissues.

Recent efforts to elucidate the stress tolerance mechanism to salt and saline-alkali stresses in soybean focused on a transcriptomic profiling analysis of seedling roots and leaves performed using high-throughput Illumina sequencing technology of the salt stress tolerant line HJ-1. The whole plant transcriptomic profile approach identified stress-regulated genes that were more up-regulated in roots than in leaves. The genes involved in stress signaling and transcription factors represented the most abundant categories expressed in response to these stresses (Fan et al., 2013). 
TABLE 2

Recent references describing major elements concerned in different salt stress tolerance mechanisms in model legumes

\begin{tabular}{|c|c|c|c|}
\hline & Medicago truncatula & Glycine max & Lotus japonicus \\
\hline Osmoprotectants & $\begin{array}{l}\text { Amino acids: proline } \\
\text { (Armengaud } \text { et al., 2004) } \\
\text { Sugars and polyols: } \\
\text { trehalose (Lopez et al., } \\
\text { 2008) }\end{array}$ & $\begin{array}{l}\text { Amino acids: proline (Aghaei } \text { et al., } \\
\text { 2008) } \\
\text { Sugars and polyols: pinitol } \\
\text { (reviewed in Phang } \text { et al., 2008) } \\
\text { Dimethyl sulfonium compounds: } \\
\text { glycinebetaine (reviewed in Phang } \\
\text { et al., 2008) } \\
\text { Alkaloids: trigonelline (reviewed in } \\
\text { Phang } \text { et al., 2008) }\end{array}$ & $\begin{array}{l}\text { Amino acids: proline (Sanchez } \\
\text { et al., 2008; Rubio et al., } \\
\text { 2009), Serine and Asparagine } \\
\text { (Sanchez et al., 2008) } \\
\text { Organic acids: glutamic, } \\
\text { succinis, citric, malic, } \\
\text { malonic, threonic acids } \\
\text { (Sanchez et al., 2008) } \\
\text { Sugars and polyols: maltose, } \\
\text { ononitol, pinitol, arabitol, } \\
\text { erythritol (Sanchez et al., } \\
\text { 2008) }\end{array}$ \\
\hline $\begin{array}{l}\text { Reactive oxygen } \\
\text { scavengers }\end{array}$ & $\begin{array}{l}\text { Antioxidant enzymes: } \\
\text { superoxide dismutase, } \\
\text { total peroxidase, } \\
\text { glutathione reductase, } \\
\text { ascorbate peroxidise, } \\
\text { guaicacol peroxidise } \\
\text { (Bianco and Defez, 2009; } \\
\text { Kang et al., 2010; } \\
\text { Mhadhbi } \text { et al., 2011) }\end{array}$ & $\begin{array}{l}\text { Antioxidant enzymes: superoxide } \\
\text { dismutase, ascorbate peroxidise, } \\
\text { Glutathione reductase (reviewed in } \\
\text { Sobhanian } \text { et al., 2011) } \\
\text { Non-enzymatic ROS scavengers: } \\
\text { ascorbic acid, carotenoid and } \\
\text { glutathione (reviewed in } \\
\text { Sobhanian } \text { et al., 2011) }\end{array}$ & $\begin{array}{l}\text { Antioxidant enzymes: } \\
\text { superoxide dismutase, } \\
\text { catalase, glutathione } \\
\text { peroxydase and } \\
\text { ascorbate-glutathione cycle } \\
\text { enzymes (Rubio et al., 2009) }\end{array}$ \\
\hline Stress proteins & $\begin{array}{l}\text { LEA (Late Embryogenesis } \\
\text { Abundant) } \\
\text { proteins (Soares-Cavalcanti } \\
\quad \text { et al., 2012) }\end{array}$ & $\begin{array}{l}\text { LEA proteins: group } 1 \\
\text { (Soares-Cavalcanti } \text { et al., 2012), } \\
\text { groups } 3 \text { and } 4 \text { (reviewed in Phang } \\
\text { et al., 2008) }\end{array}$ & $\begin{array}{l}\text { LEA proteins (Sanchez et al., } \\
\text { 2008) }\end{array}$ \\
\hline $\begin{array}{l}\text { Ion/proton } \\
\text { transporters }\end{array}$ & $\begin{array}{l}\mathrm{Na}^{+} \text {transporters } \\
\text { (MtNHX1, MtNHX3 and } \\
\text { MtNHX4 [Zahran et al., } \\
\text { 2007]), Na+/H+ } \\
\text { antiporter (Kang } \text { et al., } \\
\text { 2010) } \\
\text { SOS-mediated signalling } \\
\text { pathways: SOS1 (Salt } \\
\text { Overly Sensitive, } \\
\text { Elmaghrabi } \text { et al., 2013), } \\
\text { SOS2 (Kang } \text { et al., 2010) }\end{array}$ & $\begin{array}{l}\mathrm{Na}^{+} \text {transporters: GmNHX1 } \\
\text { Vacuolar Na+/H+ (reviewed in } \\
\text { Phang } \text { et al., 2008) H+-PPiase } \\
\text { (GmVP1), H+-ATPase } \\
\text { (GmVHA-C), Inward-rectifying } \\
\text { K+ channel (GmAKT1), Vacuolar } \\
\text { CLC chloride channel (GmCLC1), } \\
\text { Cyclic nucleotide-gated cation } \\
\text { channel (GmCNGC), Glutamate } \\
\text { receptor (GmGLR3), } \\
\text { Na+/K+/Cl- co-transporter } \\
\text { (GmNKCC), Cation/proton } \\
\text { exchanger (GmCAX1, [reviewed } \\
\text { in Phang et al., 2008]) } \\
\text { SOS-mediated signalling } \\
\text { pathways: GmSOS1 Na+/H+ } \\
\text { antiporter (Phang } \text { et al., 2008) }\end{array}$ & $\begin{array}{l}\text { Putative K+ transporter } \\
\text { (chr5.CM0911.54.1) and } \\
\text { putative chloride channel } \\
\text { (Ljwgs_016759.2, [Sanchez } \\
\text { et al., 2008]) }\end{array}$ \\
\hline
\end{tabular}

In L. japonicus, 912 differentially expressed genes responding in a dose-dependent manner during salt acclimatization were identified using the Affymetrix Lotus GeneChip ${ }^{\circledR}$ Genome Array in the glycophyte L. japonicus var. Gifu (Sanchez et al., 2008). To test the robustness of these data, experiments were performed during two consecutive years and around $30 \%$ of the transcriptional responses to salt stress were not reproducible in the second year. This highlights the difficulty to control the complex nutritional or environmental factors, even in greenhouse conditions present during stress responses (Sanchez et al., 2010).

A complementary strategy to understand salt stress adaptation consists of comparing legume genotypes displaying contrasting physiological salt stress responses. Several 
salt-stress related genes were shown to be more highly expressed in roots of tolerant vs. sensitive $M$. truncatula genotypes (Jemalong A17 vs. R108, respectively) even in the absence of stress, linking these genes with genotype-specific regulatory pathways involved in salt stress responses (De Lorenzo et al., 2007). Recently, a comparison between the salt-adapted TN1.11 and the reference Jemalong A17 M. truncatula genotypes was performed using a transcriptomic approach allowing the detection of important variations in root apex expression profiles in response to salt. The authors also found that a basic Helix-Loop-Helix transcription factor (MtbHLH-658), was differentially regulated only in the tolerant genotype and increased adaptation of root growth to salt stress. De-regulation of this pathway under salinity conditions may explain the naturally diverging responses to salt stress of these genotypes (Zahaf et al., 2012). This MtbHLH-658 may be a gene associated with salt stress adaptation of the TN1.11 tolerant genotype.

In soybean roots, a digital gene expression profile experiment highlighted a higher ratio of up/down-regulated genes in the salttolerant G. soja than in a salt-sensitive genotype of G. $\max$ (Ali et al., 2012). In this study, 490 salt-responsive genes involved in the control of different steps of the salt regulatory pathway including many transcription factors were identified.

In addition, in L. japonicus, transcriptomic analysis of contrasting salt-tolerant model and cultivated species indicated that less than $1 \%$ of the transcriptional responses to salinity were found in all genotypes. The majority of these responses were unique to single or a few genotypes demonstrating the importance of genotype-specific transcriptional changes observed in salt stress adaptation (Sanchez et al., 2011).

An integrated view of the salt tolerance mechanisms in legumes has benefited from other -omics approaches, including proteomic and metabolomics, that were recently developed to better understand the salt tolerance mechanisms (Aghaei et al., 2008; Sobhanian et al., 2010, 2011; Sanchez et al., 2011; Xu et al., 2011; Hakeem et al., 2012). Growing evidence showed that transcription factors are key regulators of the plant responses relevant in salt stress adaptation (as exemplified in Merchan et al., 2003; Chen et al., 2007; Udvardi et al., 2007; Liao et al., 2008; Zhou et al., 2008; de Lorenzo et al., 2009; Pinheiro et al., 2009; Wei et al., 2009; Ariel et al., 2010; Zhang et al., 2010; de Zélicourt et al., 2012; Cheng et al., 2013; Zhai et al., 2013). Recent studies pointed out that the expression of certain salt-responding transcription factors may be controlled by epigenetic changes (for example DNA methylation and/or histone modifications), modulating soybean tolerance to salt stress (Song et al., 2012).

The use of QTL mapping for salinity tolerance based on recombinant inbred lines (RILs) generated from contrasting parental salt-responding genotypes was used to understand genotype-specific stress responses and to generate stresstolerant plants for breeding programs. In a $M$. truncatula RIL population (Jemalong A17 $\times$ F83005.5), putative QTLs associated with the response of leaves, stem and roots to $\mathrm{Na}+$ and $\mathrm{K}+$ uptake traits under control and salt-stress treatments, were mapped to several genomic regions (Arraouadi et al., 2012). In soybean, major salt tolerance QTLs were identified and shown to be conserved between wild and cultivated species (Lee $e t$ al., 2004; Hamwieh and Xu, 2008). Salt tolerance phenotypes seem to be dominated by major loci further suggesting the appearance of major genotype-specific mechanisms dealing with the adaptation of legumes to saline growing conditions.

In conclusion, the mechanisms involved in salt stress are complex although major advances have been achieved through genome sequencing and transcriptomics. The use of -omic approaches provide further insight into the regulation of salt tolerance in legumes. Several regulatory networks leading to salt stress adaptation seem genotype-specific and there may not be unique strategies in legumes used to cope with such a complex stress. Combination of QTL approaches associated with salt tolerance and genomics will contribute to understanding the diversity of mechanisms involved in salt stress responses and possibly result in novel candidate genes that could be useful for breeding programs.

\section{Cold Stress}

Plants are grouped into two broad categories based on their level of sensitivity to sub-optimal temperatures. Some are sensitive to temperatures ranging from 0 to $-15^{\circ} \mathrm{C}$ (chilling stress), while others are capable of withstanding freezing temperatures. The first case corresponds to species native to tropical and subtropical regions. Species of temperate and cold regions belong to the second category. The degree of cold tolerance is variable among species and the freezing tolerance generally increases after exposure to cold and non-freezing temperatures. The response to cold exposure conducive to an increased freezing tolerance is often referred to as 'cold acclimation.'

The levels of cold tolerance are different between the galegoid clade (including M. truncatula and L. japonicus) and those in the phaseoloid clade (that includes G. max) reflect their geographical origins. Species of the galegoid clade are often described as cold and freezing tolerant while the phaseoloid species are considered cold and freezing sensitive.

Regarding the response to cold, most of the studies on model legumes were performed on M. truncatula. There are only two reports on chilling effects in L. japonicus seedlings: the down regulation of a long-chain fatty alcohol oxidase $(\mathrm{LjFAO})$ in the apex and the cotyledons of seedlings at $4{ }^{\circ} \mathrm{C}$ (Zhao et al., 2008) and the induction in seedlings of a non-symbiotic hemoglobin (Shimoda et al., 2005) were identified.

Experiments on cold acclimation and freezing tolerance in $M$. truncatula are mostly limited to controlled conditions (Bounejmate et al., 1994; Brandsæter et al., 2000; Antolin et al., 2005; Hekneby et al., 2006; Pennycooke et al., 2008; Thapa et al., 2008; Zhang et al., 2011; Avia et al., 2013). Antolin et al. (2005) studied growth, net photosynthesis rate and chlorophyll fluorescence induction kinetics among annual legumes including M. truncatula $\mathrm{cv}$. Paraggio under cold acclimation $\left(10 / 5^{\circ} \mathrm{C}\right)$ and non-acclimation $\left(20 / 15^{\circ} \mathrm{C}\right)$ regimes. Growth at such low temperature resulted in a 2-fold increase in stem and root dry 
matter without any changes in leaf dry matter, when compared with the ones growing at $20^{\circ} \mathrm{C}$. The resulting photosynthetic cold acclimation was associated with a two-fold increase of quantum yield of photosystem II electron transport, pigment content, and in the activity of stromal fructose-1, 6-bis-phosphatase (sFBPase). Hekneby et al. (2006) compared growth parameters, proline, starch and sugar contents and regrowth capacity after a freezing treatment in the same accession. The root:shoot ratio increased in the cold-treated cv. Paraggio, but the total dry matter, leaf area, specific leaf area did not differ between the two applied temperature treatments $\left(10 / 5^{\circ} \mathrm{C}\right.$ vs. $\left.20 / 15^{\circ} \mathrm{C}\right)$. In the same study, increased levels of soluble sugars and proline were also observed, as well as lower ice nucleation temperature and lower $\mathrm{LT}_{50}$ (lethal temperature of $50 \%$ of the population). The authors concluded that $M$. truncatula genotypes had an ineffective cold acclimation process because of impaired sucrose phosphate synthase (SPS) activity in leaves and low starch reserves in roots which resulted in poor regrowth of the cultivar. This is in agreement with the results of another study, in which M. truncatula cv. Parabinga exhibited one of the poorest levels of frost tolerance in legumes after an acclimation at $2^{\circ} \mathrm{C}$ for 2 weeks (Brandsaeter et al., 2000). Additionally, these authors suggested that the poor survival of the plants could be related to the fact that they had already initiated flowering when cold temperatures were induced in the growth chamber.

Divergent cold responses have been described for the cultivar Jemalong (A17) across different experiments. For this accession, Zhang et al. (2011) observed increased levels of sucrose, fructose, lactose, proline, osmolality, survival rates and a decrease in $\mathrm{EL}_{50}$ (temperature that kills $50 \%$ of tissues due to electrolyte leakage) after a cold exposure at $4{ }^{\circ} \mathrm{C}$. Alternatively, Pennycooke et al. (2008) did not find any significant improvement in the freezing tolerance for this Jemalong cultivar, after cold exposure at $2^{\circ} \mathrm{C}$. This contrasted behavior for the same genotype could be due to differences in the age of the seedlings (three and four weeks in the first and the latter study, respectively) or in the temperature and length of exposure utilized during acclimation. Two other accessions, namely W6 5018 and Jemalong-6, had an increased ability to improve their frost tolerance following the exposure to a three-step acclimation program $\left(10 / 5^{\circ} \mathrm{C}, 7 / 4^{\circ} \mathrm{C}, 3.5 /-1^{\circ} \mathrm{C}\right)$ as evidenced by a significant decrease in $\mathrm{LT}_{50}$ (Thapa et al., 2008). In these experiments, the $\mathrm{LT}_{50}$ was the freeze temperature at which $50 \%$ injury occurs and injury was estimated using the electrolyte leakage or EL method. Recently, 15 lines from different geographical origins, including Jemalong, revealed natural variation for freezing tolerance evaluated by freezing damage and EL after cold exposure in a two-step program $\left(12 / 12^{\circ}, 8 / 2^{\circ} \mathrm{C}\right.$ ) (Avia et al., 2013). The accessions originating from lower latitudes (Algeria, Cyprus, and Syria) were found to be more sensitive than those from France. However, no clear relationship was found between freezing tolerance and the altitude of the area of origin. In general, it seems that some $M$. truncatula genotypes have the ability to cold ac- climate better than others when exposed to a gradual decrease in temperatures.

Regions of the $M$. truncatula genome determining variation for freezing tolerance have been identified using a QTL mapping approach (Avia et al., 2013) to identify three QTLs located on chromosomes 1,4 , and 6. A major freezing tolerance QTL (Mt-FTQTL6) accounting for $40 \%$ of the phenotypic variation was mapped to a region of $M$. truncatula chromosome 6 coinciding with an assembly gap in the Jemalong A17 euchromatic in the version Mt3.0 of the genome assembly (Tayeh et al., 2013a). A high-density genetic map of the Mt-FTQTL6 revealed colinearity with a QTL related to freezing damage on pea (Pisum sativum) linkage group VI and syntenic markers were developed for transferability across 11 additional legume species (Tayeh et al., 2013a). These cross-legume markers will be useful in future efforts aimed at investigating the conservation of Mt-FTQTL6 in cool-season legumes and subsequently the existence of common mechanisms for response to freezing shared between $M$. truncatula and crop legumes.

At the molecular level, the $M$. truncatula freezing tolerance response has been studied through the expression of the CBF/DREB1 gene family. This is a small family of transcriptional activators binding to the $\mathrm{C}$-repeat/dehydration-responsive element, which is present in the promoters of many coldresponsive genes. To date, four $\mathrm{CBF}$ genes have been identified and studied in M. truncatula, namely MtCBF1-4 (Pennycooke et al., 2008; Zhang et al., 2010; Li et al., 2011). MtCBF2 and $M t C B F 3$ were found to be rapidly induced under low temperatures (Pennycooke et al., 2008; Zhang et al., 2011). A transient increase of $M t C B F 1$ transcripts has also been observed under these conditions (Zhang et al., 2011). Transformation of $M$. truncatula for overexpression of MtDREB1C, identical to MtCBF3, suppressed shoot growth, and enhanced freezing tolerance (Chen et al., 2010). MtCBF4, isolated during osmotic stress experiments was induced in $M$. truncatula during cold stress (Li et al., 2009). The expression of CBFs seems to induce the expression of effector genes such MtCAS15 and MtCAS31 (M. truncatula cold acclimation-specific 15 and 31) containing cis CRT/DRE elements (Pennycooke et al., 2008). For example, over-expression of MtCBF4 in transgenic M. truncatula improved cold tolerance $\left(4^{\circ} \mathrm{C}\right)$ and activated expression of downstream genes containing the DRE elements $M t$ CAS15 and MtCAS31 (Li et al., 2011). The MtCAS31 protein is a dehydrin isolated during osmotic stress experiment $(\mathrm{Li}$ et al., 2009) which was also expressed during cold exposure $\left(4^{\circ} \mathrm{C}\right.$ ) in $M$. truncatula (Xie et al., 2012). MtCAS31 protein expressed in transgenic Arabidopsis interacted with Arabidopsis thaliana inducer of $\mathrm{CBF}$ expression 1 protein (Xie et al., 2012) which is an up-regulator of the expression of CBF3 (reviewed by Medina et al., 2011). These results confirm the crucial role of these genes in the cold-response regulatory pathway. Recently, twelve $C B F / D R E B 1$ genes including 10 new sequences in $M$. truncatula were identified and localized to 
Mt-FTQTL6 (Tayeh et al., 2013b). They revealed unique features characterizing $C B F / D R E B 1$ genes such as alternative splicing and large tandem duplication.

Other transcription factors are known to be expressed in response to $4^{\circ} \mathrm{C}$ treatment in $M$. truncatula roots: DOF207, HD1374, MYB634, MYB636, MYB1070, NAC969, NAC1081 and NAC1126 (Gruber et al., 2009) and AP2-like transcription factors, MtZpt2-1, MtZpt2-2, MtAp2, and a salt-induced receptor-like kinase MtSrlk (Merchan et al., 2007). These genes are also expressed during osmotic and heat stresses (Gruber et al., 2009) or salt stresses (Merchan et al., 2007). Transgenic plants of Arabidopsis that constitutively expressed MtHB2 (transcription factor belonging to the HD-Zip II subfamily) were more sensitive to freezing stress than wild-type plants. Expression of MtHB2 in Arabidopsis revealed that the transgenic plants accumulated lower amounts of proline and soluble sugars and greater amounts of malondialdehyde and $\mathrm{H}_{2} \mathrm{O}_{2}$ than their wildtype counterparts grown with and without abiotic stresses. The osmoregulation observed in transgenic plants was less effective and plants were more susceptible to oxidative damage under the conditions of cold stress. This demonstrated that MtHB2 likely plays a negative role in regulating cold stress responses (Song et al., 2012).These studies focused on the effects of cold acclimation in heterotrophic seedling growth.

During crop establishment, cold can decrease plant germination and heterotrophic growth and lead to drastic losses in crop yield and quality. QTL for seed mass in M. truncatula (chromosomes 5 and 8), germination (chromosomes 3 and 8) and heterotrophic growth (chromosomes 1,2, and 8) were found at sub-optimal temperatures (Barreto Dias et al., 2011). Based on data mining approaches, these authors also identified a set of putative candidate genes already identified during cold stress and involved in membrane protection and repair (LEA like proteins, HSP70 proteins) or those involved in regulation (RD22, ZAT10, ICE1, CBF1, CSDP1, OBF4). MtSAP1 (M. truncatula stress-associated protein 1) a protein with A20 and AN1 zincfinger domains was necessary to achieve successful germination and was induced in the embryo axis during acquisition of tolerance to desiccation and cold stress (Gimeno-Gilles et al., 2011). Compared to wild type, tobacco plants over-expressing MtSAPI were less affected in their growth and development at $4{ }^{\circ} \mathrm{C}$ which confirms the involvement of this gene in the response of cold stress (Charrier et al., 2013).

Medicago truncatula shows genetic variability for cold acclimation and freezing tolerance. The responses of this species to cold stress are sometimes common with those to drought, heat and osmotic stress, suggesting cross-talk between these abiotic stress responses. CBF genes are involved in freezing tolerance in M. truncatula although the details of their regulation remain unknown. Recent results have demonstrated syntenic relationships between QTL for frost tolerance in M. truncatula and P. sativum which highlights the potential benefit of using this model species to help decipher the determinism of cold tolerance among cultivated legumes.

\section{Symbiosis under Abiotic Stress}

Legume plants are able to establish intimate symbiosis with $\mathrm{N}_{2}$-fixing soil bacteria collectively referred to as rhizobia. This symbiotic interaction results in the formation of a unique organ, the nodule, where atmospheric $\mathrm{N}_{2}$ is reduced to ammonium in a differentiated form of the rhizobium bacteria (bacteroids) via symbiotic nitrogen fixation (SNF). This reduced $\mathrm{N}$ is exported from the nodule to the whole plant, so that the plant obtains a source of nitrogen and the bacteria is provided with photoassimilates in exchange.

For a successful symbiosis interaction to occur, the environmental requirements of both partners should be fulfilled. Any abiotic stress that alters soil conditions, such as drought, high temperature, salt or soil acidity, also affects the soil microbial community, thus compromising the symbiotic interaction (Tate, 2000). In general, rhizobia are more tolerant than their respective plant host to stress (Zahran, 1999), exhibiting different coping strategies including osmoregulation and homeostasis maintenance processes (Ghittoni and Bueno, 1996; Priefer et al., 2001). For instance, Dominguez-Ferreras et al. (2009a, b) showed the importance of potassium uptake and trehalose metabolism for Sinorhizobium meliloti osmotolerance. Other responses such as modification of cell morphology or extracellular polysaccharides pattern have been also observed (Vriezen et al., 2007). The role of the microsymbiont conferring stress tolerance to the host has been shown for Sinorhizobium strains overproducing cytokines (Xu et al., 2012). However, the tolerance of the legume host highly determines the effectiveness of the symbiotic interaction under stress conditions (Craig et al., 1991; Zahram, 1999). The different stages of the plant-bacteria interaction, root hair curling, bacterial colonization, infection thread formation and nodule development are highly reduced under stress conditions, influencing the success of the SNF process (Zahran and Sprent, 1986).

Reduction in the rate of SNF was described in both model (Larrainzar et al., 2007, 2009; Lopez-Gómez et al., 2011; GilQuintana et al., 2013a) and crop legumes (González et al., 1995, 1998; Ramos et al., 1999; Gil-Quintana et al., 2013b; Palma et al., 2013) when exposed to drought and salt stresses. In this context, it is worth noting that studies on L. japonicus, the genetic model for determinate nodule-forming legumes, are scarce and the state of the art is mainly based on pea, soybean, common bean (Phaseolus vulgaris) and M. truncatula.

Despite considerable research efforts, the molecular mechanism(s) responsible for the inhibition of SNF remain largely unknown. The complexity of the SNF process and the particular environment where it occurs, increase the number of possible factors altering this process under abiotic stress. Among them, several inhibiting factors have been proposed and these include oxygen limitation, carbon shortage, and regulation by nitrogen metabolism. Although drought, similarly to other abiotic stresses, does cause an increase in nodular oxygen diffusion resistance (Durand et al., 1987), increasing the oxygen concentration around the rhizosphere of drought-stressed 
nodules does not fully restore SNF rates, suggesting that other factors may be involved (Del Castillo et al., 1994, 1995). Several studies performed in grain legumes (i.e., pea, soybean, common bean) subjected to drought showed that the reduction of SNF rates was related to a concurrent inhibition of sucrose synthase activity, followed by an accumulation of sucrose and a decrease in malate to fuel bacteroid respiration (Gonzalez et al., 1995, 1998; Gordon et al., 1997; Ramos et al., 1999). Nevertheless, a different cause was suggested for the forage legume alfalfa (Medicago sativa) (Naya et al., 2007) and M. truncatula (Larrainzar et al., 2007, 2009), since SNF inhibition occurred before any measurable decline in either the activity rate or concentration of nodule carbon metabolism enzymes. In this regard, the level of malate did not show significant changes in these forage legumes (Naya et al., 2007; Larrainzar et al., 2009), suggesting that a different regulatory mechanism may be taking place in forage vs. grain legumes. In this sense, a large accumulation of amino acids was originally observed in $M$. sativa exposed to salt-stress (Fougere et al., 1991) and, more recently, LopezGomez et al. (2011) identified several nodule osmoprotectors with a putative role on salt stress in $L$. japonicus compared to M. truncatula. In leaves of model and forage legumes of the Lotus genus, Sanchez et al. (2012) noted the high diversity of responses occurring among the different species and partial similarities between the salt- and drought-responsive metabolites. Nevertheless, information is still limited and further studies are needed to fully understand the role of carbon metabolism on SNF regulation in the different model and crop legumes.

The $\mathrm{N}$ status of the whole plant was also proposed as a factor regulating SNF via a feedback inhibition of nitrogenase activity. The hypothesis of a N-driven regulation of SNF during drought stress has received much attention in tropical legume research, mostly due to studies in soybean, where the accumulation of $\mathrm{N}$ compounds such as ureides, and the amino acids Asn and Asp in different plant organs has been reported (Serraj et al., 1999; Vadez et al., 2000). Serraj et al. (2001) refined this model further by proposing two possible origins for this feedback inhibition: (i) a direct feedback inhibition within nodules, and (ii) an indirect feedback process due to $\mathrm{N}$ signals coming from the aerial part. However, for many years, this last hypothesis has only been formally tested in ureide-exporter legumes, but not in amide-exporters. In a recent study, Gil-Quintana et al. (2013a) challenged the $\mathrm{N}$-feedback hypothesis in the amide-exporter legume, M. truncatula when it was subjected to drought stress implemented using a split root system. This study showed that the regulation of SNF during drought occurs at the local level, similarly to the case of pea (Marino et al., 2007) and soybean (Gil-Quintana et al., 2013b). In these three species, SNF declines exclusively in nodules from the water-stressed part of the root, whilst nodules on the well-watered root portion did not display stress symptoms, thus supporting a local regulation system. Also, the concept of a $\mathrm{N}$-signal coming from individual amino acids, acting as $\mathrm{N}$-feedback inhibitors was tested. When the pattern of accumulation of single amino acids in different plant tissues was compared, the conclusion was that a more intricate regulation of $\mathrm{N}$ metabolism actually occurs. Indeed, the observed amino acid accumulation in roots and nodules, regardless of SNF rates, appears to be a general drought stress response that cannot be directly related to SNF. In agreement with these observations, ureide accumulation was recently shown to be induced by changes of ureide metabolic enzymes in drought-stressed soybean (Gil-Quintana et al., 2013b).Ureide accumulation was also observed in non-fixing plants (Alamillo et al., 2010) suggesting a constitutive response to drought stress and thus, not exclusive of nodulated legumes. Accumulation of $\mathrm{N}$ compounds occurring in different tissues may respond to the inhibition of protein synthesis of water-stressed tissues, as previously reported (Hsiao, 1973; Good and Zaplachinski, 1994), yet poorly investigated. Another unresolved question is how stress affects the vascular interactions between roots and nodules, a subject that has raised speculation (Pate et al., 1969), and that requires further testing. Interestingly, a transcription factor related to salt tolerance has been recently shown to have a dual involvement in root and nodules with antagonistic response (de Zelicourt et al., 2012), suggesting common regulatory mechanisms in both organs.

In summary, future research on the molecular mechanism(s) responsible for the inhibition of SNF should focus on the nodule environment and the regulatory role initially given to $\mathrm{N}$ compounds accumulated under stress conditions needs to be further evaluated. Additionally, information on SNF regulation coming from the temperate model legume $M$. truncatula may be more applicable to other forage legumes, regardless of their origin, than to grain legumes, even if their origin is from a similar geographical zone.

\section{ABIOTIC STRESS RESPONSE OF LEGUME CROPS}

Legume improvement should focus on a myriad of challenges for grain legumes and forages, namely concerning improvement towards abiotic stress resistance or tolerance. Common bean, chickpea (Cicer arietinum), pea and faba bean (Vicia $f a b a$ ) are some examples of the most cultivated staple food legumes for direct human consumption in the world. Soybean is the world's leading economic oilseed crop and vegetable protein for food and feed (Manavalan et al., 2009). However, due to its characteristics and genomic or genetic resources available, it is now rightly considered as well a model species (Cannon, 2013) and thus it was addressed on the previous model legume section. Others, such as cowpea (Vigna unguiculata), pigeon pea (Cajanus cajan), lentil (Lens culinaris), and grass pea (Lathyrus sativus) also have also an important role as staple crops mainly in some of the most marginal and harsh regions of the world. Our review will focus not only on the achievements and prospects for the above mentioned crops, but also on forage legumes belonging to the Medicago, Trifolium and Lotus genera, since they are essential components of livestock production in agricultural systems. Although model legumes have provided 
valuable tools and knowledge to understand legume adaptation to harsh environments, the challenge to transfer this information for the benefit of crops or forages grown under field conditions remains (Deikman et al., 2012).

\section{A. Common Bean}

Common bean is the grain legume for direct human consumption with the greatest total production in the world, estimated at around 12 million tons per year, mainly in Latin America and Africa (Beebe, 2012). Like other legumes, beans are a source of protein, complex carbohydrates, fiber, minerals and folate. Yields of common bean are severely limited by abiotic stress, especially climate-related and soil-related constraints (Rao, 2014). This review section will consider aspects of common bean response to different stresses, and will suggest an ideotype with a combination of desirable traits to deal more effectively with the unpredictability of abiotic stress, and with possible interactions among stresses.

\section{Abiotic stress responses}

a. Drought. Mechanisms by which plants resist drought include: dehydration avoidance and desiccation tolerance (Beebe et al., 2013b). Resistance to severe drought can be critical in natural dryland ecosystems, but has little relevance to increasing or stabilizing crop productivity. Increasing crop yield in drought-prone areas requires the optimization of the physiological processes involved in plant response to soil water deficit. Dehydration avoidance mechanisms serve to ameliorate the effects of drought by reducing either the water deficit or the crop's exposure to it, and are defined as the plant's ability to maintain its water status under conditions of soil water deficit. Early maturity is the most common escape mechanism, and cultivars with this strategy are favored by many farmers, at least in part to minimize exposure to terminal drought (White and Singh, 1991), as with the extra early common bean cultivar 'ICTA Ligero' in Guatemala. However, each day of reduced growth cycle was estimated to reduce yield potential by $74 \mathrm{~kg} \mathrm{ha}^{-1}$ (White and Singh, 1991).

Superior drought performance of genotypes BAT 477 and San Cristobal was attributed to an avoidance mechanism that involves deeper rooting in response to soil drying (Sponchiado et al., 1989). A grafting experiment in which shoots and roots of susceptible and resistant genotypes were interchanged confirmed that resistance was attributed to the roots (White and Castillo, 1992). QTL for this trait, as expressed in a greenhouse soil tube method, were identified but did not correspond to QTL for yield under field conditions with moisture deficit (Asfaw and Blair, 2012). A dehydration avoidance mechanism is also reflected in stomatal control, whereby the crop reduces its evapotranspiration during its vegetative phase, thus conserving moisture for the grain filling period. This mechanism was recognized in soybean (Sinclair et al., 2000; Sinclair, 2012) and initial studies in a greenhouse trial revealed a similar trait in elite common bean lines resulting from the drought selection (Devi et al., 2013).

Desiccation tolerance and water use efficiency (WUE) are likely to be very different from escape or avoidance mechanisms and thus require different strategies to elucidate and utilize them. Similarly, induced mechanisms must be treated differently from constitutive mechanisms. WUE is the ratio of total dry matter to evapo-transpiration and other losses of water from the system that is not transpired through the plant. An increase in transpiration efficiency (TE; defined as the ratio of accumulated plant mass to water transpired) or a reduction in soil evaporation will increase WUE (Blum, 2010). However the real challenge is to increase the effective use of water for transpiration when water is limiting (Blum, 2009). Sinclair (2012) concluded that TE is not a variable that can be easily resolved for use in many breeding programs. He suggested that component traits contributing to TE need to be studied to increase the effective use of available water through the growing season. High TE is obtained by partial stomatal closure, and consequently by a decrease of transpiration that could lead to lower crop yields. Developments in infrared thermography could provide new and feasible screening methods for detecting genetic variation in the stomatal response to water deficit in controlled environments and in the field (Munns et al., 2010).

Breeding for drought resistance in common bean has been based on measuring yield under drought conditions and this approach has been successful in enhancing crop productivity under drought stress (see Beebe et al., 2013b for a review). Most progress has occurred within the Middle American gene pool, and has resulted from combining the small seeded race Mesoamerica with the Durango race originating from the dry highlands of Mexico. Lines with superior drought yield in Colombia display better remobilization of photosynthate to pod formation and to grain during the grain filling period (Beebe et al., 2008; Rao et al., 2009; Beebe et al., 2013b; Rao et al., 2013). This resulted in greater harvest index (HI), and this result is consistent with other studies reporting that maintenance of HI under drought is key to drought resistance (Ramirez-Vallejo and Kelly, 1998; Klaedtke et al., 2012; Habibi, 2013). This trait could be particularly important during terminal drought as a desiccation tolerance mechanism when stress becomes increasingly acute at the end of the season. It is a trait with wide utility under multiple patterns of drought, in shallower soils of hillsides agroecosystems with limited potential for deep rooting, under other types of stress and even under optimal conditions (Beebe et al., 2008, 2013a, b; Beebe, 2012). Pod harvest index (PHI; seed weight / total pod weight x 100) has been employed as an indicator of photosynthate remobilization capacity under stress (Rao et al., 2013). Assefa et al. (2013) found that under drought, PHI had higher heritability than yield under drought, and that selection for PHI would result in greater genetic gain than direct selection for drought yield, and would also enhance non-stressed yield. This was consistent with results of Beebe et al. (2008) who found superior yield potential under favorable 
conditions among drought selected lines. These results were interpreted in the context of correcting deficiencies inherited from the wild ancestor that likely addressed intermittent drought by repressing its reproductive development until rainfall resumed. Selection for greater pod set and grain filling under drought serves to reverse this ancestral tendency and to identify genotypes with better partitioning to reproductive structures. Multienvironment QTL analysis for photosynthate remobilization traits under drought stress indicated that QTL for grain yield and photosynthate remobilization traits were independent of QTL for rooting depth or rooting pattern in a RIL population derived from BAT 477 and DOR 364 (Asfaw and Blair, 2012; Asfaw et al., 2012). Genotypes that could combine earliness, deep rooting and photosynthate mobilization could be more resilient for use in smallholder farm conditions minimizing risk from climate change and low soil fertility.

Tepary bean (Phaseolus acutifolius) evolved under a very different environment than the common bean. In contrast to wild $P$. vulgaris that had to compete for light with shrubs and weedy species, light is abundant in the desert environments where P. acutifolius evolved. Clearly, water is the most limiting factor in these environments. Tepary bean exhibits several drought resistance traits: early maturity, excellent remobilization capacity under stress, deep rooting to avoid dehydration, small leaves for reduced water use, and stomatal control but not with osmotic adjustment (Mohamed et al., 2005). This suggests that superior adaptation to drought can result from the combination of multiple traits, and in this sense tepary may serve as a model for improvement of drought resistance in common bean (Rao et al., 2013). Such traits may be sought within common bean germplasm, or they may be introduced from tepary through interspecific crosses. A reserve of tepary by common bean hybrid progenies exist (Mejía-Jiménez et al., 1994; Muñoz et al., 2004) and these may be explored for genes contributing to drought resistance.

b. Heat. Beans are grown across a wide range of latitudes with mean air temperature of $14^{\circ} \mathrm{C}$ to $35^{\circ} \mathrm{C}$. The Andean gene pool typically adapts best at mid-high altitudes (14002800 masl) or cooler climates, with race 'Nueva Granada' being more heat tolerant than race 'Peru'. The Mesoamerican gene pool adapts to higher temperatures at low (400 masl) to midhigh altitudes (2000 masl), and Mesoamerican race 'Durango' is adapted to the semi-arid highlands of Mexico. Given its midto-high altitude origin, bean is sensitive to high temperatures (Porch and Jahn, 2001).

Various authors reported on the effects of high temperature on common bean during and after anthesis, and during day and night hours. In the snap bean cultivar 'Tenderette', all reproductive parameters (pods and seeds per plant; pod length and weight) declined when night temperatures reached $27^{\circ} \mathrm{C}$ (Konsens et al., 1991). These effects were aggravated by day temperatures above $27^{\circ} \mathrm{C}$. In a trial with the dry bean cultivar 'Montcalm' under increasing temperatures, but with a constant day/night differentials, Prasad et al. (2002) only found an ef- fect on pod set above $37 / 27^{\circ} \mathrm{C}$, although seed set was reduced linearly beginning at $28 / 18^{\circ} \mathrm{C}$ onwards. Gross and Kigel (1994) found that a 5-day treatment of $32 / 27^{\circ} \mathrm{C}$ at 10 to 12 days prior to anthesis in cultivars PI-271998 and BBL-47 reduced pod and seed set to zero, suggesting that sporogenesis is the most sensitive period. On the other hand, Monterroso and Wien (1990) showed effects on flower and pod abscission with treatments of $35^{\circ} \mathrm{C}$ day temperatures and $20^{\circ} \mathrm{C}$ night temperatures. Based on the implementation of different levels of stress in different genotypes at different growth stages, these studies suggest that high temperature can be detrimental at any stage in the days pre- and post anthesis. An estimate of the potential impact of improving common bean for heat tolerance suggested that it could benefit 7.2 million ha (some of which would also benefit by drought tolerance) and this could also expand the highly suitable areas for growth by 54\% (Beebe et al., 2011). Bean-producing regions that will be subject to increasing heat stress in the short term are lowland central America, central Brazil, northern Uganda, and southern D. R. Congo (Beebe et al., 2013b).

c. Soil constraints. Low phosphorus $(P)$ availability: $\mathrm{P}$ availability is a limiting factor to bean productivity, especially in tropical soils (Lynch and Beebe, 1995). Root architecture has a great influence on the ability of bean plants to acquire $\mathrm{P}$ from the soil (Liao et al., 2001; Lynch, 2011). The Peruvian landrace 'Chaucha Chuga' was identified as relatively efficient in acquiring P from low P soils (Lynch and Beebe, 1995). QTL were identified in 'Chaucha Chuga' for a range of root traits that contribute to enhanced P uptake: total root length (Beebe et al., 2006), root hair density and organic acid production (Yan et al., 2004), and root orientation in relation to soil depth (Liao et al., 2004). In addition to $\mathrm{P}$ acquisition, differences in $\mathrm{P}$ use efficiency (PUE) have been reported among breeding lines (Beebe et al., 2013a). The underlying mechanism for this trait remains unknown although PUE appears to be related to an enhanced capacity for remobilization of photosynthates. Some drought resistant lines with improved remobilization expressed superior yield under P limited conditions (Beebe et al., 2008; Beebe et al., 2013b). Recently, a comparative study using two common bean genotypes with contrasting response to P deficiency (P-tolerant BAT 477 and P-sensitive DOR 364) indicated variations in the microRNA 399-mediated $\mathrm{PvPHO} 2$ regulation within the PvPHR1 transcription factor-signaling pathway (Ramírez et al., 2013). Results showed that higher $\mathrm{PvPHO}$, resulting from less efficient PvmiR399-mediated mRNA degradation, in DOR 364 would result in increased $\mathrm{PvPHO2}$-mediated degradation of Presponsive proteins, such as $\mathrm{P}$ transporter PHT1, which would cause a decrease in $\mathrm{P}$ content and $\mathrm{P}$ use efficiency in P-sensitive DOR 364.

Aluminum (Al) toxicity: $\mathrm{Al}$ toxicity affects as much as $40 \%$ of the global bean production, especially in the tropics (Thung and Rao, 1999). In Africa, an estimated $23 \%$ of the bean areas are affected by toxic levels of $\mathrm{Al}$ (Wortmann et al., 1998). The primary effect of $\mathrm{Al}$ toxicity is to inhibit root elongation, and thus crops suffering from Al toxicity are assumed to be at greater 
risk of drought due to limited root development (Yang et al., 2013). Differences in growth of bean plants in Al-toxic soil were previously noted (Foy, 1988). The P. coccineus accession $\mathrm{G}$ 35346 had excellent vigor in an acid soil in the field and superior root elongation in Al-toxic soil and hydroponic systems in the greenhouse (Butare et al., 2011), and was utilized in crosses to the drought resistant common bean SER 16. The derived line 'ALB 91' expressed much of the root vigor of the tolerant parent and has been used extensively in crosses (Butare et al., 2012).

Mechanisms of $\mathrm{Al}$ resistance in common bean were defined using the $\mathrm{Al}$ resistant genotype 'ICA Quimbaya' and the $\mathrm{Al}$ sensitive VAX-1 (see review by Yang et al., 2013). It was shown that the induced and sustained $\mathrm{Al}$ resistance of 'Quimbaya' is mediated by reducing the stable-bound $\mathrm{Al}$ in the apoplast thus allowing cell elongation and division to resume. Resistance to $\mathrm{Al}$ in common bean is attributed to the release of citrate by the root apex which is mediated by the multidrug and toxin extrusion (MATE) citrate transporter gene. Al resistance was mainly dependent on the capacity to sustain citrate synthesis, thereby maintaining the cytosolic citrate pool that enables exudation. The initial Al-induced inhibition of root elongation in both Al-resistant and Al-sensitive genotypes was correlated with the expression of the 1-aminocyclopropane-1-carboxylic acid oxidase gene (Yang et al., 2013).

Nitrogen deficiency: P. vulgaris is considered, in general terms, to be a poor nitrogen fixer, although field experiments report as much as $100 \mathrm{~kg} \mathrm{ha}^{-1}$ fixed $\mathrm{N}$ in favorable conditions (Hardarson et al., 1993). Common beans with a climbing growth habit consistently fix N (Graham and Rosas, 1977), and can contribute to improved maize yields in crop association (Pineda et al., 1993) or in a crop rotation scheme with maize (CIALCA, 2007). However, SNF in common bean is very sensitive to stress due to drought, low available soil P (Sinclair and Vadez, 2002), or high temperatures. A drought resistant breeding line ('BAT 477') with a bush growth habit maintained a relatively higher level of SNF under drought stress in field trials in Mexico (Castellanos et al., 1996) and in field and greenhouse trials in South Africa (Amsala Fenta, 2012), possibly due to a more vigorous root system that avoided drought and alleviated stress on SNF. A wider selection of drought resistant lines maintained a higher level of acetylene reduction in a greenhouse soil drying experiment (Devi et al., 2013). The same lines also fixed more $\mathrm{N}$ in the well watered treatment, suggesting that selection for drought resistance had contributed to SNF capacity.

\section{Genomics and multiple stress tolerance}

Interactions of a particular stress with other factors in the environment, especially other stresses, complicate the selection for stress tolerance (Beebe et al., 2013a; Yang et al., 2013). Drought stress can interact with higher temperatures, or with poor soil fertility that limits root development. Identifying the critical interactions and incorporating these into a selection program is perhaps the most challenging aspect of improving adaptation to abiotic stress factors. Most bean improvement efforts for abiotic stress have been focused on individual stresses, but a few studies considered the effects of multiple stress conditions. Butare et al. (2011) found that roots of $P$. coccineus accession G35346-3Q developed better than those of common bean under a combined stress of acid soil toxicity and drought. A few interspecific progenies expressed tolerance to combined stress. For example, the breeding line 'ALB 91' had 12\%, 71\% and 20\% higher yield in Al stress, drought stress and irrigated treatments, respectively, compared to the commercial check. Shallow root development in common bean favors $\mathrm{P}$ acquisition, while deeper root development is preferable for accessing moisture and improving drought resistance (Ho et al., 2005; Henry et al., 2010). Yang et al. (2010) characterized the combined effects of Al toxicity and drought stress on root growth, with emphasis on the root apex of common bean. Using polyethylene glycol (PEG) to create osmotic stress (OS) and to simulate drought stress, they found that $\mathrm{OS}$ enhances $\mathrm{Al}$ resistance by inhibiting $\mathrm{Al}$ accumulation in the root apices of the Al-sensitive genotype (VAX-1). This effect was related to the alteration of cell wall porosity caused by PEG-induced dehydration of the root apoplast. Physiological and molecular analysis of this phenomenon indicated that genes related to cell wall assembly and modification $(X T H s$, $B E G, H R G P$ ) play important roles in the PEG-induced decrease in cell wall porosity (Yang et al., 2011). Studies on short-term effects of Al toxicity and drought stress on root growth in acid, Al-toxic soil showed that drought alleviates Al injury, but $\mathrm{Al}$ renders the root apex more drought-sensitive, particularly by impacting the gene regulatory network involved in ABA signal transduction and cross-talk with other phytohormones that are necessary for maintaining root growth under drought stress (Yang et al., 2012).

\section{Strategies for breeding the ideal phenotype}

The phenotype of an organism is fundamentally a manifestation of the genotype's interaction with the environment. An ideotype is a plant with an ideal phenotype that combines the desirable traits and mechanisms to enable its adaptation to a target environment. An integrated improvement of resistance to abiotic stresses is likely to be more productive than considering stresses in isolation (Yang et al., 2013). This raises the question of whether a common ideotype might respond to several constraints simultaneously. We suggest that a common bean ideotype for most bean growing areas (with no risks of terminal drought) with multiple stress resistance would have an extended vegetative period to favor water and nutrient acquisition and accumulation of leaf area and biomass, followed by vigorous remobilization of photosynthates to grain for better harvest index. The aim is to optimize the balance between internal use of carbon resources for structural development, and the benefits gained from such investments in terms of fraction of photosynthates that are translocated to economically important products. By definition this should lead to better yield, and is useful only if it leads us to focus on the factors that maximize each of the two multipliers of biomass and HI. 
Soil fertility and Al toxicity in particular limit biomass accumulation. Based on a modeling exercise, Nord et al. (2011) concluded that $\mathrm{P}$ acquisition would be favored by a longer growth cycle. Time translates into more resource acquisition, which is to say, more $\mathrm{P}$, potassium, calcium, and other nutrients. The rate of root elongation in common bean is drastically reduced in the presence of Al toxicity (Butare et al., 2011; Yang et al., 2013). Slower root growth would likewise be compensated by a longer vegetative phase. In the case of SNF, greater fixation is associated with genotypes with a longer growth cycle, such as is the case of the climbing beans that may mature in 100 to 250 days (Graham and Rosas, 1977; Manrique et al., 1993), compared to bush beans that typically have a cycle of 70 to 90 days. A longer vegetative cycle may result in more carbon for SNF.

On the flip side, a longer vegetative cycle also exposes the crop to risk of drought for a longer time, and augments the expenditure of water from the soil, running the risk of exhausting this resource before the critical grain filling stage. Stomatal control and higher values of TE can ameliorate this risk (Sinclair, 2012), and bean has shown variability for this trait (Devi et al., 2013). To take advantage of greater biomass production under drought, maintaining HI through enhanced remobilization of photosynthate is critical (Ramirez-Vallejo et al., 1998; Assefa et al., 2013; Habibi, 2013; Rao et al., 2013). This trait is of wide value not only in the presence of water deficit (Beebe et al., 2013c), but also to address any potential $\mathrm{P}$ deficiency and Al toxicity (Beebe et al., 2008; Beebe, 2012; Beebe et al., 2013a, b). The Colombian landrace 'G21212' has showed excellent photosynthate remobilization capacity under both drought stress and low P availability, and others found that G21212 was also superior under soil compaction (Smith, 2004). Thus, enhanced remobilization and HI represent a generalized tolerance mechanism for major abiotic stresses. Recently, the 'SWEET' sugar transporters were identified; these are plasma membrane proteins located in the phloem parenchyma, a cell type inside the veins that exports sucrose to SUT1 sugar loaders (Chen et al., 2012). Since the photosynthate mobilization to grain and relative distribution of carbon between vegetative and reproductive growth for optimizing sink capacity critically determine crop yield, further research work is needed to define the role of these SWEET proteins in improving multiple stress tolerance. Functional genomics may contribute significantly to understanding key steps that serve to maintain translocation under stress.

Regarding resource acquisition from the soil, at least two overall root architecture traits appear to be valuable. Longer root hairs would augment the absorptive surface of roots and have almost no energetic cost (Yan et al., 2004; Miguel, 2004). A second trait with wide utility could be greater specific root length, although this strategy might have limitations in compacted or heavy textured soils if roots with a smaller diameter have a diminished ability to penetrate the soil (Butare et al., 2012).

Finally, if the crop cycle terminates with a rapid and synchronized maturity and "dry down" of the crop, this bean ideotype will be more acceptable to farmers. This will avoid a crop cycle that is excessively long, or a crop that reverts to vegetative growth under late season rainfall - a situation that complicates harvest or results in green leaves that stain the grain with chlorophyll during threshing.

If such a productive ideotype can be established, other stressspecific traits can be built around this model. While apparently a very simple model, maximizing remobilization is contrary to the underlying evolutionary tendencies of a bean crop that is vegetatively vigorous. We have referred to the wild bean model whereby extreme vegetative vigor is accompanied by low HI. In other words, in the balance between vegetative growth and reproductive development, partitioning may be tipped one way or the other, and it is not easy to optimize both in well synchronized succession that would augment yield. The search for an unambiguous shift to reproductive development under different climatic and edaphic conditions is a key to complement strategies that lead to greater biomass, either genetically or through agronomic management. Continuing selection under drought stress has revealed breeding lines with superior capacity for nutrient remobilization (Beebe et al., 2008). Another strategy to enhance sink strength is to introgress genes to common bean from $P$. acutifolius (Rao et al., 2013). Results in this regard are promising. One or the other of these strategies could assure grain fill even under drought stress, while permitting progress in tolerance or resistance to other types of abiotic stress.

\section{B. Chickpea}

Being grown under rainfed conditions in most production regions (90\%, Kumar and Abbo, 2001) drought is by far the major abiotic stress for chickpea in cultivation during the post-rainy season in Asia. There the crop is fully grown under residual moisture and is bound to face water limitation at some point during its cropping cycle, usually around and after flowering. Drought also affects chickpea Mediterranean type production environments where the crops depend on incoming rainfall during the season, but finish its cycle without rain and also faces terminal stress. Heat stress is now becoming an important constraint for chickpea production in India, where the production area (about $6 \mathrm{M}$ ha), i.e., about two third of the world area, has largely shifted from North to South. Therefore it is now cultivated mostly under short cropping seasons where flowering meets with the first heat waves of the summer during flowering (Gaur et al., 2010). Over the last few decades, chickpea planting area has been reduced in favor of wheat production, and therefore pushed to more marginal areas where soil salinity is also a problem. In conclusion and by order of importance, drought, heat and salinity are the main three abiotic stresses that limit chickpea productions.

\section{Abiotic stress responses}

a. Drought. Terminal drought, i.e., a water deficit occurring around and after anthesis is the main type of drought that chickpea faces, both in tropical and temperate environments. 
The first strategy used by breeders to cope with terminal stress has been to develop shorter duration varieties in which duration matches water supply (Summerfield et al., 1990; Berger et al., 2011), and quantitative trait loci (QTL) for flowering time have been identified (Kumar and van Rheenen, 2000). In India, it was stated that the different latitudes of production needed cultivars having different phenological characteristics, namely longer duration in northern latitudes and shorter durations in the South (Berger et al., 2006). This has shaped the phenological characteristics of cultivars that breeding programs have developed across India in the last few decades. The rationale is that northern environments have cooler temperatures during the February-March season allowing longer grain filling period while the season is shorter in the South and requires early flowering to escape heat. These views have been challenged recently: in India there would actually be no need for any particular phenological requirements and that an intermediate duration type with about 820 thermal unit to reach flowering and about 660 thermal units for the grain filling period would allow the highest possible yields across a range of latitudes from about 13 to $32{ }^{\circ} \mathrm{N}$ (Vadez et al., 2013a). These modeling results in fact agree with experimental results from Berger et al. (2011).

Much of the work on drought in the last three decades (Saxena, 1984) or so have focused on developing chickpea cultivars with deeper and more profuse root systems to tap more water from the soil profile. Some positive relationships have been identified between rooting depth and density and seed yield (Kashiwagi et al., 2005). However, in that study the relationship held only under the harsher stress conditions and not under milder stress, and using a 257 recombinant inbred line (RIL) population developed between two parents contrasting for root traits, no relationship was found between the root traits and seed yield (Serraj et al., 2004). The difficulty to sample and assess root systems in the field has led to the development of cylinder-based cultivation to assess root growth, and this method has allowed revealing a very large range of variation for root traits in the mini-core collection of chickpea (Kashiwagi et al., 2006). The contrasting germplasm from that study has been taken further by the breeding to develop cultivars with improved root systems (Gaur et al., 2008). Using populations developed earlier, a QTL on linkage group 5 for root trait has been identified, explaining about $30 \%$ of the phenotypic variation (Chandra et al., 2004). A number of QTL hot spots has more recently been identified using several RIL populations, including one on linkage group 5 where the QTL for root traits was initially discovered (Varshney et al., under review). SuperSAGE, an improved version of the serial analysis of gene expression (SAGE) technique, has also been employed to analyse transcriptome changes induced by drought in chickpea roots (Molina et al., 2008). This comprehensive study demonstrated that signal transduction, transcription regulation, osmolyte accumulation, and ROS scavenging undergo a strong transcriptional remodeling in chickpea roots in early drought stress responses, suggesting potential targets for breeding for drought tolerance.

More recently, chickpea genotypes contrasting for their seed yield under terminal drought conditions have been identified (Krishnamurthy et al., 2010). Some of these have been used to investigate traits, other than root, that could also contribute to terminal drought adaptation. Water conservation traits (low leaf conductance at vegetative stage, smaller leaf canopy, higher soil moisture thresholds for the transpiration decline) have been identified as common traits among germplasm achieving the highest yield under terminal stress (Zaman-Allah et al., 2011a). The rationale behind these traits is that conserving water at vegetative stage would make more water available for the reproduction and grain filling period. Indeed, a recent study carried out in a lysimetric system (Zaman-Allah et al., 2011b) has shown that higher yielding genotypes were those extracting less water during the vegetative stage, in the absence of any stress, and those extracting more water during reproduction and pod filling. The total water extracted from the soil profile varied between genotypes, but did not distinguish the 8 sensitive genotypes from the 12 tolerant lines tested (Zaman-Allah et al., 2011b). These data offer new insight on drought tolerance research in chickpea and demonstrate that coping with terminal water stress also depends on water conservation traits. Similar strategy has been characterized in other crops facing terminal stress like cowpea (Belko et al., 2012) or pearl millet (Vadez et al., 2013b). These traits may be antagonistic to the root trait QTL reported above, which reflect a higher speed of rooting. Indeed, the root trait QTL identified earlier co-maps with a shoot QTL explaining more than $50 \%$ of the phenotypic variation (Chandra et al., 2004) that might represent a vigor QTL. Higher early vigor would lead to fast soil water depletion and therefore the water saving traits may work in opposition to the fast rooting. Two modeling studies in soybean and chickpea are showing exactly this, i.e., a faster root growth would lead to yield decrease in most environments (Sinclair et al., 2010; Vadez et al., 2012a), although in chickpea a faster rooting would still have a beneficial effect in the case of short duration cultivars evolving in short duration environments (Vadez et al., 2012a). In fact, increased water extraction at depth by $20 \mathrm{~cm}$ would increase yield by about $10 \%$, while a modest irrigation of $30 \mathrm{~mm}$ at the beginning of seed growth would increase yield by 30-40\% (Vadez et al., 2012a), which gives a perspective on avenues for crop improvement under drought in chickpea.

In summary, while much of research on drought in the past four decades has focused on developing short duration genotypes and on harnessing deeper and more profuse rooting traits, new insights are coming from water conserving traits, which would allow the crop to have water available during critical stages of the crop cycle. However, none of these traits offers a solution to all drought situations and none of these traits should be seen as a one-fits-all. Therefore, future research on drought needs to tackle how plant traits fit to particular stress 
environments. In this research, crop simulation modeling is a critical tool to guide the choice of breeding targets.

\section{Heat and salinity}

These two abiotic stresses are grouped together because there has been much less research, but also because both seem to be affecting mainly the reproductive biology, as it has been reported earlier in other legumes (Duthion and Pigeaire, 1991). In chickpea, only recently has heat stress been tackled and short exposure to temperature above $35^{\circ} \mathrm{C}$ decreased pod number (Wang at al., 2006). Sensitivity of male and female reproductive organ is hypothesized as sensitive to heat stress (Nayyar et al., 2005). Chickpea genotypes tolerant to heat stress have been recently identified (Krishnamurthy et al., 2011). Pollen viability and germination was more sensitive than stigma receptivity in chickpea and at a regime of $35^{\circ} \mathrm{C} / 20^{\circ} \mathrm{C}$ day / night temperature, the pollen germination of the tolerant genotype was down to about $40 \%$ while that of sensitive genotype was $0 \%$ (Devasirvatham et al., 2012).

In relation to salinity, we will refer to a recent exhaustive review written on the topic (Flowers et al., 2009). While much of the early work has been carried out at vegetative stage, looking at plant growth response to salt stress, recent reports have focused on looking at yield response under a controlled saline treatment with homogenous stress application in large pots set up outdoors (Vadez et al., 2007; Krishnamurthy et al., 2011). These studies have revealed that large variation for seed yield under salinity exists. Vadez et al. (2007) reported that differences in yield were not related to differences in shoot growth, although shoot growth could still play a role on this (Vadez et al., 2012b). Also, differences in seed yield were not related to differences in $\mathrm{Na}$ accumulation in the shoot, which brings a new insight in salinity tolerance research, although sensitive lines had slightly higher $\mathrm{Na}$ in the seed for a limited number of genotypes (Turner et al., 2013). In fact, tolerant entries produce simply more flowers and have more tertiary branches than sensitive lines (Vadez et al., 2012c). Differences between tolerant and sensitive lines also seem to relate to the capacity to keep a large number of seeds under salt stress (Vadez et al., 2007), although pollen viability, germination, and growth in vivo were not affected by salinity (Turner et al., 2013). Future work on salinity would need to untangle what mechanism of the reproductive biology is affected by salt stress and then whether the salt application has an effect through ion toxicity or osmotic effect.

\section{Pea}

Pea is a crop cultivated world-wide being consumed as dry pulses mainly for animal feed, or as fresh peas for human consumption (Smýlkal et al., 2012). It is the third pulse crop in importance with over 6 million hectares following soybeans and beans (FAO, 2011). Abiotic stresses caused by adverse environmental conditions are responsible for heavy economic losses on pea crop being drought, high/low temperatures, and salinity the most important abiotic constraints. The extent of the yield losses depend largely on the intensity, duration and distribution of the adverse conditions. For instance, water requirements of pea are relatively high particularly during germination and flowering. Thus, water limitations at flowering lead to a shorter flowering period and abortion of flowers (Ney et al., 1994; Gallegos and Shibata, 1989). As a consequence, pod and seed numbers are reduced decreasing yield dramatically (Andersen and Aremu, 1991). During pod-filling phase, the sensitivity of peas to water stress is lower reducing mainly the number of pod seeds (Mahieu et al., 2009). Flowering is also a crucial stage in which sensitivity to high and low temperatures is particularly accused (Ali et al., 1994).

Development of new pea varieties adapted to a wide range of environmental conditions is the main aim of pea breeding programs (Moneim et al., 1990) being a crucial goal for improving competitiveness. As example, competitiveness could be improved by the development of autumn-sown peas in order to benefit from a higher biomass production, as well as, to avoid drought and heat stresses of late spring. Breeding programs are thus carried out to release winter hardy cultivars, able to survive freezing temperatures and other associated winter stresses. Although selection for winter hardiness has generally been performed through the field observation of winter damages and/or winter survival, which are largely attributable to insufficient freezing tolerance, it would benefit from the knowledge on physiological traits associated to freezing tolerance (Stoddard et al., 2006). Indeed, breeding for tolerance of any of the abiotic stresses above mentioned is a complex phenomenon for which a sound knowledge of the mechanisms leading to abiotic stress tolerance is crucial.

\section{Abiotic stress responses}

Under water and salinity stress the uptake of water and minerals is disturbed and hence photosynthetic activity decreases. Particularly, photosynthesis is well known to be sensitive to heat stress (Berry and Bjorkman, 1980). Reduction of up to $78 \%$ in photosynthesis has been described in pea following drought (Moran et al., 1994) reaching up to $80 \%$ of reduction when temperature increased to $45^{\circ} \mathrm{C}$ (Haldimann and Feller, 2005). According to this, diverse chlorophyll fluorescence parameters have been shown to reflect the ability of pea plants to maintain photosynthesis under chilling $\left(4^{\circ} \mathrm{C}\right.$ to $\left.10^{\circ} \mathrm{C}\right)$ and genetic variability for some of these parameters has been evidenced (Georgieva and Lichtenthaler, 1999, 2006). Reduced photosynthesis, lead to reduction of growth, by mean of fresh and dry weight and leaf area in pea (Magyar-Tabori et al., 2011).

Tolerance responses of pea to abiotic stresses include a series of morphological/physiological features that allow pea plants maintaining photosynthesis. Thus, the level of photoassimilation has been reported as an appropriate screening parameter for salt tolerance in pea genotypes (Shahid et al., 2012). Maintenance of photosynthesis under stress, particularly drought or salinity, implied a delicate equilibrium between the water loss and $\mathrm{CO}_{2}$ uptake. Thus, morphological changes to 
increase water access have been reported in pea cultivars in which, resistance to drought was correlated with a smaller rootto-shoot ratio than in sensitive genotypes (Grzesiak et al., 1997). In addition, field peas exposed to water stress had thinner roots that grow deeper into the soil to access water resources (Benjamin and Nielsen, 2006). By contrary, osmotic stress, provoked by PEG 6000 in pea plants, induced a shortening of the primary root and an increase of the lateral root number (Kolbert et al., 2008). In addition, under salinity conditions, roots became constricted above apex, thickening the region over the constriction and curving root tips (Solomon et al., 1986). Semi-leafless pea types are reputed as more tolerant to water deficit than leafed type peas attributing this tolerance to the reduced leaf area of the semi-leafless plants (Gonzalez et al., 2002). However this tolerance was not associated to a lower transpiration of the semileafless plants, that was not significantly different from the conventional leafy plants, but to a higher osmolarity of tendrils of the epidermal vacuoles (Gonzalez et al., 2002). Structural changes related with the cuticle have also been described in both drought and salt tolerant pea plants (Poljakoff-Mayber, 1975; Sanchez et al., 2001). Particularly epicuticular waxes, that control the loss of water from the cuticle, increased significantly together with an increase of the residual transpiration rate in peas under drought (Sanchez et al., 2001).

Under most environmental stresses the reduction of photosynthesis is correlated with an increase in photorespiration. However, studies conducted in pea, under a variety of conditions provide partly contradictory data. For example, Fedina et al. $(1993,1994)$ showed an increase in different parameters indicative of high photorespiration such as the $\mathrm{CO}_{2}$ compensation point or the activity of the glycolate oxidase as consequence of salt stress, whereas other authors showed a reduction of up to $44 \%$ in the glycolate oxidase under drought (Moran et al., 1994). This contradiction may be due to the intensity of the stress since, under severe stress, reactions of the Calvin cycle might have been inhibited, which could result in reduced contents of RuBP (Sharkey and Seemann, 1989) and, consequently, in lower rates of RuBP oxygenation.

Linked with the photorespiration and/or as a consequence of the imbalance between the $\mathrm{CO}_{2}$ and the electrons derived from the light reactions, reactive oxygen species (ROS) are generated in plants subjected to most environmental stresses. Indeed, this imbalance occurs under drought, cold, heat, high light intensity, UV radiation or salinity stress (Shao et al., 2008). In addition, toxic metals not considered as redox-active metals such as nickel has also been reported to stimulate the production of ROS in pea (Gajewska and Sklodowska, 2005). Thus, generation of ROS is an acknowledged feature of peas under most environmental stresses (Moran et al., 1994; Hernandez and Almansa, 2002; Gajewska and Sklodowska, 2005; Noreen and Ashraf, 2009; Panda and Matsumoto, 2010). Excess of ROS may cause peroxidation of membrane lipids leading to a loss of the membrane integrity and hence cell functionality. Tolerance responses linked to the reduction of the damage caused by ROS, may be achieved by reducing the generation of ROS or increasing the antioxidant machinery to scavenge the generated ROS. Indeed, over-expression of antioxidant genes has been shown to confer drought tolerance in pea (Hernandez et al., 2000; Alexieva et al., 2001; Hernandez and Almansa, 2002). In plant cells the enzymatic scavenging system for reactive oxygen intermediates consists of enzymes such as, superoxide dismutase (SOD), catalase (CAT), ascorbate peroxidase (APX), monodehydroascorbatereductase (MDAR), dehydroascorbatereductase (DHAR), glutathione peroxidase (GPX), and glutathione reductase (GR) included in the so-called water-water cycle (Asada, 2000). Alexieva et al. (2001) reported that in pea plants subjected to water stress the specific activities of antioxidant enzymes increased. Interestingly the same authors found a reduction of catalase and SOD activity whereas Moran et al. (1994) found a decrease of pea catalase, but an increase of SOD under water stress. These differences may arise from the different tolerance level of the genotypes tested, since an increase of SOD suggests a major photosynthetic imbalance leading to higher ROS generation. Interestingly both authors reported an increase of peroxidase activity leading to a reduction of $\mathrm{H}_{2} \mathrm{O}_{2}$. In addition, increases of the transcript levels of the ascorbate peroxidase and SOD have been described to parallel the decrease of stomatal conductance in drought-stressed pea plants (Mittler and Zilinskas, 1994). Overall, under salt stress, a rapid increase of SOD followed by increase of ascorbate peroxidase has been related to stress tolerance (Hernandez et al., 2000; Hernandez and Almansa, 2002). However, in a recent study on pea plants subjected to salt stress, the response of tolerant and sensitive cultivars with respect to the generation of enzymatic and nonenzymatic antioxidant metabolites was not consistent and only catalase activity was found to be a reliable marker of salt tolerance (Noreen and Ashraf, 2009). The low consistency in the results might be due to the different level of stress experimented by the plants since induced tolerance mechanisms are engaged after a determinate threshold. A high induction of a determinate stress associated metabolite/enzyme may indeed indicate that the plant is suffering the damages associated to this stress. Hence, it is important to distinguish between the responses engaged to alleviate advanced damages from those avoiding the damage in the plant which can be considerate as more effective tolerance response (Sanchez et al., 2011). Induction of ROS and antioxidant enzymes of the water-water cycle has been also reported in pea plants following exposure to heavy metals such as aluminum, nickel or cadmium (Gajewska and Sklodowska, 2005; Rodriguez-Serrano et al., 2009; Panda and Matsumoto, 2010) highlighting the importance of the antioxidant machinery to cope with environmental stresses.

In addition to the energy consumption by photorespiration, and the dissipation of energy by electron transport to $\mathrm{O}_{2}$ by antioxidant enzymes/metabolites of the water-water cycle (Asada, 2000), non-photochemical quenching linked to the formation of zeaxanthin in the xanthophyll cycle and an increased proton gradient across the thylakoid membrane have been reported to 
contribute in pea to drought tolerance (Iturbe-Ormaetxe et al., 1998).

Linked with oxidative damage, but not only related to it, accumulation of osmotically active metabolites such as amino acids, glycine betaine, sugars, or sugar alcohols are known to occurr in the cytoplasm contributing to high turgor and to protein and membrane stabilization, alleviating stress associated damages in pea (Sanchez et al., 1998; Shahid et al., 2012). Thus, drought tolerant pea genotypes have been reported to have better turgor maintenance by accumulation of soluble sugars and proline. Although all plants subjected to water stress increased the sugar content proportionally to osmotic adjustment, sugar accumulation was higher in the most resistant genotypes (Sanchez et al., 1998). Significant increases of proline, valine, myo-inositol, GABA, threonine, homoserine and trigonelline have also been detected in a metabolomic analysis of pea plants subjected to drought stress (Charlton et al., 2008). In addition, accumulation of soluble sugars in the leaves during the low temperature treatment preceding frost in a controlled conditions experiment has also been reported (Bourion et al., 2003). Similarly, under salt stress, Shahid et al. (2012) showed that pea tolerance was due to a higher osmolyte accumulation in their tissues. However, field experiments with pea genotypes had not always found a significant correlation between osmotic adjustment and yield performance, highlighting the complexity of the improvement of yield under drought (Khan et al., 1996).

Beyond the redox and osmotic properties of several of above mentioned metabolites, some of them such as $\mathrm{H}_{2} \mathrm{O}_{2}$, sugars or polyamines, act as signal molecules that may impact ABA, auxin and ethylene signaling (Hanson and Smeekens, 2009). Signaling is particularly important during the abiotic stress responses due to the complexity of metabolic pathways and processes engaged during the tolerance responses. Whereas most of knowledge on signaling during abiotic stress responses has been developed on model plants (Xiong et al., 2002), recent advances on the functions of the signaling molecule nitric oxide (NO) during abiotic stress have been attained in pea (Corpas et al., 2008; RodriguezSerrano et al., 2009; Ortega-Galisteo et al., 2012). These showed that most abiotic stresses including low and high temperature, continue light and high intensity induced increases of NO and $S$-nitrosothiols together with an increase in the proportion of $S$-nitrosylated proteins (Corpas et al., 2008). In addition, during cadmium stress in pea, six peroxisomal proteins were identified as putative target of $S$-nitrosylation involved in photorespiration, $\beta$-oxidation and reactive oxygen species detoxification. Interestingly, the activity of three of these proteins, catalase, malate deshydrogenase and glycolate oxidase was inhibited by NO donors (Ortega-Galisteo et al., 2012).

\section{Breeding approaches}

Although efforts have been made to apply molecular approaches for breeding pea under abiotic stress, there is no comparison with what have been done for disease improvement. Thus, 76 QTLs have been described so far in pea for 11 traits, but none of them with the exception of the recently reported freeze tolerance QTLs, were related to abiotic stress (Dita et al., 2006; Mc Phee, 2007). Using the Pop2 RIL population, derived from a cross between the freezing tolerant line Champagne and the sensitive line Terese, Lejeune-Hénaut et al. (2008) and Dumont et al. (2009) repeatedly detected four main QTL regions for frost tolerance in field or controlled conditions. Coinciding with two of these regions, QTL for physiological traits assumed to be associated with freezing tolerance, were also reported. Such were QTL for glucose and raffinose content in the leaves and for the activity of RuBisCO. Candidate genes underlying freeze tolerance QTL in pea have sometimes been identified. It is the case for the flowering $\mathrm{Hr}$ locus colocalizing with the most explanatory freezing tolerance QTL in Pop2, which is suspected to influence winter frost tolerance by delaying floral initiation until after the main winter freezing periods have passed (Lejeune-Hénaut et al., 2008). $\mathrm{Hr}$ has been shown to be an ortholog of EARLY FLOWERING 3 (ELF3) known to be involved in circadian clock function (Weller et al., 2012). Other positional candidate genes related to freezing tolerance mechanisms were proposed by Legrand et al. (2013) following mapping of genes differentially expressed between Champagne and Terese under cold exposure.

Proteomic and transcriptomic approaches, combined to physiological measurements, have also been carried out in pea. Taylor et al. (2005) compared the effects of different abiotic stresses, i.e., drought, chilling, and herbicide, on the mitochondrial proteome of pea and tackled quantitative differences in more than 30 proteins. Proteins commonly induced under the different stresses were observed. In particular, the degradation of glycine decarboxylase and serine hydroxymethyltransferase was provoked by the three treatments, although with quantitative differences. Interestingly, the treatments induced also very different responses for various classes of HSPs: a HSP90 was found to be induced by drought and chilling but not by the herbicide; a HSP70 decreased in response to the herbicide only; HSP22 was induced by all three treatments. In addition recent work explored the protein responses to cold within the pea species (Dumont et al., 2011; Grimaud et al., 2013). In order to discriminate chilling from freezing tolerance responses, the freezing tolerant line Champagne and the freezing sensitive line Terese were compared under low temperature and control treatments. Grimaud et al. (2013) showed that cold exposure induces higher aerial biomass production, while freezing tolerance is more related to early higher number of chloroplasts and higher amounts of chlorophylls. The capability of Champagne to develop freezing tolerance is also linked to an early ability to maintain optimal energy production, which is achieved by preventing photo-inhibition through optimization of the photosystems stoichiometry, capability to start additional pathways such as cyclic electron transport around PSI and to induce dynamic changes in carbohydrate and protein synthesis and/or turnover, which support the previous physiological work above stated. At the transcriptomic level, Lucau-Danila et al. (2012) also pointed 
out that Champagne showed a better capability to adjust its photosynthetic apparatus to resist photoinhibition in comparison to Terese. Higher concentrations of raffinose in Champagne also observed in this study could be in compliance with a stabilizing action of this molecule on PS II. Besides, genes related to the response to oxidative stress, stabilization of proteins or RNA secondary structures, hormone metabolism or cell wall composition were also found to be up-regulated in Champagne. Most of the freezing tolerance mechanisms suggested at the transcriptomic level were also revealed by the proteomic study of Dumont et al. (2011).

\section{Future perspectives}

Efforts have been made to produce pea stress tolerant genotypes based on the knowledge of the plant response to stress and the mechanisms involved described above but improvement by traditional breeding methods are limited by the complexity and multigenic nature of the tolerance responses. For some traits like recently frost tolerance, QTL mapping is however paving the way toward marker assisted selection. Despite the complexity of most abiotic stresses, stress tolerant cultivars have been bred in several occasions introducing traits from stress-adopted wild relatives or landraces (Bartels and Sunkar, 2005). Particularly landraces have considerable potential to improving abiotic stress tolerance since the transfer of beneficial traits from them is relatively straight-forward in that there is no barrier to crossing. For instance, a deep rooting landrace well adapted to a high range of temperatures from Ethiopia has been reported (JI1432). In addition, P. fulvum is a possible source of stress tolerance for cultivated pea, particularly for drought, since, its main root penetrate to greater depths at a rapid rate in the soil (Ali et al., 1994). Accessions of $P$. elatius adapted to frozen temperatures have also been reported (Ali et al., 1994). In addition, since genetically modified pea has a relatively low risk for the environment (outcrossing level $<1 \%$ ), gene transformation could arise as an useful tool for pea breeding (Mc Phee, 2008). However, up to date very few gene transformation work were carried out for improving pea for abiotic stress tolerance may be due to the complexity of the plant tolerance mechanisms above presented (Grant and Cooper 2003; Jewell et al., 2010). Interestingly, several genes related to osmolyte production in pea were recently cloned, and the mannitol phosphate dehydrogenase $(m t 1 D)$ introduced in the pea genotype "Akt" for improving its drought tolerance, albeit the conclusion on the tolerance of the regenerants was not delivered yet (Molnár, 2008).

\section{Faba Bean}

Up to today, faba bean improvement of adaptation to abiotic stresses was mainly achieved indirectly via breeding for grain yield. In spite of such progress, a main common characteristic of the species - beneath its basic tolerance to slightly saline soil (Katerji et al., 2011) and to mild frost - is its preference of cool, moist conditions, such as spring and summer in England or winters and spring of the Mediterranean Basin. Faba bean is sensitive to drought stress, whether occurring as intermittent or terminal water deficit (e.g., McDonald and Paulsen, 1997).

To uncover, understand and exploit genetic variation for stress tolerance, the stress needs to be specified. As an example, level and pattern of applied drought stress varies widely among researchers (e.g., Grzesiak et al., 1997; Nerkar et al., 1981). Under water stress, the plant may find virtually unlimited amount of water yet hard to take up or a limited offer of water as in terminal drought. With intermittent stress, plants are allowed to recover. Nevertheless, genetic differences for recovery have been barely analysed so far (Khan et al., 2010). Drought stress may or may not be separated from heat stress, from low air humidity and from further intervening features (Amede et al., 1999; Link et al., 1999).

\section{Abiotic stress responses}

a. Drought. In general, promising traits to be analyzed for drought tolerance are shoot and root morphology and developmental pattern, small-scale anatomy such as stomata features, physiological traits belonging to osmotic adjustment or to wateruse efficiency and related items.

In temperate and semi-arid climate, fast development is generally decreasing drought penalty. In Germany, spring faba bean need about 12 days from sowing to first photosynthesis, whereas e.g., spring pea needs only 7 days, mainly because faba beans are sown deeper, need a higher temperature sum $\left(5700^{\circ} \mathrm{C}>\right.$ $3300^{\circ} \mathrm{C}$ ) than pea and more water per seed (about $3.8 \mathrm{~g}>1.5 \mathrm{~g}$ ) to germinate (Schmidtke, 2012). Smaller-seeded crops and weeds realize, compared to faba bean, a head start. Water that is transpired by weed or lost by evaporation because ground cover is not yet realized increases threat of future drought. On the other hand, speedy canopy closure to minimize evaporation may be a minor topic for autumn-sown beans. Autumn-sowing reduces the drought-threat-driven haste; ground cover will anyway occur only after winter and much earlier than with spring sowing; and larger seeds produce more vigorous, larger-leaved juvenile plants. This may speak in favor of winter faba beans being larger-seeded than spring faba beans.

The genetic diversity of reactions to temperature and day length does seemingly not limit a timely approach of locally adapted faba beans to flowering in the many established growing regions (e.g., China, Ethiopia, Nile Valley, Mediterranean Basin, Central, West and North Europe, Andean South America).

The peculiar reproductive mode of faba bean is a further moment of loss of time, thus of increased risk to suffer from drought. Vicia faba is partly cross-fertilized by honey bees and bumble bees. Its roughly $40 \%$ to $50 \%$ of outcrossing is highly depending on genotype, inbreeding status and actual environment (Palmer et al., 2009). Drought considerably reduced autofertiliy, thus reducing options to escape by speedy development (Stoddard, 1986).

Prospects of monogenetic, altered morphology such as terminal inflorescence types, stable types (stiff-straw) and of independent vascular supply types for dry environments are raising 
little optimism (Frauen and Sass, 1989; Sass and Stelling, 1989; Patrick and Stoddard, 2010). No stiff-straw cultivars (Boss, Mythos) are on the market any more, in spite of this type causing shorter, thinner stem and smaller leaflets, candidate features of a drought-tolerant ideotype. The 'terminal inflorescence' type may promise escape because of earlier maturity, yet is barely discussed in relation to drought escape. The so-called 'independent vascular supply,' coined by Gates et al. (1983) to reduce intra-raceme competition between pods was "quietly dropped" (Link, 2009; Patrick and Stoddard, 2010).

Müller and Ehlers (1986) compared spring faba bean cv. Diana with spring oats $\mathrm{cv}$. Leanda for root and stomata features across two years in field trials. The majority of roots faba bean were found within $1 \mathrm{~m}$ soil depth, whereas oats has roots up to $1.5 \mathrm{~m}$ deep. These findings support that oats could extract more water from soil. Moreover, faba bean showed stomata conductance of below $4 \mathrm{~g} \mathrm{H}_{2} \mathrm{O} /\left(\mathrm{m}^{2} \mathrm{~s}\right)$, compared to about $8 \mathrm{~g} \mathrm{H}_{2} \mathrm{O} /\left(\mathrm{m}^{2} \mathrm{~s}\right)$ of oats. Thus, faba bean is characterized by an early, very sensitive stomata closure, avoiding marked water loss. Such behavior reduces the faba beans yield capacity. Breeders should pre-pone faba bean's maximum development by about two weeks - this is promised by winter faba beans. Moreover, root length and depth should be genetically increased and mutual shading of the faba bean canopy could be decreased by breeding.

For nitrogenase activity, faba bean was found to be most drought-susceptible at flowering time (Plies-Balzer et al., 1995). Yet, nitrogen concentration in stressed plants was never reduced compared to control, thus seemingly nitrogen fixation under drought is not a major yield-limiting factor. In pulses, we see this general discussion of competition between vegetative sink versus reproductive sinks. A mild water shortage during flowering is favorable, since it limits vegetative growth allowing a yield and harvest index as high as in non water limiting conditions (Grashoff, 1990).

Karamanos (1978) concludes from field studies that mild stress moreover may cause a gradual hardening of a faba bean crop, shown by a lessened response to future drought in leaf number and leaf area than if non-hardened. A previous stress can, as shown by Davies (1978), dramatically decrease the sensitivity of stomata for an actual stress. Thus, hardening to drought must be a feature that improves the water status under drought.

Amede et al. (1999) and Link et al. (1999) agreed in the correlation between low plant height and high drought tolerance, thus breeders may select for the higher heritable plant height pattern as a proxy for yield reactions. A simple ideotype under drougth could be a xeromorphic type, with thick small leaves, thick cuticula, few, small stomata. Yet, Nerkar et al. (1981) found that a tall, large-leaved type such as Wierboon with high transpiration per leaf area and high water use efficiency would be characterized as drought-tolerant. Wierboon had high growth rate, high net assimilation rate, and the authors conclude from their data that selection for superior water use efficiency could well be conducted under adequate irrigation as well as under stress condition.
Khazaei et al. (2011, 2013a, b) applied the FIGS (Focused identification of Germplasm Strategy) concept to two very large samples of faba beans $(N=200$ each), with provenance from dry and wet agro-ecological environments. The authors try to learn from such differential adaptation how this may have altered drought-related features of the faba bean. Under non-stress conditions, the traits identified to be most important for drought adaptation were leaflet and canopy temperature and relative water content, with marked temperature depression and high water content being associated with the dry-provenance faba beans; the dry set of faba beans had the higher mean transpiration rate and thus cooler leaves than the wet set (assessed without stress). Leaf temperature depression was negatively and significantly correlated to stomata conductance and transpiration rate $(0.59<r<0.85)$ and positively correlated with intrinsic water use efficiency ( $r=0.75$ in the dry set and $r=0.51$ in the wet set) under non-stress conditions. Looking on stomata frequency and stomata length, the dry set of faba beans had less frequent and larger stomata (assessed without stress) than what the wet set of faba beans showed. Less and larger stomata may be the genetic adaptation to drought. Looking on the effect of experimental drought stress on these faba beans, Khazaei et al. (2013a, b) reported an increase of stomata density and a decrease of their size, accompanied with the expected decrease in gas exchange. Increase of stomata density may partly be caused by drought-induced decrease of leaflet size. Finally these authors concluded that, for faba beans, there is no support of reduced stomata frequency and size being favorable under drought. The well-known drought tolerance inbred line ILB938/2 (Abdelmula et al., 1999; Khan et al., 2007) had, as example, a rather high stomata density. Stomata frequency and stomata size showed a clear negative, genetic correlation, counterbalancing each other presumed effects on drought tolerance. Hence, stomata opening and closing behavior and features such as root traits and cuticula traits must have marked impact on the drought tolerance of faba bean. Whether adaptation to drought causes a general increase or decrease of stomata frequency and size seem to not yet be fully resolved.

Opinions are divided as to osmotic adjustment (Serraj and Sinclair, 2002). Amede et al. (1999), based on greenhouse experiments, explained the clear genetic differences between solute accumulation mainly by differential accumulation due to differential water loss and not by active solute synthesis. The authors conclude that there was not true osmotic adjustment in this material. Similar to Amede et al. (1999), Katerji et al. (2002) found that the cv. Superaquadulce did not respond with osmotic adjustment to moisture stress. Balko (2005) agrees on a low ability of faba bean to osmotic adaptation. Yet, high proline accumulation was going along with low yield depression due to stress. Khan et al. (2010) doubt whether faba bean can actively adjust turgor and osmotic potential as response to drought.

Beneath proline, further compounds are discussed. El-Tayeb (2006a, b) compared Giza 40 with Giza 667. Giza 40 is a drought tolerant cultivar, whereas Giza 667 is drought susceptible 
(Soliman et al., 2011). He compared the performance of potted juvenile plants at $90 \%$ and $40 \%$ field capacity. Drought stress caused a larger increase in lipid peroxidation (measured via malondialdehyde, a breakdown product of multiply desaturated fatty acids). A low level of 0.6 malondialdehyde per $g$ fresh weight of both cultivars increased due to drought to 2.7 (tolerant cv.) and 5.4 (susceptible cv.). Similarly, he reports a greater level and drought-induced increase in catalase and peroxidase activity in the susceptible cv. than for Giza 40.

Assessment of the discrimination against the heavier carbon isotope, delta ${ }^{13} \mathrm{C}$, is meanwhile a standard approach to indirectly measure stomata conductance and water use efficiency (Condon et al., 2006; Khan et al., 2010), including in faba bean (Khan et al., 2007). The importance of ${ }^{13} \mathrm{C}$ discrimination is generally accepted, yet, selection direction seems unclear; e.g., Balko et al. (2013) found delta ${ }^{13} \mathrm{C}$ to be positively correlated to grain yield under drought stress (terminal drought) yet negatively so under non-stress conditions. Khan et al. (2010) take delta ${ }^{13} \mathrm{C}$ as the 'gold standard' of physiological drought tolerance assessment. Yet, it is rather costly compared to e.g., assessing leaf temperature depression with infrared thermometer or infrared camera (Costa et al., 2013). Indeed, leaf temperature depression as a direct result of transpiration is promising to reflect water use efficiency and stomata conductance in faba bean (Khan et al., 2007). Temperature differences are mainly meaningful under non-stress conditions, but under stress, with presumably all stomata closed, differences are insignificant, depending on the severity of the stress applied. Given the lack of markedly drought-tolerant faba bean accession, alien genes should be introgressed from other crops. Alas, faba bean cannot yet be crossed with any of its related species such as V. peregrina; thus, genetic transformation is a tempting tool to acquire additional diversity. Hanafy et al. (2013) report their recent success in transforming faba bean (tannin-free cultivar Tattoo) with the PR10a gene from potato. This transgene was taken because of its impact on salt or drought tolerance in potato. Fertile transgenic faba bean plants showed clear and convincing effects, promising a novel approach to improve drought and salt tolerance.

Environmentally-caused phenotypic modification (acclimation) as response to stress may differ in direction and size from genetic adaptation. Heterosis-caused genetic change, giving tolerance, may well differ in direction and size from a non-heterotic genetic adaptation. This is true even in spite of the very tempting gain especially under stress: Abdelmula et al. (1999) reported from $27 \mathrm{~F} 1$ hybrids along with their parents in rain-out shelters in four environments, with mid-parent heterosis (grain yield) of 52\% under stress conditions and 39\% without stress. More recently, Flores et al. $(2012,2013)$ reported high GxE interaction in faba bean adaptation to both autumn and spring sowing under European conditions, supporting specific breeding for each of the three main geoclimatic zones identified (Continental, Oceanic and Mediterranean).

b. Cold. The second main abiotic stress of faba bean is frost and in general winter conditions. The currently used winter-hardy material is of restricted genetic breadth. Recollecting winter-hardy types in promising areas or re-analysing ex-situ collections for winter hardiness should be conducted ( $\mathrm{Hu}$ et al., 2010; Mikic et al., 2011). Winter faba beans are different from the autumn-sown faba beans arround the Mediterranean Basin (Flores et al., 2012) which are challanged only by mild winters.

Summing up, the most important breeding objectives specifically for winter faba beans are (Link et al., 2010) (i) high frost tolerance after hardening; (ii) appropriate hardening requirement, hardening effect and dehardening behavior; (iii) basic frost tolerance before hardening and after dehardening; (iv) adequate vernalization requirement; (v) field resistance of long snow-cover; (vi) high tolerance to frost-drought ('FrostTrocknis'; winter drought; winter desiccation from high solar radiation during soil water is frozen); and (vii) tolerance of soil movement caused by cycles of frost and thawing (root rupture). The items after the first-mentioned one make up the main difference between frost tolerance assessment in controlled conditions and field-based breeding for winter survival. To tailor developmental rhythm of the plant to its target environment, we must look at vernalization and hardening together. Lee et al. (2001) showed for thale cress that both phenomena are to some extent genetically connected, yet Soja and Steineck (1986) reported them to be disconnected for faba bean. The major impact of an appropriate, vernalization-based postponement of flowering until after winter in pea is demonstrated by the $\mathrm{Hr}$-locus, being a major frost-tolerance gene ( $\mathrm{Hr}$; Lejeune-Henaut et al., 2004, 2008; Taye et al., 2013). However, no such results are as yet available for faba bean.

European winter faba beans can be vernalized as seed or juvenile plants at non-freezing temperatures below about $10^{\circ} \mathrm{C}$ (Herzog, 1988). Yet, spring-sown winter faba bean, being unvernalized, respond to the long-day trigger and flower, albeit later (Ellis et al., 1988a; Fujime et al., 2000). Currently we see fast progress in the understanding of 'flowering genes' such has FLC and others (http://www.flowercrop.uni-kiel.de/en).

Optimum temperature for hardening is at about $5-8^{\circ} \mathrm{C}$ in the day and $2^{\circ} \mathrm{C}$ in the night, with sufficient light at day, whereas above $7^{\circ} \mathrm{C}$ already dehardening may start (Herzog, 1988). Hardening leads to cell membrane lipid unsaturation and changes in lipid to protein ration (Hughes and Dunn, 1996). Arbaoui and Link (2008c) found faba bean leaf lipids to be significantly decreased in oleic acid content, accompanied by a significant mean increase in linolenic upon hardening. Similarly, Collins et al. (2002) found a significantly higher level of unsaturated fatty acids in white clover genotypes that survived a frost test, than in the unselected population. Hardening increases the content of osmoprotectants that can accumulate without disturbing metabolism and protect against dehydration. Examples are proline, glycinebetaine and related compounds, specific sugars and some specific proteins (Uemura et al., 2006).

Proline accumulation due to hardening is correlated with frost tolerance in faba bean (Arbaoui et al., 2008a). Similarly, 
Konstantinova et al. (2002) found increased freezing tolerance in transgenic tobacco that accumulated proline. Verification of glycinebetaine as osmotic protectant in cool-season pulses is still lacking (Stoddard et al., 2006).

Duc and Petitjean (1995) and Arbaoui et al. (2008a) positively stated that results of controlled frost tests, for instance with potted juvenile plants in growth chambers, agreed with overwintering in the true field situation. Our current experience (Link and Sallam, 2013, unpublished) says that high frost tolerance in controlled conditions is a strict requirement to good survival of harsh winters, yet, is no sufficient guarantee. Obviously and understandably, there are furthers factors acting in the field (such as winter drought and soil movement (frost heaving by repeated freezing and thawing of soil; see above).

Central European winter faba beans such as the Göttingen Winter Bean Population, the cvs. Hiverna, Husky, Nordica, Diva, survive field temperatures down to -15 or $-16^{\circ} \mathrm{C}$ if adequately hardened. At Göttingen, meanwhile further gain from selection for tolerance in controlled conditions was realized (Link and Sallam, 2013, unpublished; http://www.unigoettingen.de/en/48273.html).

A common feature of drought and frost stress is water loss. Under frost, water moves from the cells into intercellular space (Thomashow, 1998). This water is found as ice crystals in the intercellular space. Ice crystals hurt cell membranes, and after thawing, hurt cells loose turgor and may die. Solutions to this threat, realized by some plant species and genotypes are 'avoidance of ice formation,' for instance via 'depression of the freezing temperature by osmotic adjustment,' and 'supercooling below the freezing point,' employment of 'antifreeze proteins' (Nilsen and Orcutt 1996; Thomashow 2001; Reyes-Díaz et al., 2006; Uemura et al., 2006). The existence and impact of such phenomena in faba bean are barely known.

Birch et al. (1985) reported superior frost tolerance of accession of $V$. narbonensis and $V$. johannis. Yet, with interspecific hybridization being unsuccessful, so far all attempts to exploit the secondary gene pool of faba bean failed. Duc and Petitjean (1995) found high and favourable heterosis for tolerance of potted, juvenile plants. This is corroborating our own findings (unpublished data) at Göttingen. Yet, heterosis can only partly be exploited in synthetic cultivars, because not hybrid cultivars are yet on the market (Link, 2009).

Molecular genetic work on frost tolerance was started and is in the pipeline. Arbaoui et al. (2008b) analyzed a set of recombinant inbred lines for frost tolerance, putatively uncovering three useful QTL for frost tolerance.

\section{E. Forage Legumes}

Forage legumes are key components of livestock operations whether grazed or harvested as hay or silage. Most forage legumes important to agriculture are perennials or annuals belonging to the Medicago, Trifolium and Lotus genera. Although several other forage legumes are adapted to and grown in different environments, alfalfa, also referred to as lucerne, is the most predominant forage legume grown worldwide. Alfalfa is a high-yielding perennial species with the capacity to adjust or adapt physiologically and morphologically over a certain range of temperature and rainfall to persist for a few years or from generation to generation over a period of years. The range of adaptability is genetically controlled and thus most species perform well in a characteristic region or adaptation zone. Cultivated alfalfa, an outcrossing autoteptraploid $(2 \mathrm{n}=4 \mathrm{x})$ species, can be harvested multiple times in each growing season, is highly nutritious and an integral component for the beef and dairy industries. In addition to its broad economic value, alfalfa also has the capacity for symbiotic nitrogen fixation.

Forage legumes differ from seed legumes in the relative significance of vegetative leaf tissue, especially under a grazing system that requires a continuous supply of vegetative production. Although some forage crops are grown on soils ideal for agricultural, most forage species are grown on weathered soils that might be shallow, sandy, have fertility issues or those that have low water-holding capacity. Management techniques can be used to mitigate the effect of climatic constraints or stresses to extend the areas where desirable genotypes can be grown economically (Baron and Belanger, 2007). However, unlike annuals, perennials are long-lived and thus will likely encounter multiple impediments to plant growth and crop production during their lifespan. These limiting factors include abiotic stress conditions that account for extensive losses in agriculture. For a more detailed review on general forage legumes breeding please refer to Annicchiarico et al. (2014, this issue).

\section{Abiotic stress responses}

Increased demands for food production to feed a growing global population have pushed agricultural systems towards marginal lands. This shift in agricultural production will require the development of forage legume cultivars adapted to less-than-optimal conditions. Environmental factors that negatively affects plant growth and development represents a stress, and these stressors include limited water availability, temperature extremes, nutrient deficiencies, soil acidity and salinity. Usually one type of stress is accompanied or followed by another stress. For example, heat stress is accompanied by drought stress due to the physical loss of water and/or high atmospheric evaporative demand, and freezing stress is followed by drought stress due to the physiological unavailability of water (Agarwal and Zhu, 2005).

a. Drought. Erratic rainfall patterns have reduced agricultural productivity while areas in which fields are irrigated are at increased risk for salinization of field soils. Increased demands for water have also pushed agricultural systems towards rain-fed systems, further reducing forage biomass yield. Given the uncertainty over future water supplies in the realm of climate change (MacCracken, 2008; Erigayama et al., 2009) and the increasing demand for water for non-farm use, increased water use efficiency (WUE) reflected in the amount of biomass produced per unit of water used, is an important trait for 
alfalfa improvement. Ecologically, the best strategy for plants during water deficit is to conserve their resources. From an agronomic perspective, the ideal tolerant plants would be able to continue to grow as if unaffected by drought. In the case of perennial legumes, survival during drought and the subsequent forage production following drought is an important component of the tolerance response. Agricultural management practices can be used to mitigate additional stresses on forage plants during grazing due to the effects from defoliation. Other strategies to enable better drought adaptation include the availability of soil nutrients (fertilizers) in adequate amounts to promote healthy plants and the development of vigorous roots (Blevins and Barker, 2007).

Alfalfa is characterized by a deep taproot that can grow to a depth in excess of $7 \mathrm{~m}$ (Humphries and Auricht, 2001), thus enabling it to grow in areas ranging from $250-1500 \mathrm{~mm}$ annual rainfall. Genetic variation was identified among and between alfalfa populations in response to drought and WUE, which indicates the amount of forage and root biomass produced per unit of water transpired (Ray et al., 1998, Ray et al., 2004; Han et al., 2007). Alfalfa genotypes contrasting for biomass production under various water regimens were used to identify QTL for biomass production under both irrigated and drought conditions (Han et al., 2008). The alfalfa genotypes contrasting for drought response were further characterized for molecular, biochemical, morphological and physiological modifications. Changes in stomatal density, greater root growth following water withholding, greater accumulation of osmolytes, including raffinose and galactinol, and flavonoid antioxidants were observed (Kang et al., 2011). Osmotic adjustments results in the accumulation of nutrients and sugars to change the cell water volume (Blevins and Barker, 2007) and these changes have been associated with tolerance to drought stress. Others reported a reduction in photosynthesis in response to water deficit in mature alfalfa plants (Bell et al., 2007). Although increased cuticular wax accumulation in leaves enhanced drought tolerance (Zhang et al., 2005), the wax contents in alfalfa leaves and their responses were not consistent when multiple alfalfa cultivars were evaluated (Ni et al., 2012), suggesting this may be a genotypedependent strategy to cope with drought stress.

Genes encoding transcription factors and other regulatory proteins, and genes involved in the biosynthesis of osmolytes and flavonoids were differentially regulated between two contrasting genotypes (Kang et al., 2011). WXP1 is an example of a transcription factor that leads to improved drought tolerance when overexpressed in transgenic alfalfa (Jiang et al., 2009). The transgenic alfalfa lines showed higher net photosynthetic rate, transpiration rate, and stomatal conductance and higher efficiency of photosystem II, quantum yield of photosystem II and coefficient of photochemical quenching under water stress and in response to re-watering. The transgenic lines also showed higher relative water content and leaf water potential under water deficit conditions. In white clover, another important forage legume, the WXP1 transgenic lines had higher net photosyn- thetic rates, higher relative water content and leaf water potential under drought-stressed conditions and overall improved tolerance to drought stress (Jiang et al., 2010). Other transgenic approaches aimed at improving plant drought responses include over-expression of superoxide dismutase (McKersie et al., 1996) and trehalose-6-phosphate synthase/phosphatase (Suarez et al., 2009). Additional efforts to improve the WUE of forage legumes via traditional breeding approaches or genetic modifications can target various key processes: (a) mobilizing more of the available water through the crop rather than it being lost due to evaporation from the soil surface or drainage beyond the root zone; (b) producing more biomass in exchange for the water transpired by the crop by improving the WUE; or (c) partitioning more of the biomass into the harvested product (Condon et al., 2004).

$b$. Heat tolerance. Alfalfa grows under diverse environmental conditions. Nevertheless, temperature stress is one of the primary factors limiting its growth and expansion into new regions. High temperatures can inhibit growth, reduce yield and shorten the longevity of the stand (McKenzie et al., 1988). In many alfalfa-growing areas, air temperatures may exceed $40^{\circ} \mathrm{C}$. These temperatures are considerably above the $27^{\circ} \mathrm{C}$ temperatures established for optimal herbage growth. Temperatures not sufficiently high to kill cells may still inhibit growth, impair vigor and suppress production as a result of high respiration losses, reduced $\mathrm{N}$ fixation, reduced carbohydrate reserves in roots and crowns, or an increased resistance to $\mathrm{CO}_{2}$ diffusion due to smaller cells and leaves (Delaney et al., 1974). High temperatures also increase the rate of plant development and reduce the leaf/stem ratio and digestibility in alfalfa (Buxton, 1996). Multiple biomass harvests combined with high soil temperatures can exacerbate the deleterious effects of heat stress (McKenzie et al., 1988). The reduction of forage yield in alfalfa at high temperatures (and under limited water availability) is a complex process that cannot be ascribed to a single factor. Because breeding strategies aimed at enhancing drought tolerance will oftentimes capture the plant response to heat stress, heat tolerance is not considered by most breeders as an individual target for improvement.

c. Freezing tolerance. Forage legume breeders have emphasized temperature resistance, especially cold adaptation, for crown-forming perennials like alfalfa. Inadvertently though, the improved productivity under these conditions may be at the expense of winter hardiness (Beuselinck et al., 1994). In general, as winter approaches, many plants acquire freezing tolerance during exposure to low, non-freezing temperatures during the cold acclimation process. The acclimation process that induces freezing tolerance in certain plant species is essential and often associated with a period of slow growth and dormancy (Mohapatra et al., 1988). In alfalfa, specific cold acclimation or cas genes are expressed and metabolic changes occur (Monroy and Dhindsa, 1995). Vegetative storage proteins (VSPs) play adaptive roles in plant tolerance against freezing tolerance likely due to their antifreeze activity (Dhont et al., 2006). These VSPs are also preferentially mobilized during alfalfa shoot growth 
in the spring or during regrowth after defoliation in the summer (Justes et al., 2002). Alfalfa genotypes selected for higher autumn dormancy also showed a positive relationship between reduced winter injury and high total soluble proteins (TSP) concentrations in alfalfa roots (Cunningham et al., 1998). The accumulation of endogenous carbon $(\mathrm{C})$ and nitrogen $(\mathrm{N})$ reserves in the roots of perennial alfalfa during autumn acclimation has an influence on the capacity of the plant to withstand winter stresses (McKenzie et al., 1988; Volenec et al., 2002) and the regrowth vigor during the following Spring (Dhont et al., 2006). These findings provide insights into likely mechanisms of cold acclimation and freezing tolerance in alfalfa.

From a practical perspective, molecular markers targeting cold-inducible or cold-responsive genes can also be useful in breeding applications for cold tolerance. For example, a polymorphism in a cold-inducible dehydrin (highly hydrophilic protein) increased in frequency as a response to recurrent selection for superior freezing tolerance in alfalfa (Remus-Borel et al., 2010). The progenies from crosses between contrasting genotypes also differed in their tolerance to subfreezing temperatures. Tetraploid alfalfa populations recurrently selected for superior freezing tolerance using an indoor screening method (Castonguay et al., 2009) included positive alleles that enabled the identification of trait-related sequences with potential value for selection of alfalfa tolerance to subfreezing temperatures (Castonguay et al., 2012). Although efforts for improving winter injury have been achieved and captured in more winter-tolerant cultivars, cold tolerance can also be affected by crop management strategies.

d. Soil $\mathrm{pH}$ and aluminum toxicity. Plant nutrition management plays a key role in the success or failure of alfalfa production. The composition, potential rooting volume and the previous application of soil amendments can affect the quantity and rate of nutrient availability. Non-optimal soil conditions for crop growth include nutrient deficiencies or toxicities due to metal ions that include the presence of available aluminum (Al) ions in acidic soils. A soil pH range of 6.6 to 7.5 is ideal for alfalfa production (McKenzie et al., 1988). However, the optimum $\mathrm{pH}$ can vary with soil texture, organic matter and other soil chemical properties. Aluminum toxicity inhibits root growth and reduces yields due to insufficient intake of water and mineral nutrients (Kochian et al., 2004). The growth of alfalfa plants at low $\mathrm{pH}$ decreases in the presence of $\mathrm{Al}$ due to reduced root growth (Khu et al., 2012). Phenotypic screening methods that enable the dissection of acid-soil syndrome which consists of phytotoxicity to excess $\mathrm{Al}$ ions and protons were developed (Khu et al., 2012) and used to identify genotypes with contrasting plant growth responses under these conditions. Although genetic variation in tolerance to soil acidity exists in alfalfa, it is generally less than that found in other crops and is yet to be deployed in alfalfa cultivars. Research aimed at identifying the genetic determinants underlying variation in alfalfa tolerance responses began with the identification of $\mathrm{Al}$ tolerance QTL based on biomass production and root growth of two populations (Khu et al., 2013). Genes differentially expressed in response to $\mathrm{Al}$ stress in M. truncatula (Chandran et al., 2008) and located within Al QTL intervals in alfalfa include those associated with cell wall modification, isoflavonoid biosynthesis, general stress responses and oxidative stress (scavenging of reactive oxygen species). Transgenic plants of several species overexpressing organic acid synthesis and/or organic acid transporter genes have shown enhanced tolerance to $\mathrm{Al}$ (Kochian et al., 2004). Transgenic alfalfa expressing citrate synthase and a plasma membrane transporter showed higher $\mathrm{Al}$ and acid soil tolerance and lower levels of $\mathrm{Al}$ in shoot tissue than the nontransgenic isogenic population (Reyno et al., 2013). These findings suggest that $\mathrm{Al}$-exclusion could be driving $\mathrm{Al}$ and acid soil tolerance in the alfalfa populations evaluated so far. Current efforts aimed at enhancing productivity of alfalfa in acid soils also include evaluating the use of rhizobia strains tolerant to acid pH (Graham et al., 1994) so as to enable symbiotic nitrogen fixation under acidic conditions and improve overall plant performance.

$e$. Soil salinity. Another major limitation to the expansion of forage legume production is the issue of soil salinity. Salt stress, particularly on irrigated land, has and will continue to reduce crop production in many parts of the world (Jenks and Hasegawa, 2005). Estimates suggest that $20 \%$ of the world's cultivated land and nearly half of all irrigated lands are affected by soil salinity (Rhoades and Loveday, 1990). High concentrations of salts cause ion imbalances and hyperosmotic stress in plants, including forage legumes. As a consequence of salt stress disrupting homeostasis in water potential and ion distribution at the cell and whole plant level, secondary stresses such as oxidative damage often occur (Zhu, 2001). The capacity of legumes to grow on saline soils varies among species and depends on the concentration of salts present in the rootzone and on various environmental conditions (Maas and Hoffman, 1977). Although alfalfa has been characterized as moderately sensitive to saline conditions with yield decreases proportional to the saturation extract salinity (Maas and Hoffman, 1977), it is more salt tolerant than other forage legumes including clovers (Munns, 2005). Progress from selection was made when seedlings were germinated under salt stress and further evaluated using callus cultures or whole plants (Scasta et al., 2012). The biomass yields of alfalfa cultivars differ when grown in saline field conditions (Scasta et al., 2012) and high fibrous rooting characteristics in alfalfa have shown some usefulness as a salinity stress avoidance mechanism (Vaughan et al., 2002). These findings suggest that salinity problems can potentially be ameliorated through selection and development of salt tolerant cultivars. Although cellular and molecular responses to soil salinity have been identified (Hasegawa et al., 2000), the specific mechanisms of tolerance to salinity in alfalfa are unknown. Initial evaluations suggest that alfalfa is able to regulate the uptake and translocation of ions to prevent excessive accumulation of these ions in the leaves (Munns, 2005). The development of salt-tolerant cultivars adapted to a wide range of environments combined 
with timely on-farm management decisions can contribute to profitable production of alfalfa on salt-affected soils.

\section{Breeding approaches}

Alfalfa cultivars are synthetic populations generated mainly through phenotypic recurrent selection. In contrast to the inbred and homozygous crop legumes, alfalfa cultivars consist of highly variable, heterozygous plants with complementary alleles. Long-term, traditional breeding programs to improve alfalfa yield under stress conditions are underway (Vasconcelos et al., 2008; Li et al., 2010). Breeding for broad spectrum disease and insect resistance should also continue to be a priority since these are likely to be more prevalent in environments under which abiotic stress is rampant. Moving forward, research aimed at identifying genes and tolerance mechanisms that are common both at the onset and during several abiotic stresses (Hirayama and Shinozaki, 2010) could be useful to breeders aimed at utilizing genetic markers targeting genes that enable a plant to increase (or at least maintain) biomass yields in multiple environments. Knowledge of the mechanisms underlying the activation and regulation of specific stress-related genes, the integration of molecular markers available in alfalfa (Han et al., 2011, 2012; Li et al., 2012) and genomic selection methodologies have the potential to accelerate the rate of genetic gains during each cycle of selection.

The development of perennial forage legume (alfalfa) cultivars that are able to thrive, persist and be productive under abiotic stress environments, can be used to bridge the gap between potential and realized crop yields and contribute to the implementation of sustainable agricultural systems worldwide.

\section{F. Minor Grain Legumes}

The term 'minor' is often used to characterize the range of plant species whose potential contribution to food security, health, income generation, and environmental services is not currently exploited due to their limited competitiveness with commodity-improved crops that are part of mainstream agriculture (Padulosi et al., 2011). Indeed several of these species are grain legume staple crops grown in semi-arid tropics of Africa, Asia and South America (Varshney et al., 2012b) and by being naturally exposed to various biotic and abiotic stresses, they are also being selected for increased resistance or tolerance.

Here we focus on four minor legume species representing the two main Papilionoideae subdivisions, to illustrate present achievements and challenges faced by minor legume species in relation to abiotic stresses. From the warm-season or tropical legumes (phaseoloid clade), cowpea and pigeonpea are included, and from the cool-season or temperate legumes (galegoid clade), lentils and grass pea were considered.

\section{Abiotic stress responses}

All of the four selected species are adapted to harsh environments with the presence of abiotic stress constraints. Cowpea is a widely adapted, stress tolerant grain, vegetable, and fodder crop grown in warm to hot regions of Africa, Asia, and the Americas, and to a lesser extent, in parts of Southern Europe (Ehlers and Hall, 1997). Pigeonpea is an important grain legume of the semiarid tropics and sub-tropics being grown in Asia, Africa, Latin America, and the Caribbean, since it is considered a hardy, widely adapted, drought-tolerant crop with a large temporal variation (90-300 days) for maturity (Varshney et al., 2012a). Lentil is an annual legume crop that is produced throughout the world, and has special value in many of the semi-arid regions primarily due to its drought avoidance (Muehlbauer et al., 2006). Finally, grass pea is a dual purpose (grain and forage) annual crop with a remarkable resistance to extreme environmental conditions (Vaz Patto et al., 2006) and rightly considered one of the most promising sources of energy and protein for the vast and expanding populations of drought-prone and marginal areas of Asia and Africa. Due to its relative low input requirement, it is a model crop for sustainable agriculture and an interesting alternative for cropping systems diversification in marginal lands in Europe, Australia and America (Vaz Patto et al., 2006; Almeida et al., 2014).

All of these four species have considerable adaptation to drought. In pigeon pea, the ability to withstand severe drought is attributed to its deep roots and osmotic adjustment in the leaves. This species is capable of maintaining photosynthetic function during stress compared to other drought-tolerant legumes such as cowpea, and its unique polycarpic flowering habit further enables the crop to shed reproductive structures in response to stress (reviewed in Odeny, 2007). Additionally to its tolerance to drought, grass pea is also tolerant to excessive rainfall and can be grown on land subject to flooding. Its capacity to withstand moderate salinity has also been recognized (Campbell et al., 1994). It has a very hardy and penetrating root system and therefore can grow on a wide range of soil types, including very poor soil, of fine texture, with neutral to alkaline $\mathrm{pH}$, and heavy clays (Campbell, 1997). Grass pea has a high biological nitrogen fixation rate, which assists in maintaining soil fertility, and thus requires minimal production inputs (Campbell et al., 1994). Cowpea also maintains adequate levels of SNF, effective symbiosis with mycorrhizae, and has the ability to withstand both acid and alkaline soil conditions what makes this legume tolerant to low soil fertility (Ehlers and Hall, 1997, and references therein). In this way, cowpea grows well even in poor sandy soils with low P levels (Singh et al., 2003). Equally interesting is the high efficiency in $\mathrm{P}$ uptake of pigeonpea compared to other crops when grown on low P soils containing aluminum (Al) and its high tolerance to acid soils (Odeny, 2007, and references therein). Grass pea has been reported to be tolerant to a deficiency in essential nutrients and is able to store large amounts of lead in its root tissues (Brunet et al., 2008), which could be a useful trait for new rhizofiltration systems.

\section{Challenges due to abiotic constraints}

Even though these four legume species show considerable adaptation to harsh environmental conditions, some abiotic 
stresses can nevertheless cause detrimental impacts on their production. As an example, cowpea suffers damage to reproductive processes when night temperatures exceed $20^{\circ} \mathrm{C}$ due to pollen sterility and indehiscence of anthers (Hall, 2004). Likewise, heat is also considered one of the most important stresses affecting lentil production worldwide (Muehlbauer et al., 2006). Additionally both of these legume species are sensitive to chilling temperatures, exemplified by the reduction of cowpea's germination rate and final plant emergence when soil temperatures are below $19^{\circ} \mathrm{C}$ (Ehlers and Hall, 1997). Increased chilling tolerance at emergence in cowpea, as well as in lentil, especially in west Asia and North Africa regions and at high elevations (Muehlbauer et al., 2006; Erskine et al., 2011), would allow earlier planting in spring or even winter, and thus extend the growing season.

Similarly, salinity can also become a major problem for pigeonpea and lentil production especially under drought conditions in certain areas of Australia, Canada, and South and West Asia, and North Africa (Muehlbauer et al., 2006; Odeny, 2007). Germplasm with tolerance to salt stress has been identified in cultivated lentil and also promising variation for tolerance to salinity was identified in wild related species such as L. culinaris ssp. orientalis or in several wild pigeonpea relatives (Erskine et al., 2011; Upadhyaya et al., 2013). Although cowpea is considered as an intermediate salt tolerant species salt stress can impose a multifaceted injury to cowpea plants particularly for seed germination, vegetative growth, and yield (Chen et al., 2007). Nevertheless, significant variation was observed in this species for salt tolerance and thus it is likely feasible to select and breed for salt-tolerant cultivars.

Drought is considered one of the most important abiotic stresses for lentil production worldwide, as is the case for pigeonpea and cowpea particularly in its later stages of development (Muehlbauer et al., 2006; Varshney et al., 2010). Nevertheless, cowpea presents several broad adaptation mechanisms to drought. These include: drought escape, drought avoidance by decreasing leaf area or closure of stomata to reduce water loss and cessation of growth, dehydration avoidance, and vegetative stage drought tolerance by osmotic adjustment and continued slow growth or delayed leaf senescence (DLS) (Hall, 2004, and references therein). DLS allows the crop to remain alive through a midseason drought and recover when rainfall resumes (Gwathmey and Hall, 1992) and this adaptation mechanism appears to be conferred by a single gene involving resistance to premature death caused by Fusarium solani f. sp. phaseoli (Ismail et al., 2000). Kulkarni et al. (2000) suggested that the intrinsic capacity of cowpea varieties for ABA synthesis could also play an important role in regulating stomatal conductance in a drying soil and provide useful selection criteria for tolerance to drought stress. However in the majority of the minor plant species, physiological studies to understand the mechanisms and physiological traits conferring abiotic stress tolerance are scarce. For instances, drought stress responses in grasspea were evaluated through ecophysiological parameters, such as water extraction, stomatal responses or water use efficiency (Silvestre et al., 2014, and references therein). Nevertheless, a recent report suggested that improved drought tolerance in grass pea can be correlated with an increased accumulation of proline and soluble sugars together with improved strategies to dissipate reactive oxygen species under stress conditions (Jiang et al., 2013). Additionally, the lack of adequate screening methodologies, account for the under utilization of drought resistance traits from this minor legume species broadly in legume breeding programs. Recent advances in the development of efficient methods to screen for abiotic stress responses were implemented in the development of large scale Lathyrus drought and salt stress screening methods (Talukdar, 2011; Silvestre et al., 2014).

Soil imbalance in key minerals such as iron and boron constrains lentil yield similarly to the reduced productivity in pigeonpea from Al toxicity (Choudhary et al., 2011; Erskine et al., 2011). However, these stresses remain of local importance and variation exists within the cultivated germplasm. For instances, germplasm screening indicates that tolerance to iron deficiency is common among lentils from Syria and Turkey and landraces from Nepal and Bangladesh were identified as tolerant to boron deficiency (Erskine et al., 2011, and references there in). Furthermore, Al tolerant pigeonpea accessions have been consistently discriminated from sensitive genotypes using a rapid method based on hydroponic or sand assay seedlings growth response traits (Choudhary et al., 2011), with tolerance attributed to the exclusion of aluminum from the root.

Finally, water logging during the early developmental stages is an important constraint for pigeonpea and lentil production (Erskine et al., 1994; Varshney et al., 2010). Nevertheless, lentil genotypes that are more resistant to flooding were identified and these are characterized by large aerenchyma or air-spaces in their roots and by higher stomatal conductance compared to the more sensitive ones (Stoddard et al., 2006, and references therein). The highly flood resistant grass pea does have one important constraint that might be related to its higher survival rates under harsh conditions. Grass pea contains a toxic non-protein amino acid ( $\beta$-ODAP, $\beta$-N-oxalyl-L- $\alpha, \beta$ diaminopropionic acid) (Campbell et al., 1994) which levels were reported to vary in different tissues during plant development, and to be affected by a wide range of environmental stresses (Jiao et al., 2011). Xing et al. (2001) speculated that $\beta$-ODAP could scavenger the hydroxyl radicals to protect glycolate oxidase activity under water stress. Nevertheless, the role of $\beta$-ODAP in Lathyrus genotypes is still unknown. From the existing literature it is unclear if the initial $\beta$-ODAP content of a particular genotype would influence its behavior under drought or other abiotic stress conditions, and if the $\beta$-ODAP accumulation can be correlated with improved resistance. The clarification of these particular aspects requires further studies.

\section{Breeding achievements}

The development of productive early maturing cowpea cultivars has been one of the major important achievements from 
breeding efforts aimed at enhancing drought stress tolerance and is based on one of the previously described cowpea broad adaptation mechanisms (Ehlers and Hall, 1997). Early maturing cultivars can escape the end-of-season drought occurring in semiarid zones. Taking this into consideration, Hall (2004) considered that breeding should focus on two types of cultivars and these should be grown simultaneously to enhance the likelihood that significant grain production would be achieved every year. One type would be the early maturing with synchronous flower production, and the other type would began flowering later, with a more sequential rather than synchronous flowering. Accordingly, whereas the first cultivar type, if exposed to intermittent drought during the vegetative or reproductive stages would perform poorly, the second type, exhibiting greater resistance to midseason drought, would survive, but with a diminished ability to escape late-season drought.

Drought escape has been implicated on lentil adaptation to drought through early flowering, early growth vigor and rapid root growth (Erskine et al., 2011). Useful genetic variation was reported in response to drought stress within the lentil cultivated germplasm and variation has also been noted within wild Lens species particularly L. culinaris ssp. orientalis, often found in habitats receiving low average rainfall (Erskine et al., 2011). In particular, drought tolerant lentil cultivars exhibit lower cellmembrane injury and higher seedling growth, osmotic regulation and higher WUE (Stoddard et al., 2006).

In relation to heat stress, cowpea tolerant germplasm has been developed that is effective in both long-day and short-day conditions (Ehlers and Hall, 1997). Tolerance to heat-induced suppression of floral buds appears to be conferred by a major recessive gene, whereas the ability to set pods under hot conditions is controlled by a single dominant gene (Ehlers and Hall, 1997, and references therein). A close relationship between heat tolerance during pod set and slow electrolyte leakage from leaf discs subjected to heat stress was identified and this was used as a rapid method for heat tolerance screening (Hall, 2004). In cowpea, chilling tolerant germplasm was identified and the dehydrin protein seems to confer an incremental tolerance based on single nuclear gene inheritance (Hall, 2004, and references therein).

As previously mentioned, cowpea and lentil production can be increased significantly by shifting sowing from spring to early spring or winter (Ehlers and Hall, 1997; Erskine et al., 2011), only if the cultivar is winter hardy. Considerable variation for winter hardiness and cold tolerance was identified in lentil cultivated germplasm and also among wild relatives (Erskine et al., 2011). The inheritance winter hardiness in lentil was described as polygenic and QTL mapped (Kahraman et al., 2004a, b). Molecular markers associated with these QTL could be used in a marker assisted selection (MAS) program for winter hardiness after being validated and could include the use of the microsatellite marker ubc808-12 (Muehlbauer et al., 2006). Eujayl et al. (1999) also identified a RAPD marker (OPS-16750) that could be useful for MAS due to its linkage to a dominant seedling frost tolerance gene, Frt.
Until recently another factor that limited the improvement of abiotic stress resistance in some of these minor legumes was the limited number of genomic resources available (Varshney et al., 2012a). Nevertheless, presently many minor legumes are becoming "genomic resources rich crops" (Varshney et al., 2009). For example, a genome sequence is now available for pigeonpea (Varshney et al., 2012a). Cowpea genomics is also progressing and several QTL associated with seedling drought tolerance, based on maintenance of stem greenness and recovery of dry weight (Muchero et al., 2009), were identified. Several genederived markers that co-segregate with these QTLs were developed (Muchero et al., 2010). Additionally, more than a dozen genes associated with drought stress response were cloned and characterized (Muchero et al., 2010, and references therein). However, the specific role of these genes remains unknown. Additional resources in cowpea include numerous miRNAs that were identified under saline stress conditions using a homology searches based on cowpea miRNAs that are conserved in other plants (Paul et al., 2011). Likewise, Barrera-Figueroa et al. (2011), identified miRNAs that may play important roles in drought tolerance and may be key factors in determining the level of drought tolerance in the different cowpea genotypes. Further characterization of the targets of abiotic stressassociated miRNAs will help understand mechanisms of stress tolerance in cowpea.

Promising results are being obtained through MAS for lentil disease resistance genes and the same molecular breeding achievements are expected for abiotic stress resistance improvement in the near future given recent efforts in transcriptome profiling in this species (Sharpe et al., 2013). In the case of grass pea, although progress was achieved in obtaining genomic information from the Lathyrus genus, these resources are still comparatively modest. Nevertheless, the marker technologies with cross amplification in different species (Almeida et al., 2014) and the gene expression analyses in Lathyrus (Vaz Patto et al., 2011) allowed the identification of gene-specific molecular markers for the construction of high-density genetic linkage maps. These enhanced maps will facilitate the localization of useful abiotic stress resistance genes and QTLs for grass pea MAS, with the possibility of alignment with other species thus providing opportunities to use interesting abiotic stress resistance from grass pea in other related species.

\section{CONCLUSIONS}

In many regions of the world, especially under more marginal conditions, legumes play an essential role in enhancing food security, and promoting the development of a range of economic, social and environmental benefits. Like in many other crops, legume cultivation and productivity is affected by abiotic constraints, and the threatening aggravated scenario imposed by climate changes (IPCC, 2012) highlights the need for a globally concerted research approach. A collective research approach will facilitate the development of legumes (and other crops) that are able to adapt to and be productive under environmental 
limitations thus increasing yield and quality under abiotic stress and thus contributing to the implementation of a sustainable agricultural system.

Advances in genomics and the development of breederfriendly toolboxes have revolutionized plant improvement strategies by integrating complex biological data to inform genome-assisted breeding approaches (Wang et al., 2013). From this review we can conclude that model legumes have provided a valuable resource for translational approaches aimed at dissecting the molecular and physiological responses to abiotic stresses. By utilizing the genomic resources and highthroughput technologies available, genes associated with plant abiotic stress response(s) were deployed to generate stress tolerant legumes, via conventional and novel molecular breeding approaches. Nevertheless, research on abiotic stress resistance in legumes has mainly been conducted using discipline-specific or single gene based approaches, despite the level of complexity and complementarity observed (Table 1). The emphasis has shifted to the translation of the information gained in model systems in controlled environments to crops or forages in field conditions characterized by the simultaneous occurrence of different abiotic stresses. The research developed using soybean, as a model crop species, is one relevant example of successful translational research undertaken. The use and development of methodologies based on System Biology approaches will circumvent the barriers that previously blocked the translation of knowledge to generate new crop genomic resources (Cramer et al., 2011). Additional opportunities for the genetic improvement of abiotic stress tolerance in both grain and forage legumes include harnessing post-transcriptional gene regulation (Sunkar et al., 2007) and the corresponding databases to explore miRNAabiotic stress regulation including miRBASE (Kozomara and Griffiths-Jones, 2011) and PASmiR (Zhang et al., 2013). Moreover, the emerging innovative high-throughput phenotyping strategies provide the opportunity to assess spatial and dynamic differences in abiotic stress resistance traits relevant to the field performance of legumes (Tuberosa, 2012; Claeys and Inzé, 2013; McAusland et al., 2013). The combination of multiple complementary strategies should be an integral part of legume improvement strategies and is expected to enable researchers and breeding to more efficiently address the current and future demands of modern agriculture and food production presently exacerbated by the variability in global climate change.

\section{ACKNOWLEDGMENT}

The authors would like to acknowledge Prof. Manuela Chaves for critically reviewing the manuscript.

\section{FUNDING}

This research was partly supported by the following funding institutions/projects: Fundação para a Ciência e a Tecnologia, Portugal (PEst-OE/EQB/LA0004/2013, PTDC/AGR-TEC/ 3555/2012, PTDC/AGR-GPL/099866/2008, PTDC/AGR-GPL/
011244/2009, MCVP and SSA Ciência 2008 Research Contracts); Spanish Ministry of Economy and Competitiveness AGL2010/15936AGR and AGL2011-23738; EU FP6 project GLIP; Saclay Plant Sciences Program SPS, ANR-10-LABX40; Samuel Roberts Noble Foundation, Oklahoma Bioenergy Center and the U.S. Department of Agriculture; BMZ-GIZ, Germany, CGIAR Generation Challenge Program, Bill and Melinda Gates Foundation of USA.

\section{REFERENCES}

Abdelmula, A. A., Link, W., von Kittlitz, E., and Stelling, D. 1999. Heterosis and inheritance of drought tolerance in faba bean (Vicia faba L.). Plant Breeding 118: 485-490.

Adamska, I. 1997. ELIPs - Light-induced stress proteins. Physiol. Plant. 100: 794-805.

Agarwal, M., and Zhu, J. K. 2005. Integration of abiotic stress signaling pathways. In: Plant Abiotic Stress. p. 270. Jenks, M. A., and Hasegawa, P. M., Eds., Blackwell Publishing, Oxford, UK.

Aghaei, K., Ehsanpour, A. A., Shah, A. H., and Komatsu, S. 2008. Proteome analysis of soybean hypocotyl and root under salt stress. Amino Acids 36: 91-98.

Alamillo, J. M., Diaz-Leal, J. L., Sanchez-Moran, M. V., and Pineda, M. 2010. Molecular analysis of ureide accumulation under drought stress in Phaseolus vulgaris L. Plant Cell Environ. 33: 1828-1837.

Alexieva, V., Sergiev, I., Mapelli, S., and Karanov, E. 2001. The effect of drought and ultraviolet radiation on growth and stress markers in pea and wheat. Plant Cell Environ. 24: 1337-1344.

Ali, Z., Zhang, D. Y., Xu, Z. L., Xu, L., Yi, J. X., He, X. L., Huang, Y. H., Liu, X. Q., Khan, A. A., Trethowan, R. M., and Ma, H. X. 2012. Uncovering the salt response of soybean by unravelling its wild and cultivated functional genomes using Tag sequencing. PLoS ONE 7: e48819.

Ali, S. M., Sharma, B., and Ambrose, M. J. 1994. Current status and future strategy in breeding pea to improve resistance to biotic and abiotic stresses. Euphytica 73: 115-126.

Almeida, N. F., Leitão, S. T., Caminero, C., Torres, A. M., Rubiales, D., and Vaz Patto, M. C. 2014. Transferability of molecular markers from major legumes to Lathyrus spp. for their application in mapping and diversity studies. Mol. Biol. Rep. 41: 269-283.

Amede, T., von Kittlitz, E., and Schubert, S. 1999. Differential drought responses of faba beans (Vicia faba L.) inbred lines. J. Agron. Crop Sci. 183: 35-45.

Amsalu Fenta, B. 2012. Investigation of the Physiological Responses in Soybean and Common Bean to Water Deficit. PhD thesis, University of Pretoria, Pretoria. http://upetd.up.ac.za/thesis/available/etd-05042013-151442/

An, P., Inanaga, S., Cohen, Y., Kafkafi, U., and Sugimoto, Y. 2002. Salt tolerance in two soybean cultivars. J. Plant Nutr. 25: 407-423.

Andersen, M. N., and Aremu, J. A. 1991. Drought sensitivity, root development and osmotic adjustment in field-grown peas. Irrigation Sci. 12: 45-51.

Annicchiarico, P., Barrett, B., Brummer, E. C., Julier, B, and Marshall, A. H. 2014. Achievements and challenges in improving temperate perennial forage legumes. 34(1-3): 325-378.

Antolin, M. C., Hekneby, M., and Sanchez-Diaz, M. 2005. Contrasting responses of photosynthesis at low temperatures in different annual legume species. Photosynthetica 43: 65-74.

Aoki, T., Kamizawa, A., and Ayabe S. 2002. Efficient Agrobacterium-mediated transformation of Lotus japonicus with reliable antibiotic selection. Plant Cell Rep. 21: 238-243.

Araújo, S. D. S., Duque, A. S. R. L. A., Santos, D. M. M. F., and Fevereiro, M. P. S. 2004. An efficient transformation method to regenerate a high number of transgenic plants using a new embryogenic line of Medicago truncatula cv. Jemalong. Plant Cell Tiss. Organ Cult. 78: 123-131.

Arbaoui, M., Balko, C., and Link, W. 2008a. Study of faba bean (Vicia faba L.) winter-hardiness and development of screening methods. Field Crops Res. 106: 60-67. 
Arbaoui, M., Link, W., Satovic, Z., and Torres, A. M. 2008b. Quantitative trait loci of frost tolerance and physiologically related traits in faba bean (Vicia faba L.). Euphytica 164: 93-104.

Arbaoui, M., and Link, W. 2008c. Effect of hardening on frost tolerance and fatty acid composition of leaves and stems of a set of faba bean (Vicia faba L.) genotypes. Euphytica 162: 211-219.

Ariel, F., Diet, A., Verdenaud, M., Gruber, V., Frugier, F., Chan, R., and Crespi, M. 2010. Environmental regumation of lateral root emergence in Medicago truncatula requires the HD-ZipI transcription factor HB1. Plant Cell 22: 2171-2183.

Armengaud, P., Thiery, L., Buhot, N., Grenier-De March, G., and Savouré, A. 2004. Transcriptional regulation of proline biosynthesis in Medicago truncatula reveals developmental and environmental specific features. Physiol. Plant. 120: 442-450.

Arraouadi, S., Badri, M., Abdelly, C., Huguet, T., and Aouani, M. E. 2012. QTL mapping of physiological traits associated with salt tolerance in Medicago truncatula Recombinant Inbred Lines. Genomics 99: 118-125.

Asada, K. 2000. The water-water cycle as alternative photon and electron sinks. Philos. T. Roy. Soc. B. 355: 1419-1430.

Assefa, T., Beebe, S. E., Rao, I. M., Cuasquer, J. B., Duque, M. C., Rivera, M., Battisti, A., and Lucchin, M. 2013. Pod harvest index as a selection criterion to improve drought resistance in white pea bean. Field Crops Res. 148: 24-33.

Asfaw, A., Almekinders, C. J. M., Blair, M. W., and Struik, P. C. 2012. Participatory approach in common bean (Phaseolus vulgaris L.) breeding for drought tolerance for southern Ethiopia. Plant Breeding 131: 125-134.

Asfaw, A., and Blair, M. W. 2012. Quantitative trait loci for rooting pattern traits of common beans grown under drought stress versus non-stress conditions. Mol. Breeding 30: 681-695.

Asraf, M., and Harris, P. J. C. 2004. Potential indicators of salinity tolerance in plants. Plant Sci. 166: 3-16.

Atkinson, N. J., and Urwin, P. E. 2012. The interaction of plant biotic and abiotic stresses: from genes to the field. J. Exp. Bot. 63: 3523-3544.

Avia, K., Pilet-Nayel, M. L., Bahrman, N., Baranger, A., Delbreil, B., Fontaine, V., Hamon, C., Hanocq E., Niarquin, M., Sellier H., Vuylsteker, C., Prosperi, J. M., and Lejeune-Henaut, I. 2013. Genetic variability and QTL mapping of freezing tolerance and related traits in Medicago truncatula. Theor. Appl. Genet. 126: 2353-2366.

Badri, M., Chardon, F., Huguet, T., and Aouani, M. E. 2011. Quantitative trait loci associated with drought tolerance in the model legume Medicago truncatula. Euphytica 181: 415-428.

Balko, C. 2005. Physiological parameters of drought tolerance in relation to yield and yield stability in faba beans. In: InterDrought-II. The 2nd Conf. on Integrated Approaches to Sustain and Improve Plant Production under Drought Stress. p. 5.08. Rome, Italy.

Balko, C., Giesemann, A., and Link, W. 2013. Delta ${ }^{13} \mathrm{C}$ in faba beans and its implication in drought stress response. In: Conference on Isotopes of Carbon, Water, and Geotracers in Paleoclimatic Research. University of Bern, German Association for Stable Isotope Research.

Baron, V. S., and Belanger, G. 2007. Climate and forage adaptation. In: Forages: The Science of Grassland Agriculture. pp. 83-104. Vol. II. Barnes R. F., et al., Eds., Blackwell publishing, Ames, Iowa.

Barrera-Figueroa, B., Gao, L., Diop, N. N., Wu, Z., Ehlers, J. D., Roberts, P. A., Close, T. J., Zhu, J. K., and Liu, E. 2011. Identification and comparative analysis of drought-associated microRNAs in two cowpea genotypes. BMC Plant Biol. 11: 127.

Barreto Dias, P. M., Brunel-Muguet, S., Durr, C., Huguet, T., Demilly, D., Wagner, M. -H., and Teulat-Merah, B. 2011. QTL analysis of seed germination and pre-emergence growth at extreme temperatures in Medicago truncatula. Theor. Appl. Genet. 1222: 429-444.

Bartels, D., and Sunkar, R. 2005. Drought and salt tolerance in plants. Crit. Rev. Plant Sci. 24: 23-58.

Basu, U. 2012. Identification of molecular processes underlying abiotic stress plants adaptation using "omics" technologies. In: Sustainable Agriculture and New Technologies. pp.149-172. Benkeblia, N., Ed., CRC Press, Boca Raton, FL.
Beebe, S. E. 2012. Common bean breeding in the tropics. Plant Breeding Rev. 36: 357-426.

Beebe, S., Ramirez, J., Jarvis, A., Rao, I. M., Mosquera, G., Bueno, G., and Blair, M. 2011. Genetic improvement of common beans and the challenges of climate change. In: Crop Adaptation to Climate Change. pp. 356-369. 1st ed. Yadav, S. S., Redden, R. J., Hatfield, J. L., Lotze-Campen, H., and Hall, A. E., Eds., Wiley, New York.

Beebe, S. E., Rao, I. M., Cajiao, C., and Grajales, M. 2008. Selection for drought resistance in common bean also improves yield in phosphorus limited and favorable environments. Crop. Sci. 48: 582-592.

Beebe, S., Rao, I. M., Mukankusi, C., and Buruchara, R. 2013a. Improving resource use efficiency and reducing risk of common bean production in Africa, Latin America and the Caribbean. In: Eco-Efficiency: From Vision to Reality. pp. 117-134. Hershey, C., and Neate, P., Eds., CIAT, Cali, Colombia.

Beebe, S., Rao, I. M., Blair, M., and Acosta, J. 2013b. Phenotyping common beans for adaptation to drought. Front. Plant Physiol. 4: 35.

Beebe, S., Rao, I., Devi Mura, J., and Polania, J. 2013c. Common beans, biodiversity, and multiple stress: Challenges of drought resistance in tropical soils. In: InterDrought, 2-6 September 2013. Perth, Australia.

Beebe, S., Rojas-Pierce, M., Yan, X., Blair, M. W., Pedraza, F., Muñoz, F., Tohme, J., and Lynch, J. P. 2006. Quantitative trait loci for root architecture traits correlated with phosphorus acquisition in common bean. Crop Sci. 46: 413-423.

Belko, N., Zaman-Allah, M., Diop, N. N., Cisse, N., Ehlers, J. D., Ndoye, O., Zombre, G., and Vadez, V. 2012. Lower soil moisture threshold for transpiration decline under water deficit correlates with lower canopy conductance and higher transpiration efficiency in drought tolerant cowpea. Funct. Plant Biol. 39: 306-322.

Bell, L. W., Williams, A. H., Ryan, M. H., and Ewing, M. A. 2007. Water relations and adaptations to increasing water deficit in three perennial legumes, Medicago sativa, Dorycnium hirsutum and Dorycnium rectum. Plant Soil 290: 231-243.

Benjamin, J. G., and Nielsen, D. C. 2006. Water deficit effects on root distribution of soybean, field pea and chickpea. Field Crops Res. 97: 248253.

Berger, J. D., Ali, M., Basu, P. S., Chaudhary, B. D., Chaturvedi, S. K., Deshmukh, P. S., Dharmaraj, P. S., Dwivedi, S. K., Gangadhar, G. C., Gaur, P. M., Kumar, J., Pannu, R. K., Siddique, K. H. M., Singh, D. N., Singh, D. P., Singh, S. J., Turner, N. C., Yadava, H. S., and Yadav, S. S. 2006. Genotype by environment studies demonstrates the critical role of phenology in adaptation of chickpea (Cicer arietinum L.) to high and low yielding environments of India. Field Crop Res. 98: 230-244.

Benedito, V. A., Torres-Jerez, I., Murray, J. D., Andriankaja, A., Allen, S., Kakar, K., Wandrey, M., Verdier, J., Zuber, H., Ott, T., Moreau, S., Niebel, A., Frickey, T., Weiller, G., He, J., Dai, X., Zhao, P. X., Tang, Y., and Udvardi, M. K. 2008. A gene expression atlas of the model legume Medicago truncatula. Plant J. 55: 504-513.

Benedito, V. A., Li, H., Dai, X., Wandrey, M., He, J., Kaundal, R., Torres-Jerez, I., Gomez, S. K., Harrison, M. J., Tang, Y., Zhao, P. X., and Udvardi, M. K. 2010. Genomic inventory and transcriptional analysis of Medicago truncatula transporters. Plant Physiol. 152: 1716-1730.

Berger, J. D., Milroy, S. P., Turner, N. C., Siddique, K. H. M., Imtiaz, M., and Malhotra, R. 2011. Chickpea evolution has selected for contrasting phenological mechanisms among different habitats. Euphytica 180: $1-15$.

Berry, J., and Bjorkman, O. 1980. Photosynthetic response and adaptation to temperature in higher-plants. Ann. Rev.Plant Physiol. Plant Mol. Biol. 31: 491-543.

Betti, M., Pérez-Delgado, C., García-Calderón, M., Díaz, P., Monza, J., and Márquez, A. 2012. Cellular stress following water deprivation in the model legume Lotus japonicus. Cells. 1: 1089-1106.

Beuselinck, P. R., Bouton, J. H., Lamp, W. O., Matches, A. G., McCaslin, M. H., Nelson, C. J., Rhodes, L. H., Sheaffer, C. C., and Volenec, J. J. 1994. Improving legume persistence in forage crop systems. J. Prod. Agric. 7: 311-322. 
Bianco, C., and Defez, R. 2009. Medicago truncatula improves salt tolerance when nodulated by an indole-3-acetic acid-overproducing Sinorhizobium meliloti strain. J. Exp. Bot. 60: 3097-3107.

Birch, A. N. E., Tithecott, M. T., and Bisby, F. A., 1985. Vicia johannis and wild relatives of the faba bean (Vicia faba), a taxonomic study. Econ. Bot. 39: 177-190.

Blevins, D. G., and Barker, D. J. 2007. Nutrients and water in forage crops. In: Forages: The Science of Grassland Agriculture. pp. 67-80. Vol. II. Barnes, R. F., Nelson, C. J., Moore K. J., and Collins M., Eds., Blackwell Publishing, Ames, Iowa.

Blum, A. 2009. Effective use of water (EUW) and not water-use efficiency (WUE) is the target of crop yield improvement under drought stress. Field Crops Res. 112: 119-123.

Blum, A. 2010. Plant Breeding for Water-Limited Environments. p. 272. Springer, New York.

Bounejmate, M., Loss, S. P., and Robson, A. D. 1994. Effects of temperature and frost on genotypes of Medicago truncatula $\mathrm{L}$. and Medicago aculeata $\mathrm{L}$. from contrasting climatic origins. J. Agron. Crop Sci.172: 236-227.

Bourion, V., Lejeune-Hénaut, I., Munier-Jolain, N., and Salon, C. 2003. Cold acclimation of winter and spring peas: carbon partitioning as affected by light intensity. Eur. J. Agron. 19: 535-548.

Boyer, J. S. 1982. Plant Productivity and Environment. Science 218: 443-448.

Boyer, J. S., and Meyer, R. F. 1979. Osmoregulation in plants during drought. Basic Life Sci. 14: 199-202.

Brandsæter, L. O., Smebya, T., Tronsmob, A., and Netlanda, J. 2000. Winter annual legumes for use as cover crops in row crops in northern regions: II. Frost resistance study. Crop Sci. 40: 248-254.

Brunet, J., Repellin, A., Varrault, G., Terryn, N., and Zuily-Fodil, Y. 2008. Lead accumulation in the roots of grass pea (Lathyrus sativus L.): a novel plant for phytoremediation systems? Com. Rend. Biol. 331: 859-864.

Bustos-Sanmamed, P., Bazin, J., Hartmann, C., Crespi, M., and LelandaisBrière, C. 2013. Small RNA pathways and diversity in model legumes: lessons from genomics. Front. Plant Sci. 4: 236.

Butare L., Rao, I. M., Lepoivre, P., Cajiao, C., Polania, J., Cuasquer, J., and Beebe, S. 2012. Phenotypic evaluation of interspecific recombinant inbred lines (RILs) of Phaseolus species for aluminum resistance and shoot and root growth response to aluminum-toxic acid soil. Euphytica 186: 715-730.

Butare, L., Rao, I. M., Lepoivre, P., Polania, J., Cajiao, C., Cuasquer, J. B., and Beebe, S. 2011. New sources of resistance in Phaseolus species to individual and combined aluminium toxicity and progressive soil drying stresses. Euphytica 181: 385-404.

Buxton, D. R. 1996. Quality-related characteristics of forages as influenced by plant environment and agronomic factors. Anim. Feed Sci. Tech. 59: $37-49$.

Campbell, C. G., Mehra, R. B., Agrawal, S. K., Chen, Y. Z., Abd El Moneim, A. M., Khawaja, H. I. T., Yadov, C. R., Tay, J. U., and Araya, W. A. 1994. Current status and future strategy in breeding grass pea (Lathyrus sativus). Euphytica 73: 167-175.

Campbell, C. G. 1997. Grass Pea-Lathyrus sativus L. In: Promoting the Conservation and Use of Underutilized and Neglected Crops. pp. 8-20. Campbell, C. G. Ed., Institute of Plant Genetics and Crop Plant Research Gatersleben/International Plant Genetic Resources Institute, Rome.

Cannon, S. B. 2013. The model legume genomes. Methods Mol. Biol. 1069: $1-14$.

Capitão, C., Paiva, J. P., Santos, D. M., and Fevereiro, P. 2011. In Medicago truncatula, water deficit modulates the transcript accumulation of components of small RNA pathways. BMC Plant Biol. 11: 79.

Castellanos, J. Z., Pena-Cabriales, J. J., and Acosta-Gallegos, J. A. 1996. 15Ndetermined dinitrogen fixation capacity of common bean (Phaseolus vulgaris) cultivars under water stress. J. Agr. Sci. Camb. 126: 327-333.

Castonguay, Y., Michaud, R., Nadeau, P., and Bertrand, A. 2009. An indoor screening method for improvement of freezing tolerance in alfalfa. Crop Sci. 49: 809-818.

Castonguay, Y., Dube, M. P., Cloutier, J., Michaud, R., Bertrand, A., and Laberge, S. 2012. Intron-length polymorphism identifies a Y2K4 dehydrin variant linked to superior freezing tolerance in alfalfa. Theor. Appl. Genet. 124: 809-819.

Claeys, H., and Inzé, D. 2013. The agony of choice: how plants balance growth and survival under water-limiting conditions. Plant Physiol. 162: 1768-1779.

Condon, A. G., Richards, R. A., Rebetzke, G. J., and Farquhar, G. D. 2004. Breeding for high water-use efficiency. J. Exp. Bot. 55: 2447-2460.

Cramer, G. R., Urano, K., Delrot, S., Pezzotti, M., and Shinozaki, K. 2011. Effects of abiotic stress on plants: a systems biology perspective. BMC Plant Biol. 11: 163.

Cunningham, S. M., Volenec, J. J., and Teuber, L. R. 1998. Plant survival and root and bud composition of alfalfa populations selected for contrasting fall dormancy. Crop Sci. 38: 962-969.

Chandra, S., Buhariwalla, H. K., Kashiwagi, J., Harikrishna, S., Sridevi, K. R., Krishnamurthy, L., Serraj, R., and Crouch, J. H. 2004. Identifying QTL-linked markers in marker-deficient crops. In: Proceedings of the 4th International Crop Science Congress. Fisher, T., Ed., Brisbane, Australia, 26 September-1 October 2004. The Regional Institute Ltd., Gosford, New South Wales, Australia.

Chandran, D., Sharopova, N., Ivashuta, S., Gantt, J., VandenBosch, K., and Samac, D. 2008. Transcriptome profiling identified novel genes associated with aluminum toxicity, resistance and tolerance in Medicago truncatula. Planta 228: 151-166.

Charlson, D. V, Bhatnagar, S., King, C. A., Ray, J. D., Sneller, C. H., Carter, T. E., and Purcell, L. C. 2009. Polygenic inheritance of canopy wilting in soybean [Glycine max L. Merr.]. Theor. Appl. Genet. 119: 587-594.

Charlton, A. J., Donarski, J. A., Harrison, M., Jones, S. A., Godward, J., Oehlschlager, S., Arques, J. L., Ambrose, M., Chinoy, C., Mullineaux, P. M., and Domoney, C. 2008. Responses of the pea (Pisum sativum L.) leaf metabolome to drought stress assessed by nuclear magnetic resonance spectroscopy. Metabolomics 4: 312-327.

Charrier, A., Lelievre, E., Limami, A. M., and Planchet, E. 2013. Medicago truncatula stress associated protein 1 gene (MtSAP1) overexpression confers tolerance to abiotic stress and impacts proline accumulation in transgenic tobacco. J. Plant Physiol. 170: 874-877.

Chaves, M. M. 1991. Effects of water deficits on carbon assimilation. J. Exp. Bot.42: 1-16.

Chaves, M. M., Flexas, J., and Pinheiro, C. 2009. Photosynthesis under drought and salt stress: regulation mechanisms from whole plant to cell. Ann. Bot. 103: $551-560$.

Chaves, M. M., Maroco, J. P., and Pereira, J. S. 2003. Understanding plant responses to drought- from genes to the whole plant. Funct. Plant Biol. 30: 239-264.

Chen, C., Tao, C., Peng, H., and Ding, Y. 2007. Genetic analysis of salt stress responses in asparagus bean (Vigna unguiculata (L.) ssp. sesquipedalis Verdc.). J. Hered. 98: 655-665.

Chen, J. R., Lu, J. J., Liu, R., Xiong, X. Y., Wang, T. X., Chen, S. Y., Guo, L. B., and Wang, H. F. 2010. DREB1C from Medicago truncatula enhances freezing tolerance in transgenic M. truncatula and China Rose (Rosa chinensis Jacq.). Plant Growth Regul. 60: 199-211.

Chen, L. M., Zhou, X. A., Li, W. B., Chang, W., Zhou, R., Wang, C., and Chen, S. L. 2013. Genome-wide transcriptional analysis of two soybean genotypes under dehydration and rehydration conditions. BMC Genomics. 14: 687.

Chen, L. Q., Qu, X. Q., Hou, B. H., Sosso, D., Osorio, S., Fernie, A. R., and Frommer, W. B. 2012. Sucrose efflux mediated by SWEET proteins as a key step for phloem transport. Science 335: 207-211.

Chen, M., Wang, Q. Y., Cheng, X. G., Xu, Z. S., Li, L. C., Ye, X. G., Xia, L. Q., and Ma, Y. Z. 2007. GmDREB2, a soybean DRE-binding transcription factor, conferred drought and high-salt tolerance in transgenic plants. Biochem. Biophys. Res. Commun. 353: 299-305.

Cheng, L., Li, S., Hussain, J., Xu, X., Yin, J., Zhang, Y., Chen, X., and Li, L. 2013. Isolation and functional characterization of a salt responsive transcriptional factor, LrbZIP from lotus root (Nelumbo nucifera Gaertn). Mol. Biol. Rep. 40: 4033-4045.

Choudhary, A. K., Singh, D., and Iquebal, M. A. 2011. Selection of pigeonpea genotypes for tolerance to aluminium toxicity. Plant Breeding 130: 492-495. 
CIALCA. 2007. The Consortium for Improving Agriculture-based Livelihoods in Central Africa (CIALCA). Progress Report, November 2006-December 2007.

Collins, R. P., Marshall, A. H., and Abberton M. T. 2002. Strategies for Improving Stress Tolerance in White Clover. pp. 24-27. IGER Innovations 2002.

Conde, A., Chaves, M. M., and Geros, H. 2011. Membrane transport, sensing and signaling in plant adaptation to environmental stress. Plant Cell Physiol. 52: $1583-1602$.

Condon, A.G., Richards, R. A., Rebetzhke, G. J., and Farhquhar, G. D. 2004. Breeding for high water-use efficiency. J. Exp. Bot. 55: 2447-2460.

Corpas, F. J., Chaki, M., Fernandez-Ocana, A., Valderrama, R., Palma, J. M., Carreras, A., Begara-Morales, J. C., Airaki, M., del Rio, L. A., and Barroso, J. B. 2008. Metabolism of reactive nitrogen species in pea plants under abiotic stress conditions. Plant Cell Physiol. 49: 1711-1722.

Costa, J. M., Grant, O. M., and Chaves M. M. 2013. Thermography to explore plant-environment interactions. J. Exp. Bot. 64: 3937-3949.

Craig, G. F., Atkins, C. A., and Bell, D. T. 1991. Effect of salinity on growth of Rhizobium and their infectivity and effectiveness on two species of Acacia. Plant Soil 133: 253-262.

Dabuxilatu, M. I. and Ikeda, M. 2005. Distribution of K, Na and $\mathrm{Cl}$ in root and leaf cells of soybean and cucumber plants grown under salinity conditions. Soil Sci. Plant Nutr. 51: 1053-1057.

Dam, S., Laursen, B. S., Ornfelt, J. H., Jochimsen, B., Staerfeldt, H. H., Friis, C., and Stougaard, J. 2009. The proteome of seed development in the model legume Lotus japonicus. Plant Physiol. 149: 1325-1340.

Davies, W. J. 1978. Some effects of abscisic acid and water stress on stomata of Vicia faba 1. J. Exp. Bot. 29: 175-182.

Deikman, J., Petracek, M., and Heard, J. E. 2012. Drought tolerance through biotechnology: improving translation from the laboratory to farmers' fields. Curr. Opin. Biotechnol. 23: 243-250.

Delaney, R. H., Dobrenz, A. K., and Poole, H. T. 1974. Seasonal variation in photosynthesis, respiration and growth components of non-dormant alfalfa. Crop Sci. 14: 58-61.

Dhont, C., Castonguay, Y., Avice, J. C., and Chalifour, F. P. 2006. VSP accumulation and cold-inducible gene expression during autumn hardening and overwintering of alfalfa. J. Exp. Bot. 57: 2325-2337.

Dita, M. A., Rispail, N., Prats, E., Rubiales, D., and Singh, K. B. 2006. Biotechnology approaches to overcome biotic and abiotic stress constraints in legumes. Euphytica 147: 1-24.

De Lorenzo, L., Merchan, F., Blanchet, S., Megias, M., Frugier, F., Crespi, M., and Sousa, C. 2007. Differential expression of the TFIIIA regulatory pathway in response to salt stress between Medicago truncatula genotypes. Plant Physiol. 145: 1521-1532.

De Lorenzo, L., Merchan, F., Laporte, P., Thompson, R., Clarke, J., Sousa, C., and Crespi, M. 2009. A novel plant Leucine-Rich Repeat receptor kinase regulates the response of Medicago truncatula roots to salt stress. Plant Cell 21: $668-680$

De Ronde, J. A., Cress, W. A., Krüger, G. H. J., Strasser, R. J., and Van Staden, J. 2004. Photosynthetic response of transgenic soybean plants, containing an Arabidopsis P5CR gene, during heat and drought stress. J. Plant Physiol. 161: 1211-1224.

De Zélicourt, A., Diet, A., Marion, J., Laffont, C., Ariel, F., Moison, M., Zahaf, O., Crespi, M., Gruber, V., and Frugier, F. 2012. Dual involvement of a Medicago truncatula NAC transcription factor in root abiotic stress response and symbiotic nodule. Plant J. 70: 220-230.

Del Castillo, L. D., and Layzell, D. B. 1995. Drought stress, permeability to $\mathrm{O}_{2}$ diffusion, and the respiratory kinetics of soybean root-nodules. Plant Physiol. 107: 1187-1194.

Del Castillo, L. D., Hunt, S., and Layzell, D. B. 1994. The role of oxygen in the regulation of nitrogenase activity in drought-stressed soybean nodules. Plant Physiol. 106: 949-955.

Desclaux, D., Huynh, T. T., and Roumet, P. 2000. Identification of soybean plant characteristics that indicate the timing of drought stress. Crop Sci. 40: 716.

Desclaux, D., and Roumet, P. 1996. Impact of drought stress on the phenology of two soybean Glycine max L. Merr cultivars. Field Crop Res. 46: 61-70.
Devasirvatham, V., Gaur, P. M., Mallikarjuna, N., Tokashishu, R. N., Trethowan, R. M., and Tan, D. K. Y. 2012. Effect of high temperature on the reproductive development of chickpea genotypes under controlled environments. Funct. Plant Biol. 39: 1009-1018.

Devi, J. M., Sinclair, T. R., Beebe, S. E., and Rao, I. M. 2013. Comparison of common bean (Phaseolus vulgaris L.) genotypes for nitrogen fixation tolerance to soil drying. Plant Soil 364: 29-37.

Domínguez-Ferreras, A., Munoz, S., Olivares, J., Soto, M. J., and Sanjuan, J. 2009. Role of potassium uptake systems in Sinorhizobium meliloti osmoadaptation and symbiotic performance. J. Bacteriol. 191: 2133-2143.

Domínguez-Ferreras, A., Soto, M. J., Perez-Arnedo, R., Olivares, J., and Sanjuan, J. 2009. Importance of trehalose biosynthesis for Sinorhizobium meliloti osmotolerance and nodulation of alfalfa roots. J. Bacteriol. 191: 74907499.

Du, W., Wang, M., Fu, S., and Yu, D. 2009. Mapping QTLs for seed yield and drought susceptibility index in soybean Glycine max L. across different environments. J. Genet. Genomics 36: 721-31.

Duc, G., and Petitjean, F. 1995. Study on the inheritance of freezing tolerance in Vicia faba L. In: AEP Conference 1995. pp. 130-131. AEP, Ed., Copenhagen, AEP, Paris, France.

Dumont, E., Bahrman, N., Goulas, E., Valot, B., Sellier, H., Hilbert, J. L., Vuylsteker, C., Lejeune-Henaut, I., and Delbreil, B. 2011. A proteomic approach to decipher chilling response from cold acclimation in pea (Pisum sativum L.). Plant Sci. 180: 86-98.

Dumont, E., Fontaine, V., Vuylsteker, C., Sellier, H., Bodele, S., Voedts, N., Devaux, R., Frise, M., Avia, K., Hilbert, J. L., Bahrman, N., Hanocq, E., Lejeune-Henaut, I., and Delbreil, B. 2009. Association of sugar content QTL and PQL with physiological traits relevant to frost damage resistance in pea under field and controlled conditions. Theor. Appl. Genet. 118: 1561-1571.

Duque, A. S., Almeida, A., Silva, A. B., Silva, J. M., Farinha, A. P., Santos, D., Fevereiro, P., and Araujo, S. S. 2013. Abiotic stress responses in plants: Unraveling the complexity of genes and networks to survive. In: Abiotic Stress: Plant Responses and Applications in Agriculture. Vahdati, K., and Leslie, C., Eds., InTech.

Durand, J. L., Sheehy, J. E., and Minchin, F. R. 1987. Nitrogenase activity, photosynthesis and nodule water potential in soybean plants experiencing water-deprivation. J. Exp. Bot. 38: 311-321.

Duthion, C., and Pigeaire, A. 1991. Seed lengths corresponding to the final stage in seed abortion of three grain legumes. Crop Sci. 31: 1579-1583.

Eddy, S. R. 2001. Non-coding RNA genes and the modern RNA world. Nat. Rev. Genet. 2: 919-929.

Ehlers, J. D., and Hall, A. E. 1997. Cowpea (Vigna unguiculata L. Walp.). Field Crop Res. 53: 187-204.

Ellis, R. H., Roberts, E. H., and Summerfield, R. J. 1988a. Effects of temperature, photoperiod and seed vernalization on flowering in faba bean Vicia faba. Ann. Bot. 61: 17-27.

Ellis, R. H., Roberts, E. H., and Summerfield, R. J. 1988b. Variation in the optimum temperature for rates of seedling emergence and progress towards flowering amongst six genotypes of faba bean (Vicia faba). Ann. Bot. 62 : 119-126.

Elmaghrabi, A. M., Ochatt, S., Rogers, H. J., and Francis, D. 2013. Enhanced tolerance to salinity following cellular acclimation to increasing $\mathrm{NaCl}$ levels in Medicago truncatula. Plant Cell Tiss. Organ Cult. 114: 61-70.

El-Tayeb, M. A. 2006a. Differential responses of pigments, lipid peroxidation, organic solutes, catalase and peroxidase activity in the leaves of two Vicia faba L. cultivars to drought. Int. J. Agr. Biol. 8: 116-122.

El-Tayeb, M. A. 2006b. Differential response of two Vicia faba cultivars to drought: growth, pigments, lipid peroxidation, organic solutes, catalase and peroxidase activity. Acta Agron. Hung. 54: 25-37.

Erigayama, N., Smakhtin, V., and Gamage, N. 2009. Mapping drought patterns and impacts: a global perspective. In: Research Report - International Water Management Institute. Vii: pp. 23.

Erskine, W., Tufail, M., Russell, A., Tyagi, M. C., Rahman, M. M., and Saxena, M. C. 1994. Current and future strategies in breeding lentil for resistance to abiotic and biotic stresses. Euphytica 73: 127-135. 
Erskine, W., Sarker, A., and Kumar, S. 2011. Crops that feed the world 3. Investing in lentil improvement towards a food secure world. Food Sec. 3: 127-139.

Eujayl, I., Erskine, W., Baum, M., and Pehu, E. 1999. Inheritance and linkage analysis of frost injury in lentil. Crop Sci. 39: 639-642.

FAO. 2011. http://faostat.fao.org.

FAO. 2013. Climate-Smart Agriculture Sourcebook.

Fallen, F. D., Hatcher, C. N., Allen, F. L., Kopsell, D. A., Saxton, A. M., Chen, P., Kantartzi, S. K., Cregan, P. B., Hyten, D. L., and Pantalone, R. R. 2013. Mapping QTL for seed protein and amino acids in the Benning $\times$ Danbaekkong soybean population. J. Plant Genom. Sci. 1: 68-79.

Fan, X. D., Wang, J. Q., Yang, N., Dong, Y. Y., Liu, L., Wang, F. W., Wang, N., Chen, H., Liu, W. C., Sun, Y. P., Wu, J. Y., and Li, H. Y. 2013. Gene expression profiling of soybean leaves and roots under salt, saline-alkali and drought stress by high-throughput Illumina sequencing. Gene 512: 392 402.

Fedina, I. S., Tsonev, T., and Guleva, E. I. 1993. The effect of pretreatment with proline on the responses of Pisum sativum to salt stress. Photosynthetica 29: 521-527.

Fedina, I. S., Tsonev, T. D., and Guleva, E. I. 1994. ABA as a modulator of the response of Pisum sativum to salt stress. J. Plant Physiol. 143: 245-249.

Flexas, J., and Medrano, H. 2002. Drought-inhibition of photosynthesis in C3 plants: stomatal and non-stomatal limitations revisited. Ann. Bot. 89: 183-189.

Flores, F., Nadal, S., Solis, I., Winkler, J., Sass, O., Stoddard, F. L., Link, W., Raffiot, B., Muel, F., Rubiales, D. 2012. Faba bean adaptation to autumn sowing under European climates. Agron. Sustain. Dev. 32: 727-734.

Flores, F., Hybl, M., Knudsen, J. C., Marget, P., Muel, F., Nadal, S., Narits, L., Raffiot, B., Sass, O., Solis, I., Winkler, J., Stoddard, F. L., Rubiales, D. 2013. Adaptation of spring faba bean types across European climates. Field Crops Res. 145: 1-9.

Flower, T. J., Gaur, P. M., Gowda, C. L. L., Krishnamurthy, L., Samineni, S., Vadez, V., Varshney, R., Siddique, K. M. H., Turner, N. C., and Colmer, T. C. 2009. A review of salt sensitivity in chickpea. Plant Cell Environ. 33: 490-509.

Filippou, P., Antoniou, C., and Fotopoulos, V. 2011. Effect of drought and rewatering on the cellular status and antioxidant response of Medicago truncatula plants. Plant Signal. Behav. 6: 270-277.

Fougere, F., Lerudulier, D., and Streeter, J. G. 1991. Effects of salt stress on amino acid, organic acid, and carbohydrate composition of roots, bacteroids, and cytosol of alfalfa (Medicago sativa L.). Plant Physiol. 96: 1228-1236.

Foy, C. D. 1998. Plant adaptation to acid, aluminium toxic soils. Comm. Soil Sci. Plant Anal. 19: 959-987.

Frauen, M., and Sass, O. 1989. Inheritance and performance of the stiff-strawed mutant in Vicia faba L. In: Science for Plant Breeding - XII. EUCARPIA Congress, Göttingen (Germany), 27 Feb. - 4 March 1989, Vol 15: 13-18.

Fujime, Y., Mesuda, Y., Okuda, N., and Varanyanond, W. 2000. Promotive effects of seed vernalization on flowering and pod setting of some broad bean cultivars. Acta Hortic. 533: 75-82.

Gajewska, E., and Sklodowska, M. 2005. Antioxidative responses and proline level in leaves and roots of pea plants subjected to nickel stress. Acta Physiol. Plant. 27: 329-339.

Gallardo, K., Firnhaber, C., Zuber, H., Hericher, D., Belghazi, M., Henry, C., Küster, H. and Thompson, R. 2007. A combined proteome and transcriptome analysis of developing Medicago truncatula seeds: evidence for metabolic specialization of maternal and filial tissues. Mol. Cell Proteomics 6: $2165-2179$.

Gallegos, J. A. A., and Shibata, J. K. 1989. Effect of water-stress on growth and yield of indeterminate dry-bean (Phaseolus vulgaris) cultivars. Field Crops Res. 20: 81-93.

Gates, P., Smith, M. L., White, G., and Boulter, D. 1983. Reproductive physiology and yield stability in Vicia faba L. In: Temperate Legumes: Physiology, Genetics, Nodulation. pp. 43-54. Davies, D. R., and Jones, D. G., Eds., Pitman Books Ltd., London, UK.
Gaur, P. M., Krishnamurphy, L., and Kashiwagi, J. 2008. Improving droughtavoidance root traits in chickpea (Cicer arietinum L.) - current status of research at ICRISAT. Plant Prod. Sci. 11: 3-11.

Gaur, P. M., Chaturvedi, S. K., Tripathi, S., Gowda, C. L. L., Krishnamurthy, L., Vadez, V., Mallikarjuna, N., and Varshney, R. K. 2010. Improving heat tolerance in chickpea to increase its resilience to climate change. In: Proceeding of the 5th International Food Legumes Research Conference and 7th European Conference on Grain Legume. pp. 26-30. European Association for the Grain Legume Research. Antalya, Turkey.

Georgieva, K., and Lichtenthaler, H. K. 1999. Photosynthetic activity and acclimation ability of pea plants to low and high temperature treatment as studied by means of chlorophyll fluorescence. J. Plant Physiol. 155: 416-423.

Georgieva, K., and Lichtenthaler, H. K. 2006. Photosynthetic response of different pea cultivars to low and high temperature treatments. Photosynthetica 44: 569-578.

Ghittoni, N. E., and Bueno, M. A. 1996. Changes in the cellular content of trehalose in four peanut Rhizobia strains cultured under hypersalinity. Symbiosis 20: $117-127$

Gil-Quintana, E., Larrainzar, E., Arrese-Igor, C., and González, E. M. 2013a. Is $\mathrm{N}$-feedback involved in the inhibition of nitrogen fixation in drought-stressed Medicago truncatula? J. Exp. Bot. 64: 281-292.

Gil-Quintana, E., Larrainzar, E., Seminario, A., Díaz-Leal, J. L., Alamillo, J. M., Pineda, M., Arrese-Igor, C., Wienkoop, S., and González, E. M. 2013b. Local inhibition of nitrogen fixation and nodule metabolism in drought-stressed soybean. J. Exp. Bot. 64: 2171-2182.

Gimeno-Gilles, C., Gervais, M.-L., Planchet, E., Satour, P., Limami, A., and Lelievre, E. 2011. A stress-associated protein containing A20/AN1 zingfinger domains expressed in Medicago truncatula seeds. Plant Physiol. Biochem. 49: 303-310.

González, E. M., Aparicio-Tejo, P. M., Gordon, A. J., Minchin, F. R., Royuela, M., and Arrese-Igor, C. 1998. Water-deficit effects on carbon and nitrogen metabolism of pea nodules. J. Exp. Bot. 49: 1705-1714.

Gonzalez, E. M., Arrese-Igor, C., Aparicio-Tejo, P. M., Royuela, M., and Koyro, H. W. 2002. Solute heterogeneity and osmotic adjustment in different leaf structures of semi-leafless pea (Pisum sativum L.) subjected to water stress. Plant Biol. 4: 558-566.

González, E. M., Gordon, A. J., James, C. L., and Arrese-Igor, C. 1995. The role of sucrose synthase in the response of soybean nodules to drought. $J$. Exp. Bot. 46: 1515-1523.

Gonzales, M. D., Archuleta, E., Farmer, A., Gajendran, K., Grant, D., Shoemaker, R., Beavis, W. D., and Waugh, M. E. 2005. The Legume Information System (LIS): an integrated information resource for comparative legume biology. Nucleic Acids Res. 33: D660-D665.

Good, A. G., and Zaplachinski, S. T. 1994. The effects of drought stress on free amino acid accumulation and protein synthesis in Brassica napus. Physiol. Plant. 90: 9-14.

Gordon, A. J., Minchin, F. R., Skot, L., and James, C. L. 1997. Stress-induced declines in soybean $\mathrm{N}_{2}$ fixation are related to nodule sucrose synthase activity. Plant Physiol. 114: 937-946.

Graham, P. H., Draeger, K. J., Ferrey, M. L., Conroy, M. J., Hammer, B. E., Martinez, E., Aarons, S. R., and Quinto, C. 1994. Acid pH tolerance in strains of Rhizobium and Bradyrhizobium, and initial studies on the basis for acid tolerance of Rhizobium tropici UMR1899. Can. J. Microbiol. 40: 198-207.

Graham, P. H., and Rosas, J. C. 1977. Growth and development of indeterminate bush and climbing cultivars of Phaseolus vulgaris L. inoculated with Rhizobium. J. Agr. Sci. Camb. 88: 503-508.

Grant, J. E., and Cooper, P. A. 2003. Genetic transformation in pea. In: Applied Genetics of Leguminosae Biotechnology. pp. 23-34. Jaiwal, P. K., and Singh, R. P., Eds., Kluwer Academic Publishers, Dordrecht.

Grashoff, C. 1990. Effect of pattern of water supply on Vicia faba L. 1. Dry matter partitioning and yield variability. Ned. J. Agric. Sci. 38: 21-44.

Grimaud, F., Renaut, J., Dumont, E., Sergeant, K., Lucau-Danila, A., Blervacq, A.-S., Sellier, H., Bahrman, N., Lejeune-Hénaut, I., Delbreil, B., and Goulas, E. 2013. Exploring chloroplastic changes related to chilling and freezing 
tolerance during cold acclimation of pea (Pisum sativum L.). J. Proteomics 80: $145-159$.

Gross, Y., and Kigel, J. 1994. Differential sensitivity to high temperature of stages in the reproductive development of common bean (Phaseolus vulgaris L.). Field Crops Res. 36: 201-212.

Grover, A., Kapoor, A., Laksmi, O. S., Agarwal, S., Sahi, C., Katiyar-Agarwal, S., Agarwal, M., and Dubey, H. 2001. Understanding molecular alphabets of the plant abiotic stress responses. Curr. Sci. 80: 206-216.

Gruber, V., Blanchet, S., Diet, A., Zahaf, O., Boualem, A., Kakar, K., Alunni, B., Udvardi, M., Frugier, F., and Crespi, M. 2009. Identification of transcription factors involved in root apex responses to salt stress in Medicago truncatula. Mol. Genet. Genomics 281: 55-66.

Grzesiak, S., Iijima, M., Kono, Y., and Yamauchi, A. 1997. Differences in drought tolerance between cultivars of field bean and field pea. Morphological characteristics, germination and seedling growth. Acta Physiol. Plant. 19: 339-348.

Gwathmey, C. O., and Hall, A. E. 1992. Adaptation to midseason drought of cowpea genotypes with contrasting senescence traits. Crop Sci. 32: 773778.

Habibi, G. 2011. Influence of drought on yield and yield components in white bean. World Acad. Sci. Engin. Technol. 55: 244-253.

Hahn, A., Kilian, J., Mohrholz, A., Ladwig, F., Peschke, F., Dautel, R. and Wanke, D. 2013. Plant core environmental stress response genes are systemically coordinated during abiotic stresses. Int. J. Mol. Sci. 14: 76177641.

Hakeem, K. R., Khan, F., Chandna, R., Siddiqui, T. O., and Iqbal, M. 2012. Genotypic variability among soybean genotypes under $\mathrm{NaCl}$ stress and proteome analysis of salt-tolerant genotype. Appl. Biochem. Biotechnol. 168: 2309-2329.

Haldimann, P., and Feller, U. 2005. Growth at moderately elevated temperature alters the physiological response of the photosynthetic apparatus to heat stress in pea (Pisum sativum L.) leaves. Plant Cell Environ. 28: 302-317.

Hall, A. E. 2004. Breeding for adaptation to drought and heat in cowpea. Eur. J. Agron. 21: 447-454.

Hamwieh, A. and Xu, D. H. 2008. Conserved salt tolerance quantitative trait locus (QTL) in wild and cultivated soybeans. Breeding Sci. 58: 355359.

Han, Y., Khu, D. M., and Monteros, M. J. 2012. High-resolution melting analysis for SNP genotyping and mapping in tetraploid alfalfa (Medicago sativa L.). Mol. Breeding 29: 489-501.

Han, Y., Monteros, M. J., Sledge, M. K., Ray, I., and Bouton, J. 2007. Physiological characterization and QTL analysis of drought tolerance in alfalfa. In: 5th International Symposium on the Molecular Breeding of Forage and Turf. Sapporo, Japan.

Han, Y., Ray, I. M., Sledge, M. K., Bouton, J. H., and Monteros, M. J. 2008. Drought tolerance in tetraploid alfalfa. In: XXI International Grassland Congress and VII International Rangeland Congress. pp. 419. Hohhot, China.

Han, Y., Kang, Y., Torres-Jerez, I., Cheung, F., Town, C. D., Zhao, P. X., Udvardi, M. K., and Monteros M. J. 2011. Genome-wide SNP discovery in tetraploid alfalfa using 454 sequencing and high resolution melting analysis. BMC Genomics 12: 1-11.

Hanafy, M. S., El-Banna, A., Schumacher, H. M., Jacobsen, H. J., and Hassan, F. S. 2013. Enhanced tolerance to drought and salt stresses in transgenic faba bean (Vicia faba L.) plants by heterologous expression of the PR10a gene from potato. Plant Cell Rep. 32: 663-674.

Handberg, K., and Stougaard, J. 1992. Lotus japonicus, an autogamous, diploid legume species for classical and molecular genetics. Plant J. 2: 487-496.

Hanson, J., and Smeekens, S. 2009. Sugar perception and signaling - an update. Curr. Opin. Plant Biol. 12: 562-567.

Hardarson G., Bliss, F. A., Cigales Rivero, M. R., Henson, R. A., Kipe-Nolt, J. A., Longeri, L., Manrique, A., Penacabriales, J. J., Pereira, P. A. A., Sanabria, C. A., and Tsai, S. M. 1993. Genotypic variation in biological nitrogen fixation by common bean. Plant Soil 152: 59-70.
Hasegawa, P. M., Bressa, R. A., Zhu, J. K., and Bohnert, H. J. 2000. Plant cellular and molecular responses to high salinity. Аnпи. Rev. Plant Physiol. Plant Mol. Biol. 51: 463-99.

Hekneby, M., Antolin, M. C., and Sanchez-Diaz, M. 2006. Frost resistance and biochemical changes during cold acclimation in different annual légumes. Environ. Exp. Bot. 55: 305-314.

Henry, A., Rosas, J. C., Beaver, J. S., and Lynch, J. P. 2010. Multiple stress response and belowground competition in multilines of common bean (Phaseolus vulgaris L.). Field Crops Res. 117: 209-218.

Hernandez, J. A., and Almansa, M. S. 2002. Short-term effects of salt stress on antioxidant systems and leaf water relations of pea leaves. Physiol. Plant. 115: $251-257$.

Hernandez, J. A., Jimenez, A., Mullineaux, P., and Sevilla, F. 2000. Tolerance of pea (Pisum sativum L.) to long-term salt stress is associated with induction of antioxidant defences. Plant Cell Environ. 23: 853-862.

Herzog, H. 1989. Influence of pre-hardening duration and dehardening temperatures on varietal freezing resistance in faba beans (Vicia faba L.). Agronomie 9: 55-61.

Hirayama, T., and Shinozaki, K. 2010. Research on plant abiotic stress responses in the post-genome era: past, present and future. Plant J. 61: 1041-1052.

Ho, M., Rosas, J., Brown, K., and Lynch, J. 2005. Root architectural tradeoffs for water and phosphorus acquisition. Funct. Plant Biol. 32: 737-748.

Hossain, Z., Khatoon, A., and Komatsu, S. 2013. Soybean proteomics for unraveling abiotic stress response mechanism. J. Proteome Res. 12: 4670-4684.

Hsiao, T. C. 1973. Plant responses to water stress. Annu. Rev. Plant Physiol. Plant Mol. Biol. 24: 519-570.

Hu, J., Mwengi, J. E., Coyne, C. J., and Pan, W. L. 2010. Evaluating winterhardiness of faba bean (Vicia faba L.) accessions from the USDA NPGS collection. In: IFLRC V \& AEP VII. April 26-30, 2010, Antalya, Turkey.

Hu, J., Zhang, H., and Ding, Y. 2013. Identification of conserved microRNAs and their targets in the model legume Lotus japonicus. J. Biotechnol. 164: 520-524.

Hughes, M. A., and Dunn, M. A. 1996. Review Article. The molecular biology of plant acclimation to low temperature. J. Exp. Bot. 47: 291-305.

Humphries, A. W., and Auricht, G. C. 2001. Breeding lucerne for Australia's southern dryland cropping environments. Aus. J. Agric. Res. 52: 153-169.

Hussain, K., Majeed, A., Nawaz, K., Khizar H. B., and Nisar, M. F. 2009. Effect of different levels of salinity on growth and ion contents of black seeds (Nigella sativa L.). Curr. Res. J. Biol. Sci. 1: 135-138.

IPCC. 2012. Intergovernmental Panel on Climate Change - Managing the Risks of Extreme Events and Disasters to Advance Climate Change Adaptation. Cambridge University Press, Cambridge.

Ismail, A. M., Hall, A. E., and Ehlers, J. D. 2000. Delayed-leaf-senescence and heat-tolerance traits mainly are independently expressed in cowpea. Crop Sci. 40: $1049-1055$.

Iturbe-Ormaetxe, I., Escuredo, P. R., Arrese-Igor, C., and Becana, M. 1998. Oxidative damage in pea plants exposed to water deficit or paraquat. Plant Physiol. 116: 173-181.

Jannink, J. -L., Lorenz, A. J., and Iwata, H. 2010. Genomic selection in plant breeding: from theory to practice. Briefings Funct Genomic. 9: 166-177.

Jenks, M. A., and Hasegawa, P. M. 2005. Plant Abiotic Stress. Blackwell Publishing, Oxford, UK.

Jewell, M. C., Campbell, B. C., and Godwin, I. D. (2010) Transgenic plants for abiotic stress resistance. In: Transgenic Crop Plants. pp 67-131. Kole, C., Michler, C. H., Abbott, A. G., and Hall, T. C., Eds., Springer-Verlag, Berlin.

Jiao, C. J., Jiang, J. L., Ke, L. M., Cheng, W., Li, F. M., Li, Z. X., and Wang, C. Y. 2011. Factors affecting $\beta$-ODAP content in Lathyrus sativus and their possible physiological mechanisms. Food Chem. Toxicol. 49: 543-549.

Jiang, Q., Zhang, J. Y., Guo, X., Monteros, M. J., and Wang, Z. Y. 2009. Physiological characterization of transgenic alfalfa (Medicago sativa) plants for improved drought tolerance. Int. J. Plant Sci. 170: 969-978.

Jiang, Q., Zhang, J. Y., Guo, X., Bedair, M., Sumner, L., Bouton, J., and Wang, Z. Y. 2010. Improvement of drought tolerance in white clover (Trifolium 
repens) by transgenic expression of a transcription factor gene WXP1. Funct. Plant Biol. 37: 157-165.

Jiang, J., Su, M., Chen, Y., Gao, N., Jiao, C., Sun, Z., Li, F., and Wang, C. 2013. Correlation of drought resistance in grass pea (Lathyrus sativus) with reactive oxygen species scavenging and osmotic adjustment. Biologia 68: 231-240.

Jogaiah, S., Govind, S. R., and Tran, L. S. P. 2013. Systems biology-based approaches toward understanding drought tolerance in food crops. Crit. Rev. Biotechnol. 33: 3-39.

Jones-Rhoades, M. W., Bartel, D. P., and Bartel, B. 2006. MicroRNAS and their regulatory roles in plants. Annu. Rev. Plant Biol. 57: 19-53.

Justes, E., Thiebau, P., Avice, J. C., Ourry, A., Lemaire, G., and Volenec, J. J. 2002. Influence of summer sowing dates, $\mathrm{N}$ fertilization and irrigation on autumn VSP accumulation and dynamics of spring regrowth in alfalfa (Medicago sativa L.). J. Exp. Bot. 53: 111-121.

Kahraman, A., Kusmenoglu, I., Aydin, N., Aydogan, A., Erskine, W., and Muehlbauer, F. J. 2004a. Genetics of winter hardiness in 10 lentil recombinant inbred line populations. Crop Sci. 44: 5-12.

Kahraman, A., Kusmenoglu, I., Aydin, N., Aydogan, A., Erskine, W., and Muehlbauer, F. J. 2004b. QTL mapping of winter hardiness genes in lentil. Crop Sci. 44:13-22.

Kang, J., Xie, W., Sun, Y., Yang, Q., and Wu, M. 2010. Identification of genes induced by salt stress from Medicago truncatula L. seedlings. Afric. J. Biotechnol. 9: 7589-7594.

Kang, Y., Han, Y., Torres Jerez, I., Wang, M., Tang, Y., Monteros, M., and Udvardi, M. 2011. System responses to long-term drought and re-watering of two contrasting alfalfa varieties. Plant J. 68: 871-889.

Kao, W. Y., Tsai, T. T., Tsai, H. C., and Shih, C. N. 2006. Response of three Glycine species to salt stress. Environ. Exp. Bot. 56: 120-125.

Karamanos, A. J. 1978. Water stress and leaf growth of field beans (Vicia faba L.) in the field: Leaf number and total leaf area. Ann. Bot. 42: 1393-1402.

Kashiwagi, J., Krishnamurthy, L., Crouch, J. H., and Serraj, R. 2006. Variability of root characteristics and their contributions to seed yield in chickpea (Cicer arietinum L.) under terminal drought stress. Field Crops Res. 95: 171-181.

Kashiwagi, J., Krishnamurthy, L., Upadhyaya, H. D., Krishna, H., Chandra, S., Vadez, V., and Serraj, R. 2005. Genetic variability of drought-avoidance root traits in the mini-core germplasm collection of chickpea (Cicer arietinum $\mathrm{L}$.). Euphytica 146: 213-222.

Katerji, N., Mastrorilli, M., Lahmer, F. Z., Maalouf, F., and Oweis, T. 2011. Faba bean productivity in saline-drought conditions. Eur. J. Agron. 35: 2-12.

Khan, T. N., French, R. J., and Hardie, D. C. 1996. Breeding field peas for Western Australia: progress and problems. Pisum Genet. 28: 5-12.

Khan, H., Link, W., Hocking, T. J., and Stoddard, F. L. 2007. Evaluation of physiological traits for improving drought tolerance in faba bean (Vicia faba L.). Plant Soil 292: 205-217.

Khan, H. R., Paull, J. G., Siddique, K. H. M., and Stoddard, F. L. 2010. Faba bean breeding for drought-affected environments: A physiological and agronomic perspective. Field Crops Res. 115: 279-286.

Khazaei, H., Santanen, A., Stoddard, F., and Street, K. 2011. Variation in leaf morpho-physiological traits in a world collection of faba bean germplasm. In: 24th NJF Congress and 2nd NFS Conference 2011. Abstract $\mathrm{n}^{\circ} \mathrm{C} 136$. http://orgprints.org.

Khazaei, H., Street, K., Bari, A., Mackay, M., and Stoddard, F.L. 2013a. The FIGS (Focused Identification of Germplasm Strategy) approach identifies traits related to drought adaptation in Vicia faba genetic resources. PLoS ONE 8: e63107.

Khazaei, H., Street, K., Santanen, A., Barik, A., and Stoddard, F. L. 2013 b. Do faba bean (Vicia faba L.) accessions from environments with contrasting seasonal moisture availabilities differ in stomatal characteristics and related traits? Genet. Resour. Crop Evol. (DOI 10.1007/s10722-013-0002-4).

Khu, D. M., Reyno, R., Brummer, E. C., and Monteros, M. J. 2012. Screening methods for aluminum tolerance in alfalfa. Crop Sci. 52: 161-167.

Khu, D. M., Reyno, R., Han, Y., Zhao, P. X., Bouton, J. H., Brummer, E. C., and Monteros, M. J. 2013. Identification of aluminum tolerance quantitative trait loci in tetraploid alfalfa. Crop Sci. 53: 148-163.
Kim, G. B., and Nam, Y. W. 2013. A novel $\Delta$ 1-pyrroline-5-carboxylate synthetase gene of Medicago truncatula plays a predominant role in stressinduced proline accumulation during symbiotic nitrogen fixation. J. Plant Physiol. 170: 291-302.

Klaedke, S. M., Cajiao, C., Grajales, M., Polania, J., Borrero, G., Guerrero, A., Rivera, M., Rao, I., Beebe, S. E., and Léon, J. 2012. Photosynthate remobilization capacity from drought-adapted common bean (Phaseolus vulgaris L.) lines can improve yield potential of interspecific populations within the secondary gene pool. J. Plant Breeding Crop Sci. 4: 49-61.

Knight, H., and Knight, M. R. 2001. Abiotic stress signalling pathways: specificity and cross-talk. Trends Plant Sci. 6: 262-267.

Kochian, L. V., Hoekenga, O. A., and Pineros, M. A. 2004. How do crop plants tolerate acid soils? - Mechanisms of aluminum tolerance and phosphorous efficiency. Annu. Rev. Plant Biol. 55: 459-493.

Kolbert, Z., Bartha, B., and Erdei, L. 2008. Osmotic stress- and indole-3-butyric acid-induced NO generation are partially distinct processes in root growth and development in Pisum sativum. Physiol. Plant. 133: 406-416.

Konsens, I., Ofir, M., and Kigel, J., 1991. The effect of temperature on the production and abscission of flowers and pods in snap bean (Phaseolus vulgaris L.). Ann. Bot. 67: 391-399.

Konstantinova, T., Parvanova, D., Atanassov, A., and Djilianov, D. 2002. Freezing tolerant tobacco, transformed to accumulate osmoprotectants. Plant Sci. 163: $157-164$.

Kozomara, A., and Griffiths-Jones, S. 2011. miRBase: integrating microRNA annotation and deep-sequencing data. Nucleic Acids Res. 39: D152-157.

Krishnamurthy, L., Gaur, P. M., Basu, P. S., Chaturvedi, S. K., Tripathi, S., Vadez, V., Rathore, A., Varshney, R. K., and Gowda, C. L. L. 2011. Large genetic variation for heat tolerance in the reference collection of chickpea (Cicer arietinum L.) germplasm. Plant Genet. Resour. 9: 59-69.

Krishnamurthy, L., Kashiwagi, J., Gaur, P. M., Upadhyaya, H. D., and Vadez, V. 2010. Sources of tolerance to terminal drought in the chickpea (Cicer arietinum L.) minicore germplasm. Field Crops Res. 119: 322-330.

Krishnamurthy, L., Gaur, P. M., Upadhyaya, H. D., Turner, N. C., Colmer, T. C., Siddique, K. H. M., and Vadez, V. 2011 Consistent variation across years in salinity resistance in a diverse range of chickpea (Cicer arietinum L.) genotypes. J. Agron. Crop Sci. 197: 214-227.

Kulkarni, M. J., Prasad, T. G., and Sashidhar, V. R. 2000. Genotypic variation in early warning signals from roots in drying soil: intrinsic differences in ABA synthesizing capacity rather than root density determines total ABA message in cowpea (Vigna unguiculata L.). Ann. Appl. Biol. 136: 267-272.

Kumar, J., and Abbo, S. 2001. Genetics of flowering time in chickpea and its bearing on productivity in semiarid environments. Adv. Agron. 72: 107-138.

Kumar, J., and van Rheenen, H. A. 2000. A major gene for time of flowering in chickpea. J. Hered. 91: 67-68.

Larrainzar, E., Wienkoop, S., Scherling, C., Kempa, S., Ladrera, R., ArreseIgor, C., Weckwerth, W., and Gonzalez, E. M. 2009. Carbon metabolism and bacteroid functioning are involved in the regulation of nitrogen fixation in Medicago truncatula under drought and recovery. Mol. Plant Microbe Interact. 22: 1565-1576.

Larrainzar, E., Wienkoop, S., Weckwerth, W., Ladrera, R., Arrese-Igor, C., and Gonzalez, E. M. 2007. Medicago truncatula root nodule proteome analysis reveals differential plant and bacteroid responses to drought stress. Plant Physiol. 144: 1495-1507.

Lazrek, F., Roussel, V., Ronfort, J., Cardinet, G., Chardon, F., Aouani, M. E., and Huguet, T. 2009. The use of neutral and non-neutral SSRs to analyse the genetic structure of a Tunisian collection of Medicago truncatula lines and to reveal associations with eco-environmental variables. Genetica $\mathbf{1 3 5}$ : 391-402.

Le, B. H., Wagmaister, J. A., Kawashima, T., Bui, A. Q., Harada, J. J., and Goldberg, R. B. 2007. Using genomics to study legume seed development. Plant Physiol. 144: 564-572.

Lee, G. J., Boerma, H. R., Villagarcia, M. R., Zhou, X., Carter, T. E. Jr, Li, Z. and Gibbs, M. O. 2004. A major QTL conditioning salt tolerance in S-100 soybean and descendent cultivars. Theor. Appl. Genet. 109: 1610-1619. 
Lee, H. J., Xiong, L. M, Gong, Z. Z, Ishitani, M., Stevenson, B., and Zhu, J. K. 2001. The arabidopsis HOS1 gene negatively regulates cold signal transduction and encodes a RING finger protein that displays cold-regulated nucleo-cytoplasmic partitioning. Genes Dev. 15: 912-924.

Legrand, S., Marque, G., Blassiau, C., Bluteau, A., Canoy, A. -S., Fontaine, V., Jaminon, O., Bahrman, N., Mautord, J., Morin, J., Petit, A., Baranger, A., Rivière, N., Wilmer, J., Delbreil, B., and Lejeune-Hénaut, I. 2013. Combining gene expression and genetic analyses to identify candidate genes involved in cold responses in pea. J. Plant Physiol. 170: 1148-1157.

Lejeune-Henaut, I., Morin, J., Fontaine, V., Etévé, G., Devaus, R., Thomas, M., Boilleau, M., Stampniak, J. J., Petit, A., Rameau, C., and Baranger, A. 2004. Towards genes to breed for freezing resistance in pea. In: AEP Conference 2004. p. 127. AEP, Ed., Dijon. AEP, Paris, France.

Lejeune-Hénaut, I., Hanocq, E., Béthencourt, L., Fontaine, V., Delbreil, B., Morin J., Petit, A., Devaux, R., Boilleau, M., Stempniak, J. J., Thomas, M., Lainé, A. L., Foucher, F., Baranger, A., Burstin, J., Rameau, C., and Giauffret, C. 2008. The flowering locus $\mathrm{Hr}$ colocalizes with a major QTL affecting winter frost tolerance in Pisum sativum L. Theor. Appl. Genet. 116: $1105-1116$

Li, D., Su, Z., Dong, J., and Wang, T. 2009. An expression database for roots of the model legume Medicago truncatula under salt stress. BMC Genomics 10: 517 .

Li, D., Zhang, Y., Hu, X. Shen, X., Ma, L., Su, Z., Wang, T., and Dong, J. 2011. Transcriptional profiling of Medicago truncatula under salt stress identified a novel CBF transcription factor MtCBF4 that plays an important role in abiotic stress responses. BMC Plant Biol. 11: 109.

Li, G. D., Nie, Z. N., Boschma, S. P., Dear, B. S., Lodge, G. M., Hayes, R. C., Clark B., Hughes, S. J., and Humphries, A. W. 2010. Persistence and productivity of Medicago sativa subspecies sativa, caerulea, falcata and varia accessions at three intermittently dry sites in south-eastern Australia. Crop Pasture Sci. 61: 645-658.

Li, H., Dong, Y., Yin, H., Wang, N., Yang, J., Liu, X., and Li, X. 2011. Characterization of the stress associated microRNAs in Glycine max by deep sequencing. BMC Plant Biol. 11: 170.

Li, J., Dai, X., Liu, T., and Zhao, P. X. 2012. LegumeIP: an integrative database for comparative genomics and transcriptomics of model legumes. Nucleic Acids Res. 40: D1221-D1229.

Li, W. Y. F., Wong, F. L., Tsai, S. N., Phang, T. H., Shao, G., and Lam, H. M. 2006. Tonoplast-located GmCLC1 and GmNHX1 from soybean enhance $\mathrm{NaCl}$ tolerance in transgenic bright yellow (BY)-2 cells. Plant Cell Environ. 29: 1122-1137.

Li, X., Acharya, A., Farmer, A. D., Crow, J. A., Bharti, A. K., Kramer, R. S., Wei, Y., Han, Y., Gou, J., May, G. D., Monteros, M. J., and Brummer, E. C. 2012. Prevalence of single nucleotide polymorphism among 27 diverse alfalfa genotypes as assessed by transcriptome sequencing. BMC Genomics 13: 568 .

Liao, H., Rubio, G., Yan, X. L., Cao, A. Q., Brown, K. M., and Lynch, J. P. 2001. Effect of phosphorus availability on basal root shallowness in common bean. Plant Soil 232: 69-79.

Liao, H, Yan, X., Rubio, G., Beebe, S. E., Blair, M. W., and Lynch, J. P. 2004. Genetic mapping of basal root gravitropism and phosphorus acquisition efficiency in common bean. Funct. Plant Biol. 31: 959-970.

Liao, Y., Zou, H. F., Wei, W., Hao, Y. J., Tian, A. G., Huang, J., Liu, Y. F., Zhang, J. S., and Chen, S. Y. 2008. Soybean GmbZIP44, GmbZIP62 and GmbZIP78 genes function as negative regulator of ABA signaling and confer salt and freezing tolerance in transgenic Arabidopsis. Planta 228: 225240.

Link, W., Abdelmula, A. A., von Kittlitz, E., Bruns, S., Riemer, H., and Stelling, D. 1999. Genotypic variation for drought tolerance in Vicia faba. Plant Breeding 118: 477-483.

Link, W. 2009. Züchtungsforschung bei der Ackerbohne: Fakten und Potentiale. J. Kulturpflanzen 61: 341-347.

Link, W., Balko, C., and Stoddard, F. L. 2010. Winter hardiness in faba bean: Physiology and breeding. Field Crops Res. 115: 287-296.
Liu, F., Andersen, M. N., and Jensen, C. R. 2003. Loss of pod set caused by drought stress is associated with water status and ABA content of reproductive structures in soybean. Funct. Plant Biol. 30: 271-280.

Liu, F., Jensen, C. R., and Andersen, M. N. 2004. Drought stress effect on carbohydrate concentration in soybean leaves and pods during early reproductive development: its implication in altering pod set. Field Crop Res. 86: 1-13.

Liu, Y. H., Offler, C. E., and Ruan, Y. L. 2013. Regulation of fruit and seed response to heat and drought by sugars as nutrients and signals. Front. Plant Sci. 4: 282.

López-Gómez, M., Tejera, N. A., Iribarne, C., Herrera-Cervera, J. A., and Lluch, C. 2012. Different strategies for salt tolerance in determined and indeterminate nodules of Lotus japonicus and Medicago truncatula. Arch. Agron. Soil Sci. 58: 1061-1073.

Lopez, M., Tejera, N. A., Iribarne, C., Lluch, C., and Herrera-Cervera, J. A. 2008. Trehalose and trehalase in root nodules of Medicago truncatula and Phaseolus vulgaris in response to salt stress. Physiol. Plant. 134: 575-582.

Lucau-Danila, A., Toitot, C., Goulas, E., Blervacq, A. S., Hot, D., Bahrman, N., Sellier, H., Lejeune-Hénaut, I., and Delbreil, B. 2012. Transcriptome analysis in pea allows to distinguish chilling and acclimation mechanisms. Plant Physiol. Biochem. 58: 236-244.

Luo, Q., Yua, B., and Liua, Y. 2005. Differential sensitivity to chloride and sodium ions in seedlings of Glycine max and G. soja under $\mathrm{NaCl}$ stress. J. Plant Physiol. 162: 1003-1012.

Lynch, J. P. 2011. Root phenes for enhanced soil exploration and phosphorus acquisition: tools for future crops. Plant Physiol. 156: 1041-1049.

Lynch, J. P., and Beebe, S. E. 1995. Adaptation of beans (Phaseolus vulgaris L.) to low phosphorus availability. Hort Sci. 30: 1165-1171.

Lynch, J. P., and St. Clair, S. B. 2004. Mineral stress: the missing link in understanding how global climate change will affect plants in real world soils. Field Crops Res. 90: 101-115.

Ma, M., Ma, K., Qa, K., Mm, H., Mak, M., and Ju, A. 2010. Assessment of genetic divergence in salt tolerance of soybean (Glycine max L.) genotypes. J. Crop Sci. Biotech. 13: 33-38.

Maas, E. V., and Hoffman, G. J. 1977. Crop salt tolerance, current assessment. J. Irrig. Drain. 103: 115-134.

MacCracken, M. C. 2008. Prospects for future climate change and the reasons for early action. J. Air Waste Manag. Ass. 58: 1920.

McAusland, L., Davey, P. A., Kanwal, N., Baker, N. R., and Lawson, T. 2013. A novel system for spatial and temporal imaging of intrinsic plant water use efficiency. J. Exp. Bot. 64: 4993-5007.

McDonald, G. K., and Paulsen, G. M. 1997. High temperature effects on photosynthesis and water relations of grain legumes. Plant Soil 196: 47-58.

McKenzie, J. S., Paquin, R., and Duke, S. H. 1988. Cold and heat tolerance. In: Alfalfa and Alfalfa Improvement. Hanson, A. A. et al., Eds., ASA-CSSASSSA, Madison, WI.

McKersie, B. D., Bowley, S. R., Harjanto, E., and Leprince, O. 1996. Water deficit tolerance and field performance of transgenic alfalfa overexpressing superoxide dismutase. Plant Physiol. 111: 1177-1181.

Mc Phee, K. E. 2007. Pea. In: Genome Mapping and Molecular Breeding in Plants: Pulses, Sugar and Tuber Crops. pp. 32-47. Kole, C., Ed., Springer, Berlin.

Mc Phee, K. E. 2008. Pea. In: Compendium of Transgenic Plants: Transgenic Legumes, Grains and Forages. pp. 57-70. Kole, C. T. C. H., Eds., Blackwell, Oxford.

Magyar-Tabori, K., Mendler-Drienyovszki, N., and Dobranszki, J. 2011. Models and tools for studying drought stress responses in peas. Omics 15: 829-838.

Mahieu, S., Germon, F., Aveline, A., Hauggaard-Nielsen, H., Ambus, P., and Jensen, E. S. 2009. The influence of water stress on biomass and $\mathrm{N}$ accumulation, $\mathrm{N}$ partitioning between above and below ground parts and on $\mathrm{N}$ rhizodeposition during reproductive growth of pea (Pisum sativum L.). Soil Biol. Biochem. 41: 380-387.

Manavalan, L. P., Guttikonda, S. K., Tran, L.-S., and Nguyen, H. T. 2009. Physiological and molecular approaches to improve drought resistance in soybean. Plant Cell Physiol. 50: 1260-1276. 
Manrique, A., Manrique, K., and Nakahodo, J. 1993. Yield and biological nitrogen fixation of common bean (Phaseolus vulgaris L.) in Peru. Plant Soil 152: 87-91.

Maun, M. A. 1994. Adaptations enhancing survival and establishment of seedlings on coastal dune systems. Vegetation. 111: 59-70.

Medina, J., Catala, R., and Salinas J. 2011. The CBFs: Three arabidopsis transcription factors to cold acclimate. Plant Sci. 180: 3-11.

Mejía-Jiménez, A., Muñoz, C., Jacobsen, H. J., Roca, W. M., and Singh, S. P. 1994. Interspecific hybridization between common and tepary beans: increased hybrid embryo growth, fertility, and efficiency of hybridization through recurrent and congruity backcrossing. Theor. Appl. Genet. 88: 324-331.

Merchan, F., Breda, C., Hormaeche, J. P., Sousa, C., Kondorosi, A., Aguilar, O. M., Megias, M., and Crespi, M. 2003. A kruppel-like transcription factor gene involved in salt responses in Medicago spp. Plant Soil 257: 1-9.

Merchan, F., de Lorenzo, L., Rizzo, S. G., Niebel, A., Manyani, H., Frugier, F., Sousa, C., and Crespi, M. 2007. Identification of regulatory pathways involved in the reacquisition of root growth after salt stress in Medicago truncatula. Plant J. 51: 11-17.

Mhadhbi, H., Fotopolos, V., Mylona, P. V., Jebara, M., Aouani, M. E., and Polidoros, A. N. 2011. Antioxidant gene-enzyme responses in Medicago truncatula genotypes with different degree of sensitivity to salinity. Physiol. Plant. 141: 201-214.

Miguel, M. 2004. Genotypic variation in root hairs and phosphorus efficiency in common bean (Phaseolus vulgaris L.). In: Horticulture. Penn State: University Park, PA.

Mikic, A., Mihailovic, V., Cupina, B., Dordevic, V., Milic, D., Duc, G., Stoddard, F. L., Lejeune-Hénaut, I., Marget, P., and Hanocq, E. 2011. Achievements in breeding autumn-sown annual legumes for temperate regions with emphasis on the continental Balkans. Euphytica 180: 57-67.

Mir, R. R., Zaman-Allah, M., Sreenivasulu, N., Trethowan, R., and Varshney, R. K. 2012. Integrated genomics, physiology and breeding approaches for improving drought tolerance in crops. Theor. Appl. Genet. 125: 625645.

Mittler, R., and Zilinskas, B. A. 1994. Regulation of pea cytosolic ascorbate peroxidase and other antioxidant enzymes during the progression of drought stress and following recovery from drought. Plant J. 5: 397-405.

Mohamed, M. F., Schmitz-Eiberger, N., Keutgen, N., and Noga, G. 2005. Comparative drought postponing and tolerance potentials of two tepary bean lines in relation to seed yield. Afr. Crop Sci. J. 13: 49-60.

Mohapatra, S. S., Poole, R. J., and Dhindsa, R. S. 1988. Abscisic acid-regulated gene expression in relation to freezing tolerance in alfalfa. Plant Physiol. 87: 468-473.

Molina, C., Rotter, B., Horres, R., Udupa, S.M., Besser, B., Bellarmino, L., Baum, M., Matsumura, H., Terauch, I. R., Kahl, G., and Winter, P. 2008. SuperSAGE: the drought stress-responsive transcriptome of chickpea roots. BMC Genomics 9: 553.

Molnár, Z. 2008. Genetic transformation of pea by microprojectile bombardement. In: Handbook of New Technologies for Genetic Improvement of Legumes. pp. 203-215. Kirti, P. B., Ed., Taylor and Francis Group, London.

Moneim, A., Cocks, P. S., and Mawlawy, B. 1990. Genotype-environment interactions and stability analysis for herbage and seed yields of forage peas under rain-fed conditions. Plant Breeding 104: 231-240.

Monroy, A. F., and Dhindsa, R. S. 1995. Low-temperature signal transduction: induction of cold acclimation-specific genes of alfalfa by calcium at 25 degrees C. Plant Cell Online 7: 321-331.

Monterroso, V. A., and Wien, H. C. 1990. Flower and pod abscission due to heat stress in beans. J. Am. Soc. Hortic. Sci. 115: 631-634.

Moran, J. F., Becana, M., Iturbe-Ormaetxe, I., Frechilla, S., Klucas, R. V., and Aparicio-Tejo, P. 1994. Drought induces oxidative stress in pea plants. Planta 194: $346-352$.

Muchero, W., Ehlers, J. D., Close, T. J., and Roberts, P. A. 2009. Mapping QTL for drought stress-induced premature senescence and maturity in cowpea (Vigna unguiculata (L.) Walp.). Theor. Appl. Genet. 118: 849-863.
Muchero, W., Ehlers, J. D., and Roberts, P. A. 2010. Restriction site polymorphism-based candidate gene mapping for seedling drought tolerance in cowpea (Vigna unguiculata (L.) Walp.). Theor. Appl. Genet. 120: 509-518.

Muehlbauer, F. J., Cho, S., Sarker, A., Mc Phee, K. E., Coyne, C. J., Rajesh, P. N., and Ford R. 2006. Applications of biotechnology in breeding lentil for resistance to biotic and abiotic stress. Euphytica 147: 149-165.

Müller, U., and Wilfried, W. 1986. Untersuchungen zum Wasserhaushalt der Ackerbohne I. Wurzelwachstum, Wasseraufnahme und Wasserverbrauch. KALI-BRIEFE (Büntehof) 18: 167-187.

Muñoz, L. C., Blair, M. W., Duque, M. C., Tohme, J., and Roca, W. 2004. Introgression in common bean $\mathrm{x}$ tepary bean interspecific congruity-backcross lines as measured by AFLP markers. Crop Sci. 44: 637-645.

Munns, R. 2005. Response of crops to salinity. In: International Salinity Forum. 339. pp. 25-27 April. Riverside, CA.

Munns, R. 2005. Genes and salt tolerance: bringing them together. New Phytol. 167: 645-633.

Munns, R., James, R. A., Sirault, X. R. R., Furbank, R. T., and Jones, H. G. 2010. New phenotyping methods for screening wheat and barley for beneficial responses to water deficit. J. Exp. Bot. 61: 3499-3507.

Munns, R., and Tester, M. 2008. Mechanisms of salinity tolerance. Annu. Rev. Plant Biol. 59: 651-681.

Naya, L., Ladrera, R., Ramos, J., González, E. M., Arrese-Igor, C., Minchin, F. R., and Becana, M. 2007. The response of carbon metabolism and antioxidant defenses of alfalfa nodules to drought stress and to the subsequent recovery of plants. Plant Physiol. 144: 1104-1114.

Nayyar, H., Bains, T., and Kumar, S. 2005. Low temperature induced floral abortion in chickpea: relationship to abscisic acid and cryoprotectants in reproductive organs. Environ. Exp. Bot. 53: 39-47.

Nerkar, Y. S., Wilson, D., and Lawes, D. A. 1981. Genetic variation in stomatal characteristics and behaviour, water use and growth of five Vicia faba L. Genotypes under contrasting soil moisture regimes. Euphytica 30: 335345.

Ni, Y., Guo, Y. J., Han, L., Tang, H., and Conyers, M. 2012. Leaf cuticular waxes and physiological parameters in alfalfa leaves as influenced by drought. Photosynthetica 50: 458-466.

Nilsen, E. T., and Orcutt, D. M. 1996. The Physiology of Plants Under Stress. Abiotic Factors. John Wiley and Sons, New York.

Ney, B., Duthion, C., and Turc, O. 1994. Phenological response of pea to waterstress during reproductive development. Crop Sci. 34: 141-146.

Nord, E. A., Shea, K., and Lynch, J. P. 2011. Optimizing reproductive phenology in a two-resource world: A dynamic allocation model of plant growth predicts later reproduction in phosphorus limited plants. Ann. Bot. 108: 391-404.

Noreen, Z., and Ashraf, M. 2009. Assessment of variation in antioxidative defense system in salt-treated pea (Pisum sativum) cultivars and its putative use as salinity tolerance markers. J. Plant Physiol. 166: 1764-1774.

Odeny, D. A. 2007. The potential of pigeonpea (Cajanus cajan (L.) Millsp.) in Africa. Nat. Resour. Forum 31: 297-305.

Ortega-Galisteo, A. P., Rodriguez-Serrano, M., Pazmino, D. M., Gupta, D. K., Sandalio, L. M., and Romero-Puertas, M. C. 2012. S-Nitrosylated proteins in pea (Pisum sativum L.) leaf peroxisomes: changes under abiotic stress. J. Exp. Bot. 63: 2089-2103.

Padulosi, S., Heywood, V., Hunter, D., and Jarvis, A. 2011. Underutilized species and climate change: Current status and outlook. In: Crop Adaptation to Climate Change. pp. 507-521. Yadav, S. S., Redden, R. J., and Hatfield, J. L., Eds., John Wiley \& Sons, Ltd., Blackwell Publishing Ltd.

Palma, F., Tejera, N. A., and Lluch, C. 2013. Nodule carbohydrate metabolism and polyols involvement in the response of Medicago sativa to salt stress. Environ. Exp. Bot. 85: 43-49.

Palmer, R., Perez, P., Perez, C., Maalouf, F., and Suso, M. 2009. The role of crop pollinator relationships in breeding for pollinator-friendly legumes: from a breeding prospective. Euphytica 170: $35-52$.

Panda, S. K., and Matsumoto, H. 2010. Changes in antioxidant gene expression and induction of oxidative stress in pea (Pisum sativum $\mathrm{L}$.) under $\mathrm{Al}$ stress. Biometals 23: 753-762. 
Pate, J. S., Gunning, B. E. S., and Briarty, L. G. 1969. Ultrastructure and functioning of transport system of leguminous root nodule. Planta 85: 11-34.

Patrick, J. W., and Stoddard, F. L. 2010. Physiology of flowering and grain filling in faba bean. Field Crops Res. 115: 234-242.

Paul, S., Kundu, A., and Pal, A. 2011. Identification and validation of conserved microRNAs along with their differential expression in roots of Vigna unguiculata grown under salt stress. Plant Cell Tiss. Org. Cult. 105: 233-242.

Pennycooke, J. C., Cheng, H., and Stockinger, E. J. 2008. Comparative genomic sequence and expression analyses of Medicago truncatula and alfalfa subspecies falcata COLD-ACCLIMATION-SPECIFIC genes. Plant Physiol. 146: $1242-1254$

Phang, T. H., Shao, G., and Lam, H. M. 2008. Salt tolerance in soybean. $J$. Integrat. Plant Biol. 50: 1196-1212.

Pineda, P., Kipe-Nolt, J. A., and Rojas, E. 1994. Rhizobium inoculation increases of bean and maize yields in intercrops on farms in the Peruvian sierra. Exp. Agric. 30: 311-318.

Pinheiro, G. L., Marques, C. S., Costa, M. D. B. L., Reis, P. A. B., Alves, M. S., Carvalho, C. M., Fietto, L. G., and Fontes, E. P. B. 2009. Complete inventory of soybean NAC transcription factors: Sequence conservation and expression analysis uncover their distinct roles in stress response. Gene 444: 10-23.

Poljakoff-Mayber, A. 1975. Morphological and anatomical changes in plants as a response to salinity stress. In: Plants in Saline Environments. Ecological Studies. pp. 97-117. vol 15. Poljakoff-Mayber, A., Ed., Springer-Verlag, Berlin.

Plies-Balzer, E., Kong, T., Schuber, S. and Mengel, K. 1995. Effect of water stress on plant growth, nitrogenase activity and notrogen economy of four different cultivars of Vicia faba L. Eur. J. Agron. 4: 167-173.

Porch, T. G., and Jahn, M. 2001. Effects of high-temperature stress on microsporogenesis in heat-sensitive and heat-tolerant genotypes of Phaseolus vulgaris. Plant Cell Environ. 24: 723-731.

Prasad, P. V. V., Boote, K. J., Allen, L. H., and Thomas, J. M. G. 2002. Effects of elevated temperature and carbon dioxide on seed-set and yield of kidney bean (Phaseolus vulgaris L.). Global Change Biol. 8: 710-721.

Priefer, U. B., Aurag, J., Boesten, B., Bouhmouch, I., Defez, R., Filali-Maltouf, A., Miklis, M., Moawad, H., Mouhsine, B., Prell, J., Schluter, A., and Senatore, B. 2001. Characterisation of Phaseolus symbionts isolated from Mediterranean soils and analysis of genetic factors related to $\mathrm{pH}$ tolerance. J. Biotech. 91: 223-236.

Ramírez, M., Flores-Pacheco, G., Reyes, J. L., Alvarez, A. L., Drevon, J. J., Girard, L., and Hernández, G. 2013. Two common bean genotypes with contrasting response to phosphorus deficiency show variations in the microRNA 399-mediated $\mathrm{PvPHO} 2$ regulation within the PvPHR1 signaling pathway. Int. J. Mol. Sci. 14: 8328-8344.

Ramirez-Vallejo, P., and Kelly, J. D. 1998. Traits related to drought resistance in common bean. Euphytica 99: 127-136.

Ramos, M. L. G., Gordon, A. J., Minchin, F. R., Sprent, J. I., and Parsons, R. 1999. Effect of water stress on nodule physiology and biochemistry of a drought tolerant cultivar of common bean (Phaseolus vulgaris L.). Ann. Bot. 83: 57-63.

Rao, I. M. 2014. Advances in improving adaptation of common bean and Brachiaria forage grasses to abiotic stress in the tropics. In: Handbook of Plant and Crop Physiology. pp. 847-889. Pessarakli M., Eds. NY: CRC Press, Taylor and Francis.

Rao, I. M., Beebe, S. E., Polanía, J., Grajales, M., Cajiao, C., García, R., Ricaurte, J., and Rivera, M. 2009. Physiological basis of improved drought resistance in common bean: the contribution of photosynthate mobilization to grain. In: Interdrought III: The 3rd Intl. Conf. on Integrated Approaches to Improve Crop Production under Drought-Prone Environments, Oct. 11-16, 2009, Shanghai, China.

Rao, I. M., Beebe, S. E., Polania, J., Ricaurte, J., Cajiao, C., García, R., and Rivera, M. 2013. Can tepary bean be a model for improvement of drought resistance in common bean? Afr. Crop Sci. J. 21: 265-281.

Ray, I., Townsend, M. S., and Henning, J. A. 1998. Variation for yield, water-use efficiency and canopy morphology among nine alfalfa germplasms. Crop Sci. 38: $1386-1390$.
Ray, I., Segovia-Lerma, A., and Murray, L. W. 2004. Diallel analysis of carbon isotope discrimination and its association with forage yield among nine historically recognized alfalfa germplasms. Crop Sci. 44: 1970-1975.

Remus-Borel, W., Castonguay, Y., Cloutier, J., Michaud, R., Bertrand, A., Desgagnes, R., and Laberge, S. 2010. Dehydrin variants associated with superior freezing tolerance in alfalfa (Medicago sativa L.). Theor. Appl. Genet. 120: 1163-1174.

Reyes-Díaz, M., Ulloa, N., Zúñiga-Feest, A., Gutiérrez, A., Gidekel, M., Alberdi, M., Corcuera, L. J., and Bravo, L. A. 2006. Arabidopsis thaliana avoids freezing by supercooling. J. Exp. Bot. 57: 3687-3696.

Reyno, R., Khu, D. M., Monteros, M. J., Bouton, J. H., Parrott, W., and Brummer E. C. 2013. Evaluation of two transgenes for aluminum tolerance in alfalfa. Crop Sci. 53: 1581-1588.

Rhoades, J. D., and Loveday, H. 1990. Salinity in irrigated agriculture. In: Irrigation of agricultural crops. pp. 1089-1142. Steward, B. A. and Nielsen, D. R., Eds. WI: American Society of Agronomy, Crop Science Society of America, Soil Science Society of America Publishers.

Rodriguez-Serrano, M., Romero-Puertas, M. C., Pazmino, D. M., Testillano, P. S., Risueno, M. C., del Rio, L. A., and Sandalio, L. M. 2009. Cellular response of pea plants to cadmium toxicity: Cross talk between reactive oxygen species, nitric oxide, and calcium. Plant Physiol. 150: 229-243.

Rose, R. J. 2008. Medicago truncatula as a model for understanding plant interactions with other organisms, plant development and stress biology: past, present and future. Funct. Plant Biol. 35: 253.

Rubio, M. C., Bustos-Sanmamed, P., Clemente, M. R., and Becana, M. 2009. Effects of salt stress on the expression of antioxidant genes and proteins in the model legume Lotus japonicus. New Phytol. 181: 851-859.

Sass, O., and Stelling, D. 1989. Influence of different plant types on harvestability and yield of faba beans, Vicia faba L. In: XII Eucarpia Congress Vortr. Pflanzenzuchtg, 15. paper 13-10.

Sanchez, D. H., Lippold, F., Redestig, H., Hannah, M. A., Erban, A., Krämer, U., Kopka, J., and Udvardi, M. K. 2008. Integrative functional genomics of salt acclimatization in the model legume Lotus japonicus. Plant J. 53: $973-$ 987.

Sanchez, D. H., Pieckenstain, F. L., Escaray, F., Erban, A., Kraemer, U., Udvardi, M. K., and Kopka, J. 2011. Comparative ionomics and metabolomics in extremophile and glycophytic Lotus species under salt stress challenge the metabolic pre-adaptation hypothesis. Plant Cell Environ. 34: 605617.

Sanchez, D. H., Pieckenstain, F. L., Szymanski, J., Erban, A., Bromke, M., Hannah, M. A., Kraemer, U., Kopka, J., and Udvardi, M. K. 2011. Comparative Functional Genomics of Salt Stress in related model and cultivated plants identifies and overcomes limitations to translational genomics. PLOS ONE 6 : e17094.

Sanchez, D. H., Schwake, F., Erban, A., Udvardi, M. K., and Kopka, J. 2012. Comparative metabolomics of drought acclimation in model and forage legumes. Plant Cell Environ. 35: 136-149.

Sanchez, D. H., Szymanski, J., Erban, A., Udvardi, M. K., and Kopka, J. 2010. Mining for robust transcriptional and metabolic responses to long-term salt stress: a case study on the model legume Lotus japonicus. Plant Cell Environ. 33: $468-480$.

Sanchez, F. J., Manzanares, M., de Andres, E. F., Tenorio, J. L., and Ayerbe, L. 1998. Turgor maintenance, osmotic adjustment and soluble sugar and proline accumulation in 49 pea cultivars in response to water stress. Field Crops Res. 59: $225-235$.

Sanchez, F. J., Manzanares, M., de Andres, E. F., Tenorio, J. L., and Ayerbe, L, 2001. Residual transpiration rate, epicuticular wax load and leaf colour of pea plants in drought conditions. Influence on harvest index and canopy temperature. Eur. J. Agron. 15: 57-70.

Saxena, N. P. 1984. Chickpea. In: The Physiology of Tropical Field Crops. pp. 207-232. Goldsworthy, P. R., and Fisher, N. M., Eds., Wiley, New York.

Scabo, A.M., Pantalone, V.R., Walker, D.R., Boerma, H.R., West, D.R., Walker, F.R., and Sams, C.E. 2009. Confirmation of molecular markers and agronomic traits associated with seed phytate content in two soybean RIL populations. Crop Sci. 49:426-432. 
Scasta, J. D., Trostle, C. L., and Foster, M. A. 2012. Evaluating alfalfa (Medicago sativa $\mathrm{L}$.) cultivars for salt tolerance using laboratory, greenhouse and field methods. J. Agric. Sci. 4: 90-103.

Schmidtke, K. 2012. Pflanzenbauliche Strategien zur Steigerung der Wertschöpfung im Körnerleguminosenanbau. In: 2. Körnerleguminosentag der LWK NRW und ABL, 28. 11. 2012 (Landwirtschaftszentrum Haus Düsse). http://www.vom-acker-in-den-futtertrog.de.

Serraj, R., Krishnamurthy, L., Kashiwagi, K., Kumar, J., Chandra, S., and Crouch, J. H., 2004. Variation in root traits of chickpea (Cicer arietinum L.) grown under terminal drought. Field Crop Res. 88: 115-127.

Serraj, R., Sinclair, T. R., and Purcell, L. C. 1999. Symbiotic nitrogen fixation response to drought. J. Exp. Bot. 50: 143-155.

Serraj, R., Vadez, V., and Sinclair, T. R. 2001. Feedback regulation of symbiotic $\mathrm{N}_{2}$ fixation under drought stress. Agronomie 21: 621-626.

Serraj, R., and Sinclair, T. R. 2002. Osmolyte accumulation: Can it really help increase crop yield under drought conditions? Plant Cell Environ. 25: 333-341.

Shahid, M. A., Balal, R. M., Pervez, M. A., Abbas, T., Ashfaq, M., Ghazanfar, U., Afzal, M., Rashid, A., García-Sánchez, F., and Mattson, N. S. 2012. Differential response of pea (Pisum sativum L.) genotypes to salt stress in relation to the growth, physiological attributes antioxidant activity and organic solutes. Aust. J. Crop Sci. 6: 828-838.

Shao, H. B., Chu, L. Y., Lu, Z. H., and Kang, C. M. 2008. Primary antioxidant free radical scavenging and redox signaling pathways in higher plant cells. Int. J. Biol. Sci. 4: 8-14.

Shao, G. H., Song, J. Z., and Liu, H. L. 1986. Preliminary studies on the evaluation of salt tolerance in soybean varieties. Acta Agren. Sin. 6: 30-35.

Sharkey, T. D., and Seemann, J. R. 1989. Mild water-stress effects on carbonreduction-cycle intermediates, ribulose bisphosphate carboxylase activity, and spatial homogeneity of photosynthesis in intact leaves. Plant Physiol. 89: 1060-1065.

Sharpe, A. G., Ramsay, L., Sanderson, L. A., Fedoruk, M. J., Clarke, W. E., Li, R., Kagale, S., Vijayan, P., Vandenberg, A., and Bett, K. E. 2013. Ancient orphan crop joins modern era: gene-based SNP discovery and mapping in lentil. BMC Genomics 14: 192.

Shimoda, Y., Nagata, M., Suzuki, A., Abe, M., Sato, S., Kato, T., Tabata, S. Higashi, S. and Uchiumi, T. 2005. Symbiotic rhizobium and nitric oxide induce gene expression of non-symbiotic hemoglobin in Lotus japonicus. Plant Cell Physiol. 46: 99-107.

Signorelli, S., Corpas, F. J., Borsani, O., Barroso, J. B., and Monza, J. 2013. Water stress induces a differential and spatially distributed nitro-oxidative stress response in roots and leaves of Lotus japonicus. Plant Sci. 201: 137146.

Silvestre, S., Araújo, S. S., Vaz Patto, M. C., and Marques da Silva, J. 2014. Performance index: an expeditious tool to screen for improved drought resistance in the Lathyrus genus. J. Integr. Plant Biol. (In press).

Simon-Sarkadi, L., Kocsy, G., Várhegyi, A., Galiba, G., and de Ronde, J. A. 2005. Genetic manipulation of proline accumulation influences the concentrations of other amino acids in soybean subjected to simultaneous drought and heat stress. J. Agric. Food Chem. 53: 7512-7517.

Sinclair, T. R. 2012. Is transpiration efficiency a viable plant trait in breeding for crop improvement? Funct. Plant Biol. 39: 359-365.

Sinclair, T. R., Messina, C. D., Beatty, A., and Samples, M. 2010. Assessment across the United States of the benefits of altered soybean drought traits. Agron. J. 102: 475-482.

Sinclair, T. R., and Vadez, V. 2002. Physiological traits for crop yield improvement in low N and P environments. Plant Soil 245: 1-15.

Sinclair, T. R., Purcell, L. C., Vadez, V., Serraj, R., King, C. A., and Nelson, R. 2000. Identification of soybean genotypes with $\mathrm{N}_{2}$ fixation tolerance to water deficits. Crop Sci. 40: 1803-1809.

Singh, B. B., Ajeigbe, H. A., Tarawali, S. A., Fernandez-Rivera, S., and Abubakar, M. 2003. Improving the production and utilization of cowpea as food and fodder. Field Crop Res. 84: 169-177.

Smith, J. R. 2004. Selection protocols for increased yield and stress tolerance in common bean. J. Agr. U. Puerto Rico. 88: 27-43.
Smýkal, P., Aubert, G., Burstin, J., Coyne, C. J., Ellis, N. T. H., Flavell, A. J., Ford, R., Hýbl, M., Macas, J., Neumann, P., Mc Phee, K. E., Redden, R. J., Rubiales, D., Weller, J. L., Warkentin, T. D., 2012. Pea (Pisum sativum L.) in the genomic era. Agronomy 2: 74-115.

Soares-Cavalcanti, N. M., Belarmino, L. C., Kido, E. A., Wanderley-Nogueira, A. C., Bezerra-Neto, J. P., Cavalcanti-Lira, R., Pandolfi, V., Nepomuceno, A. L., Abdelnoor, R. V., Nascimento, L. C., and Benko-Iseppon, A. M. 2012. In silico identification of known osmotic stress responsive genes from Arabidopsis in soybean and Medicago. Genet. Mol. Biol. 35: 315-321.

Sobhanian, H., Razavizadeh, R., Nanjo, Y., Ehsanpour, A. A., Rastgar Jazii, F., Motamed, N., and Komatsu, S. 2010. Proteome analysis of soybean leaves, hypocotyls and roots under salt stress. Proteome Sci. 8: 1-15.

Sobhanian, H., Aghaeib, K., and Komatsuc, S. 2011. Changes in the plant proteome resulting from salt stress: Toward the creation of salt-tolerant crops? J. Proteomics 74: 1323-1337.

Soliman, M. M., Nagat, G. A., Bakheit, M. A., Raslan, M. A., and Fergany, M. A. 2011. The genetic system and type of gene effects controlling resistance of faba bean (Vicia faba L.) to Orobance crenata. Res. J. Agr. Biol. Sci.7: 251-259.

Soja A. M., and Steineck, O. 1986. Experimentalergebnisse über die Prüfung des Vernalisationsbedarfes von Winterformen der Ackerbohne (Vicia faba L.). Bodenkultur 37: 109-120.

Solomon, M., Gedalovich, E., Mayer, A. M., and Poljakoffmayber, A. 1986. Changes induced by salinity to the anatomy and morphology of excised pea roots in culture. Ann. Bot. 57: 811-818.

Song, S., Chen, Y. Zhao, M., and Zhang, W. H. 2012. A novel Medicago truncatula HD-Zip gene, MtHB2, is involved in abiotic stress responses. Environ. Exp. Bot. 80: 1-9.

Song, Y., Ji, D., Li, S., Wang, P., Li, Q., and Xiang, F. 2012. The dynamic changes of DNA methylation and histone modifications of salt responsive transcription factor genes in soybean. PLoS ONE 7: e41274.

Sponchiado, B. N., White, J. W., Castillo, J. A., and Jones, P. G. 1989. Root growth of four common bean cultivars in relation to drought tolerance in environments with contrasting soil types. Exp. Agr. 25: 249-257.

Sprent, J. I. 2001. Nodulation in Legumes. Royal Botanic Gardens. Kew.

Stewart, C. 1996. Genetic transformation, recovery, and characterization of fertile soybean transgenic for a synthetic Bacillus thuringiensis cryIAc gene. Plant Physiol. 112: 121-129.

Stoddard, F. L. 1986. Effects of drought on autofertility in faba beans. Fabis Newsl. 15: 22-26.

Stoddard, F. L. 1986. Autofertility and bee visitation in winter and spring genotypes of faba beans (Vicia faba L.). Plant Breeding 97: 171-182.

Stoddard, F. L., Balko, C., Erskine, W., Khan, H. R., Link, W., and Sarker A. 2006. Screening techniques and sources of resistance to abiotic stresses in cool-season food legumes. Euphytica 147: 167-186.

Stützel, H. and Link, W. 1995. Faba bean. Physiology. In: Physiological Potentials for Yield Improvement of Annual Oil and Protein Crops. Advances in Plant Breeding, Vol. 17, pp. 219-238. Diepenbrock, W. and Becker, H. C., Eds., Blackwell, Berlin.

Suarez, R., Calderon, C., and Iturriaga, G. 2009. Enhanced tolerance to multiple abiotic stresses in transgenic alfalfa accumulating trehalose. Crop Sci. 49: 1791-1799.

Summerfield, R. J., Virmani, S. M., Roberts, E. H., and Ellis, R. H. 1990. Adaptation of chickpea to agroclimatic constraints. In: Chickpea in the Nineties: Proceedings of the 2nd International Workshop on Chickpea Improvement. pp. 61-72. Walby, B. J., and Hall, S. D., Eds., Patancheru, India: ICRISAT.

Sunkar, R., Chinnusamy, V., Zhu, J. K., and Zhu, J. K. 2007. Small RNAs as big players in plant abiotic stress responses and nutrient deprivation. Trends Plant Sci. 12: 301-309.

Szittya, G., Moxon, S., Santos, D. M., Jing, R., Fevereiro, M. P. S., Moulton, V., and Dalmay, T. 2008. High-throughput sequencing of Medicago truncatula short RNAs identifies eight new miRNA families. BMC Genomics. 9: 593.

Tadege, M., Trevor, W. L., Wen, J., Ratet, P., and Mysore, K. S. 2009. Mutagenesis and Beyond! Tools for Understanding Legume Biology Plant Physiol. 151: 978-984. 
Talukdar, D. 2011. Morpho-physiological responses of grass pea (Lathyrus sativus $\mathrm{L}$.) genotypes to salt stress at germination and seedling stages. Legume Res. 34: 232-241.

Tate, R. L. 2000. Soil Microbiology. 2nd ed. John Wiley \& Sons, Inc. New York.

Tayeh, N., Bahrman, N., Devaux, R., Bluteau, A., Prosperi, J. M., Delbreil, B., and Lejeune-Henaut, I. 2013. A high-density genetic map of the Medicago truncatula major freezing tolerance QTL on chromosome 6 reveals colinearity with a QTL related to freezing damage on Pisum sativum linkage group VI. Mol. Breeding 32: 279-289.

Tayeh, N., Bahrman N., Sellier, H., Bluteau, Blassiau, C., Fourment, J., Bellec, A., Debellé, F., Lejeune-Hénaut, I. and Delbreil, B. 2013. Identification and description of a tandem array of CBF/DREB1 genes that co-localizes with a major freezing tolerance QTL on Medicago truncatula. BMC Genomics 14: 814

Taylor, N. L., Heazlewood, J. L., Day, D. A., and Millar, A. H. 2005. Differential impact of environmental stresses on the pea mitochondrial proteome. Mol.Cell. Proteom. 4: 1122-1133.

Teakle, N. L., Amtmann, A., Real, D., and Colmer, T. D. 2010. Lotus tenuis tolerates combined salinity and waterlogging: maintaining $\mathrm{O}_{2}$ transport to roots and expression of an NHX1-like gene contribute to regulation of $\mathrm{Na}^{+}$ transport. Physiol. Plant. 139: 358-374.

Thapa, B., Arora, R., Knapp, A. D., and Brummer, E. C. 2008. Applying freezing test to quantify cold acclimation in Medicago truncatula. J. Amer. Soc. Hort. Sci. 133: 684-691.

Thomashow, M. F. 1998. Role of cold-responsive genes in plant freezing tolerance. Plant Physiol. 118: 1-7.

Thomashow, M. F. 2001. So what's new in the field of plant cold acclimation? Lots! Plant Physiol. 125: 89-93.

Thung, M., and Rao, I. M. 1999. Integrated management of abiotic stresses. In: Common Bean Improvement in the Twenty-First Century. pp. 331-370. Singh, S. P., Ed., Kluwer Academic Publ., Dordrecht. The Netherlands.

Trindade, I., Capitão, C., Dalmay, T., Fevereiro, M. P., and Santos, D. M. 2010. miR398 and miR408 are up-regulated in response to water deficit in Medicago truncatula. Planta 231: 705-716.

Tuberosa, R. 2012. Phenotyping for drought tolerance of crops in the genomics era. Front. Physiol. 3: 347.

Turner, N. C., Colmer, T. D., Quealy, J., Pushpavalli, R., Krishnamurthy, L., Kaur, J., Singh, G., Siddique, K. H. M., and Vadez, V. 2013. Salinity tolerance and ion accumulation in chickpea (Cicer arietinum $\mathrm{L}$.) subjected to salt stress. Plant and Soil 365: 347-361.

Udvardi, M. K., Kakar, K., Wandrey, M., Montanari, O., Murray, J., Andriankaja, A., Zhang, J. Y., Benedito, V., Hofer, J. M. I., Chueng, F., and Town, C. D. 2007. Legume transcription factors: global regulators of plant development and response to the environment. Plant Physiol. 144: 538-549.

Uemura, M., Tominaga, Y., Nakagawara, C., Shigematsu, S., Minami, A., and Kawamura, Y. 2006. Responses of the plasma membrane to low temperatures. Physiol. Plant. 126: 81-89.

Umezawa, T., Fujita, M., Fujita, Y., Yamaguchi-Shinozaki, K., and Shinozaki, K. 2006. Engineering drought tolerance in plants: discovering and tailoring genes to unlock the future. Curr. Opin. Plant Biotechnol. 17: 113-122.

Upadhyaya, H. D., Reddy, K. N., Singh, S., and Gowda, C. L. L. 2013. Phenotypic diversity in Cajanus species and identification of promising sources for agronomic traits and seed protein content. Genet. Resour. Crop Evol. 60: 639-659.

Vadez, V., Krishnamurthy, L., Gaur, P. M., Upadhyaya, H. D., Hoisington, D. A., Varshney, R. K., Turner, N. C., and Siddique, K. H. M. 2007. Large variation in salinity tolerance is explained by differences in the sensitivity of reproductive stages in chickpea. Field Crop Res. 104: 123-129.

Vadez, V., Sinclair, T. R., and Serraj, R. 2000. Asparagine and ureide accumulation in nodules and shoots as feedback inhibitors of $\mathrm{N}_{2}$ fixation in soybean. Physiol. Plant 110: 215-223.

Vadez, V., Soltani, A., Krishnamurthy, L., and Sinclair, T. R. 2012a. Modelling possible benefit of root related traits to enhance terminal drought adaption of chickpea. Field Crops Res. 137: 108-115.
Vadez, V., Krishnamurthy, L., Mahender, T., Varshney, R. K., Colmer, T. D., Turner, N. C., Siddique, K. M. H., and Gaur, P. M. 2012b. Assessment of ICCV2 x JG62 chickpea progenies shows sensitivity of reproduction to salt stress and reveals QTLs for seed yield. Mol. Breeding 30: 9-21.

Vadez, V., Krishnamurthy, L., Colmer, T. D., and Turner, N. C. 2012c. Large number of flowers and tertiary branches increase yields under salt stress in chickpea. Eur. J. Agron. 41: 42-51.

Vadez, V., Soltani, A., and Sinclair, T. R. 2013a. Crop simulation analysis of phenological adaptation of chickpea to different latitudes of India. Field Crops Res. 146: 1-9.

Vadez, V., Kholova, J., Yadav, R. S., and Hash, C. T. 2013b. Small temporal differences in water uptake among varieties of pearl millet (Pennisetum glaucum (L.) R. Br.) are critical for grain yield under terminal drought. Plant Soil 371: 447-462.

Vandecasteele, C., Teulat-Merah, B., Morère-Le Paven, M. C., Leprince, O., Ly Vu, B., Viau, L., and Buitink, J. 2011. Quantitative trait loci analysis reveals a correlation between the ratio of sucrose/raffinose family oligosaccharides and seed vigour in Medicago truncatula. Plant. Cell Environ. 34: 1473-1487.

Varshney, R. K., Ribaut, J. M., Buckler, E. S., Tuberoso, R., Rafalski, J. A., and Langridge, P. 2012b. Can genomics boost productivity of orphan crops? Nat. Biotechnol. 30: 1172-1176.

Varshney, R. K., Chen, W., Li, Y., Bharti, A. K., Saxena, R. K., Schlueter, J. A., Donoghue, M. T. A., Azam, S., Fan, G., Whaley, A. M., Farmer, A. D., Sheridan, J., Iwata, A., Tuteja, E., Penmetsa, R. V., Wu, W., Upadhyaya, H. D., Yang, S. P., Shah, T., Saxena, K. B., Michael, T., McCombie, W. R., Yang, B., Zhang, G., Yang, H., Wang, J., Spillane, C., Cook, D. R., May, G. D., Xu, X., and Jackson, S. A. 2012a. Draft genome sequence of pigeonpea (Cajanus cajan), an orphan legume crop of resource-poor farmers. Nat. Biotechnol. 30: 83-89.

Varshney, R. K., Close, T. J., Singh, N. K., Hoisington, D. A., and Cook, D. R. 2009. Orphan legume crops enter the genomics era. Curr. Opin. Plant Biol. 12: $202-210$.

Vasconcelos, E. S. D., Barioni Junior, W., Cruz, C. D., Ferreira, R. D. P., Rassini, J. B., and Vilela, D. 2008. Alfalfa genotype selection for adaptability and stability of dry matter production. Acta Sci. Agron. 30: 339-343.

Vaughan, L., MacAdam, S., Smith, S. E., and Dudley, L. M. 2002. Root growth and yield of differing alfalfa rooting populations under increasing salinity and zero leaching. Crop Sci. 42: 2064-2071.

Vaz Patto, M. C., Skiba, B., Pang, E. C. K., Ochatt, S. J., Lambein, F., and Rubiales, D. 2006. Lathyrus improvement for resistance against biotic and abiotic stresses: from classical breeding to marker assisted selection. Euphytica 147: 133-147.

Vaz Patto, M. C., Hanbury, C., Van Moorhem, M., Lambein, F., Ochatt, S., and Rubiales, D. 2011. Grass Pea (Lathyrus sativus L.). In: Genetics, Genomics and Breeding of Cool Season Grain Legumes. pp. 151-204. Perez de la Vega, M., Torres, A. M., Cubero, J. I., and Kole C., Eds., Science Publishers Inc., Plymouth, UK.

Verbruggen, N., and Hermans, C. 2008. Proline accumulation in plants: a review. Amino Acids 35: 753-759.

Verdier, J., Kakar, K., Gallardo, K., Le Signor, C., Aubert, G., Schlereth, A., Town, C.D., Udvardi, M. K. and Thompson, R. D. 2008. Gene expression profiling of M. truncatula transcription factors identifies putative regulators of grain legume seed filling. Plant Mol. Biol. 67: 567-580.

Verdier, J., Lalanne, D., Pelletier, S., Torres-Jerez, I., Righetti, K., Bandyopadhyay, K., Leprince, O., Chatelain, E., Vu, B. L., Gouzy, J., Gamas, P., Udvardi, M. K., and Buitink, J. 2013a. A regulatory network-based approach dissects late maturation processes related to the acquisition of desiccation tolerance and longevity of Medicago truncatula seeds. Plant Physiol. 163: 757-774.

Verdier, J., Torres-Jerez, I., Wang, M., Andriankaja, A., Allen, S. N., He, J., Tang, Y., Murray, J. D. and Udvardi, M. K. 2013. Establishment of the Lotus japonicus Gene Expression Atlas (LjGEA) and its use to explore legume seed maturation. Plant J. 74: 351-362.

Volenec, J. J., Cunningham, S. M., Haagenson, D. M., Berg, W. K., Joern, B. C., and Wiersma, D. W. 2002. Physiological genetics of alfalfa improvement: past failures, future prospects. Field Crop Res. 75: 97-110. 
Vriezen, J. A., De Bruijn, F. J., and Nüsslein, K. 2007. Responses of rhizobia to desiccation in relation to osmotic stress, oxygen, and temperature. Appl. Environ. Microbiol. 73: 3451-3459.

Wang, T., Chen, L., Zhao, M., Tian, Q., and Zhang, W. H. 2011. Identification of drought-responsive microRNAs in Medicago truncatula by genome-wide high-throughput sequencing. BMC Genomics, 12: 367.

Wang, M., Verdier, J., Benedito, V. A., Tang, Y., Murray, J. D., Ge, Y., and He, J. 2013. LegumeGRN: a gene regulatory network prediction server for functional and comparative studies. PLOS ONE. 8: e67434.

Wang, J., Gan, Y. T., Clarke, F., and McDonald, C. L. 2006 Response of chickpea yield to high temperature stress during reproductive development. Crop Sci. 46: 2171-2178.

Wei, W., Huang, J., Hao, Y. J., Zou, H. F., Wang, H. W., Zhao, J. Y., Liu, X. Y., Zhang, W. K., Ma, B., Zhang, J. S., and Chen, S. Y. 2009. Soybean GmPHD-type transcription regulators improve stress tolerance in transgenic Arabidopsis plants. PLoS ONE 4: e7209.

Weller, J. L., Liew, L. C., Hecht, V. F. G., Rajandran, V., Laurie, R. E., Ridge, S., Wenden, B., Vander Schoor, J. K., Jaminon, O., Blassiau, C., Dalmais, M., Rameau, C., Bendahmane, A., Macknight, R. C., and Lejeune-Hénaut, I. 2012. A conserved molecular basis for photoperiod adaptation in two temperate legumes. Proc. Natl. Acad. Sci. U S A 109: 21158-21163.

White, J.W., and Singh S. P. 1991. Sources and inheritance of earliness in tropically adapted indeterminate common bean. Euphytica 55: $15-19$.

White, J. W., and Castillo, J. A. 1992. Evaluation of diverse shoot genotypes on selected root genotypes of common bean under soil water deficits. Crop Sci. 32: 762-765.

Wortmann, C. S., Kirkby, R. A., Eledu, C. A., and Allen, D. J. 1998. Atlas of Common Bean (Phaseolus vulgaris L.) Production in Africa. p. 133 Cali, Colombia: Centro Internacional de Agricultura Tropical (CIAT).

Xie, C., Zhang, R., Qu, Y., Miao, Z., Zhang, Y. Shen, X., Wang, T., and Dong, J. 2012. Overexpression of MtCAS31 enhances drought tolerance in transgenic Arabidopsis by reducing stomatal density. New Phytol. 195: 124-135.

Xing, G. S., Cui, K. R., Li, J., Wang, Y., and Li, Z. X. 2001. Water stress and the accumulation of $\beta$-N-oxalyl-L- $\alpha, \beta$-diaminopropionic acid in grass pea (Lathyrus sativus). J. Agri. Food Chem. 49: 216-220.

Xiong, L. M., Schumaker, K. S., and Zhu, J. K. 2002. Cell signaling during cold, drought, and salt stress. Plant Cell 14: S165-S183.

Xu, J., Xiao-Lin, L., and Luo, L. 2012. Effects of engineered Sinorhizobium meliloti on cytokinin synthesis and tolerance of alfalfa to extreme drought stress. Appl. Environ. Microbiol. 78: 8056-8061.

Xu, X. Y., Fan, R., Zheng, R., Li, C. M., and Yu, D. Y. 2011. Proteomic analysis of seed germination under salt stress in soybeans. J. Zhejiang Univ. Sci B. 12: 507-517.

Yan, X., Liao, H., Beebe, S. E., Blair, M. W., and Lynch, J. P. 2004. QTL mapping of root hair and acid exudation traits and their relationship to phosphorus uptake in common bean. Plant Soil. 265: 17-29.

Yang, Z., Rao, I. M. and Horst, W. J. 2013. Interaction of aluminium and drought stress on root growth and crop yield on acid soils. Plant Soil 372: 3-25.

Yang, Z. B., Eticha, D., Rao, I. M., and Horst, W. J. 2010. Alteration of cell-wall porosity is involved in osmotic stress-induced enhancement of aluminium resistance in common bean (Phaseolus vulgaris L.). J. Exp. Bot. 61: 32453258 .

Yang, Z. B., Eticha, D., Rotter, B., Rao, I. M., and Horst, W. J. 2011. Physiological and molecular analysis of polyethylene glycol-induced reduction of aluminium accumulation in the root tips of common bean (Phaseolus vulgaris). New Phytol. 192: 99-113.
Yang, Z. B., Eticha, D., Albacete, A., Rao, I. M., Roitsch, T., and Horst, W. J. 2012. Physiological and molecular analysis of the interaction between aluminium toxicity and drought stress in common bean (Phaseolus vulgaris). J. Exp. Bot. 63: 3109-3125.

Yoshiba, Y., Kiyosue, T., Nakashima, K., Yamaguchi-Shinozaki, K., and Shinozaki, K. 1997. Regulation of levels of proline as an osmolyte in plants under water stress. Plant Cell Physiol. 38: 1095-1102.

Young, N. D., and Bharti, A. K. 2012 Genome-enabled insights into legume biology. Annu. Rev. Plant Biol. 63: 283-305.

Zahaf, O., Blanchet, S., de Zélicourt, A., Alunni, B., Plet, J., Laffont, C., de Lorenzo, L., Imbeaud, S., Ichanté, J. L., Diet, A., Badri, M., Zabalza, A., Gonzalez, E. M., Delacroix, H., Gruber, V., Frugier, F., and Crespi, M. 2012. Comparative transcriptomic analysis of salt adaptation in roots of contrasting Medicago truncatula genotypes. Mol. Plant 5: 1068-1081.

Zahran, H. H. 1999. Rhizobium-legume symbiosis and nitrogen fixation under severe conditions and in an arid climate. Microbiol. Mol. Biol. Rev. 63: 968-989.

Zahran, H. H., and Sprent, J. I. 1986. Effects of sodium chloride and polyethylene glycol on root hair infection and nodulation of Vicia faba L. plants by Rhizobium leguminosarum. Planta 167: 303-309.

Zahran, H. H., Manzano, M. C. M., Sanchez-Raya, A. J., Bedmar, E. J., Venema, K., and Rodriguez-Rosales, M. P. 2007. Effect of salt stress on the expression of NHX-type ion transporters in Medicago intertexta and Melilotus indicus plants. Physiol. Plant. 131: 122-130.

Zaman-Allah, M., Jenkinson, D., and Vadez, V. 2011a. Chickpea genotypes contrasting for seed yield under terminal drought stress in the field differ for traits related to the control of water use. Funct. Plant Biol. 38: 270-281.

Zaman-Allah, M., Jenkinson, D., and Vadez, V. 2011b. A conservative pattern of water use, rather than deep or profuse rooting, is critical for the terminal drought tolerance of chickpea. J. Exp. Bot. 62: 4239-4252.

Zhai, Y., Wang, Y., Li, Y., Lei, T., Yan, F., Su, L., Li, X., Zhao, Y., Sun, X., Li, J., and Wang, Q. 2013. Isolation and molecular characterization of GmERF7, a soybean ethylene-response factor that increases salt stress tolerance in tobacco. Gene 513: 174-183.

Zhao, S., Lin, Z., Ma, W., Luo, D., and Cheng, Q. 2008. Cloning and characterization of long-chain fatty alcohol oxidase $\mathrm{LjFAO1}$ in Lotus japonicus. Biotechnol. Progr. 24: 773-779.

Zhang, G., Chen, M., Chen, X., Xu, Z., Li, L., Guo, J., and Ma, Y. 2010. Isolation and characterization of a novel EAR-motif-containing gene GmERF4 from soybean (Glycine max L.). Mol. Biol. Rep. 37: 809-818.

Zhang, J. Y., Broecking, C. D., Blancaflor, E. B., Sledge, M. K., Sumner, L. W., and Wang, Z. Y. 2005. Overexpression of WXP1, a putative Medicago trucatula AP2 domain-containing transcription factor gene, increases cuticular wax accumulation and enhances drought tolerance in transgenic alfalfa (Medicago sativa). Plant J. 42: 689-707.

Zhang, L. L., Zhao, M. G., Tian, Q. Y., and Zhang, W. H. 2011. Comparative studies on tolerance of Medicago truncatula and Medicago falcata to freezing. Planta 234: 445-457.

Zhang, S., Yue, Y., Sheng, L., Wu, Y., Fan, G., Li, A., and Wei, C. 2013. PASmiR: a literature-curated database for miRNA molecular regulation in plant response to abiotic stress. BMC Plant Biol. 13: 33.

Zhou, Q. Y., Tian, A. G., Zou, H. F., Xie, Z. M., Lei, G., Huang, J., Wang, C. M., Wang, H. W., Zhang, J. S., and Chen, S. Y. 2008. Soybean WRKY-type transcription factor genes, GmWRKY13, GmWRKY21, and GmWRKY54, confer differential tolerance to abiotic stresses in transgenic Arabidopsis plants. Plant Biotechnol. J. 6: 486-503.

Zhu, J. K. 2001. Plant salt tolerance. Trends Plant Sci. 6: 66-71. 